\title{
Recent Advances in Polymer Organic Light-Emitting Diodes (PLED) Using Non-conjugated Polymers as the Emitting Layer and Contrasting Them with Conjugated Counterparts
}

\author{
MICHAEL Y. WONG (i] ${ }^{1,2}$ \\ 1.-School of Chemistry, University of St. Andrews, St. Andrews, Fife, UK. 2.-e-mail: \\ yw40@st-andrews.ac.uk
}

Polymer organic light-emitting diodes (PLED) are one of the most studied subjects in flexible electronics thanks to their economical wet fabrication procedure for enhanced price advantage of the product device. In order to optimize PLED efficiency, correlating the polymer structure with the device performance is essential. An important question for the researchers in this field is whether the polymer backbone is conjugated or not as it affects the device performance. In this review, recent advances in non-conjugated polymers employed as the emitting layer in PLED devices are first discussed, followed by their contrast with the conjugated counterparts in terms of polymer synthesis, sample quality, physical properties and device performances. Such comparison between conjugated and non-conjugated polymers for PLED applications is rarely attempted, and; hence, this review shall provide a useful insight of emitting polymers employed in PLEDs. 


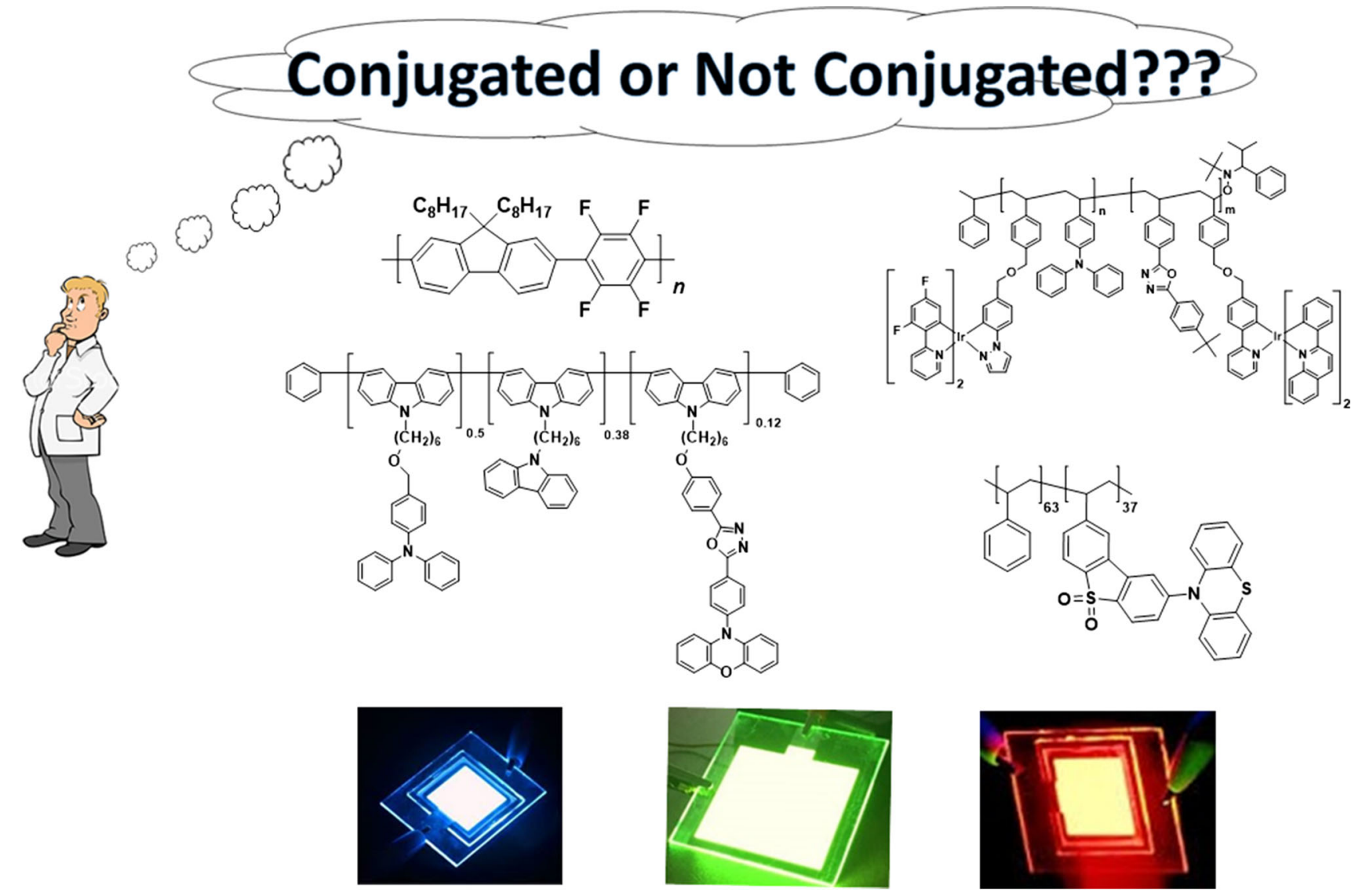

Key words: Structure-property relationship, polymer light-emitting diode (PLED), thermally activated delayed fluorescence (TADF), electroluminescence

\section{INTRODUCTION}

Organic light-emitting diodes (OLEDs, see Table SI for abbreviations used in this review) have reached the apex of display technology thanks to a number of their distinctive merits such as excellent image quality and contrast, having a large viewing angle and being light, thin and flexible. Since the pioneering report of an operational OLED device by Tang and VanSlyke in $1987^{1}$ tremendous research from both the academia and industry has been devoted to optimize the device's performance. During the past 30 years, workers in the field have witnessed an enormous enhancement in the device efficiency, escalating from the initial external quantum efficiency (EQE) of $1 \%{ }^{1}$ to the current state-ofthe-art $\mathrm{EQE}$ of $>30 \%{ }^{2-5}$ (without additional device architecture for enhanced light-outcoupling). Meanwhile, notable OLED companies such as Samsung and LG have already commercialized OLED televisions, laptops and touchscreens in mobile phones. Furthermore, being an energy-efficient technology, OLED lighting will help alleviate power consumption that at currently about $20 \%$ of total electricity consumption is devoted solely to lighting purposes. ${ }^{6}$

Apart from device efficiency, the ease of fabrication also plays an essential role in the marketability of OLED technology, because it reduces the device manufacturing cost. In this regard, the wet process (spin-casting or inkjet printing) is more beneficial than the dry process (vacuum thermal deposition), especially in the case of large-area display devices. ${ }^{7-9}$ In the wet fabrication process, materials are dissolved in a suitable organic solvent to form a solution that can be conveniently applied onto the substrate. The solution should possess a certain degree of viscosity, and the resulting film must have 
high surface quality and robust morphological stability, all of these can be fulfilled nicely by polymeric materials. ${ }^{10,11}$ As a result, polymer OLED (PLED) materials have long been the center of research efforts. The first PLED was reported by Burroughes and co-workers in 1990 when they invented the famous poly ( $p$-phenylene vinylene) (PPV, Fig. 1) as a green-yellow emitter, which offered a device EQE of $0.05 \%{ }^{12}$ This early emitting polymer was itself intractable, and; therefore, soluble polymer precursor had to be spun-coated on a substrate followed by thermal curing $\left(250^{\circ} \mathrm{C}\right)$ under vacuum to generate the polymer. Then, poly[2-methoxy-5-(2-ethylhexyloxy)-1,4-phenylenevinylene] (MEH-PPV, Fig. 1) was developed, which was a soluble derivative of PPV and gave an orange-red device, suggesting the alkoxy substituents at 2- and 5-positions impact both emission colors and solubility of the polymer. ${ }^{13}$ Polyfluorene (PFO, Fig. 1) is a classic blue-emitting polymer, which has been intensively studied. ${ }^{14,15}$ Finally, poly( $N$-vinylcarbazole) (PVK, Fig. 1$)$ is a very popular hole-transporting layer and host material employed in the emitting layer of OLED devices. ${ }^{11}$

Polymers for PLED applications can be divided into two main classes according to their architecture (Fig. 2). One of them has a conjugated backbone in which the $\pi$-electron density in one repeating unit can be delocalized over other units (Fig. 2a). While the conjugated backbone is already functional (charge transport and/or emission) on its own (Fig. 2a, top), it is sometimes decorated with a pendant electroactive group for acquiring additional properties (Fig. 2a, bottom). ${ }^{16-18}$ On the other hand, nonconjugated polymer backbones have repeating units that are electrically isolated from each other. Because the polymer backbone is insulating, it is invariably attached with electroactive groups to impart charge-transporting and/or emissive properties to the polymer (Fig. 2b). ${ }^{19-21}$ In this review, recent advances (mainly after 2010) in non-conjugated polymers employed as emitters in PLED devices will be discussed, where they can be divided into three main classes of materials: fluorescent, phosphorescent and thermally activated delayed fluorescent (TADF). Their synthetic parameters such as polymerization method and yield, molecular weight distribution and purity shall be contrasted with those of recently reported conjugated polymers (2011-present). Moreover, the PLED efficiencies and determining factors such as photoluminescence quantum yield (PLQY), glass-transition temperature ( $T_{\mathrm{g}}$, see Table SIII for symbols used in this review), and film surface roughness $(R)$ of these two classes of polymers shall also be contrasted. A literature survey reveals that such systematic comparison between non-conjugated and conjugated PLED polymers is rarely attempted. Therefore, this review shall provide a useful perspective of understanding the similarities and differences between conjugated and nonconjugated polymers for PLED applications. (a)
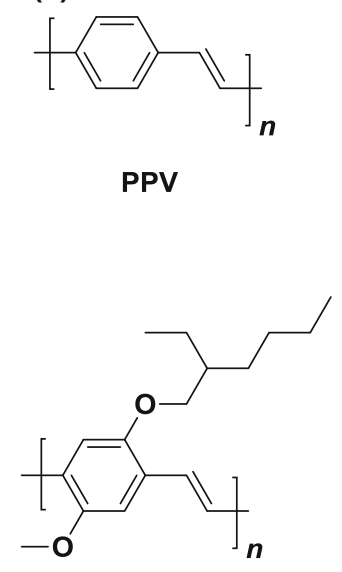

MEH-PPV (b)

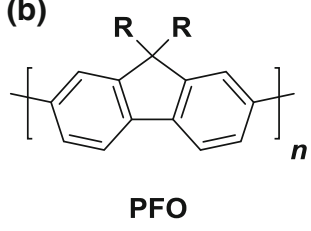

(c)

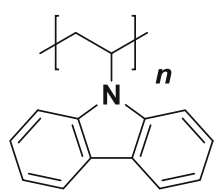

PVK
Fig. 1. Chemical structures of PPV and MEH-PPV a), PFO b) and PVK c).

\section{RECENT ADVANCES IN NON-CONJUGATED POLYMERS FOR PLED APPLICATIONS}

\section{Phosphorescent Polymers}

According to spin statistics, $75 \%$ of excitons in OLED devices are triplet in nature whose radiative transition to the ground singlet state is spin-forbidden, and; thus, they are mostly lost as heat. ${ }^{22}$ In order to solve this problem, organometallic complexes built with heavy metals such as iridium and platinum are employed as phosphorescent emitters in OLED devices. ${ }^{6,22,23}$ The large spin-orbit coupling constants $(\zeta)$ of those metals increase the rate of intersystem-crossing (ISC) to shorten phosphorescence lifetime to useful microsecond regimes. ${ }^{6,22,24}$ As a result, phosphorescent OLEDs can achieve $100 \%$ internal quantum efficiency (IQE) and devices showing stellar external quantum efficiencies (EQEs) of $>30 \%$ have been reported. ${ }^{5,25}$

Lai et al. prepared a polystyrene functionalized with dendronized iridium(III) phosphor (DIr-P1, Fig. 3) for PLED applications. ${ }^{26}$ In order to suppress interchromophore interactions, bulky 1,3-bis $(2-$ ethylhexyloxyphenyl)phenyl dendrons were decorated to impose steric hindrance around the central phosphor, which were brought close to one another by the polymer side chain. Phosphor aggregation is particularly detrimental to device efficiency because of enhanced aggregation-caused quenching (ACQ) and triplet-triplet annihilation (TTA). ${ }^{9}$ It was found that the dendronized polymer exhibited significantly better photophysical properties than the non-dendronized one (Ir-P1, Fig. 3). For example, DIr-P1 had $\Phi_{\mathrm{PL}}$ of $61 \%$ and $13 \%$ in degassed dichloromethane (DCM) solution and neat film, respectively, which were significantly higher than those of Ir-P1 ( $\Phi_{\mathrm{PL}}: 23 \%$ in degassed DCM and $<1 \%$ in neat film), although it was evident that a certain extent of aggregation was still present in the 

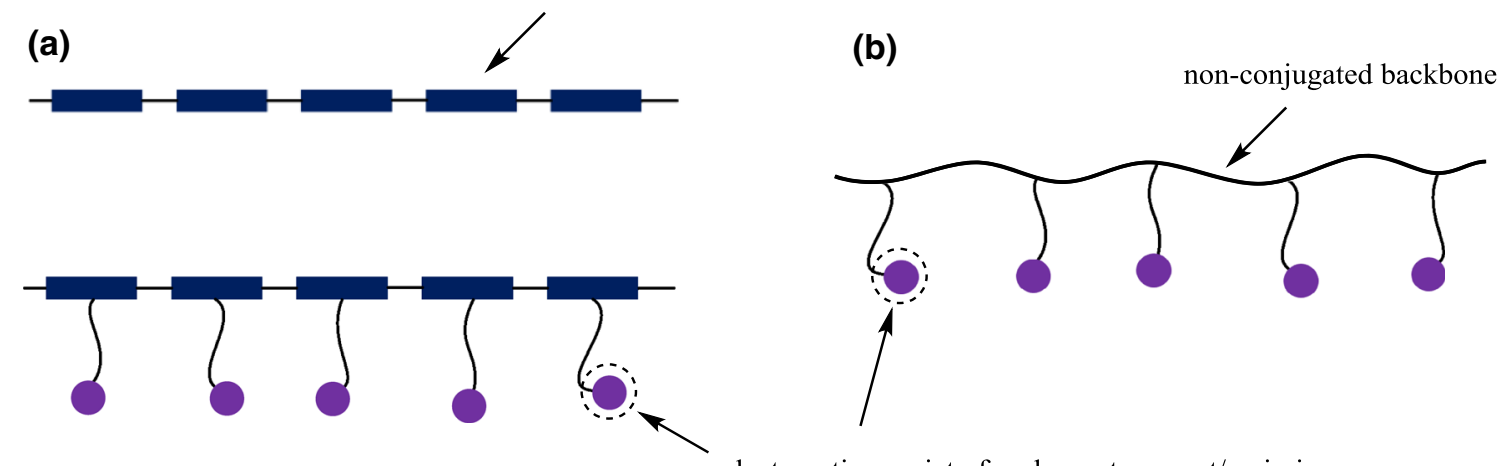

electroactive moiety for charge transport/emission

Fig. 2. Polymer with conjugated backbone, which by itself fulfils the purpose of charge transport and/or emission (a, top). Polymer with conjugated backbone with pendent electroactive moieties for additional desired properties (a, bottom). Polymer with non-conjugated backbone with pendant electroactive moieties for charge transport and/or emission (b).

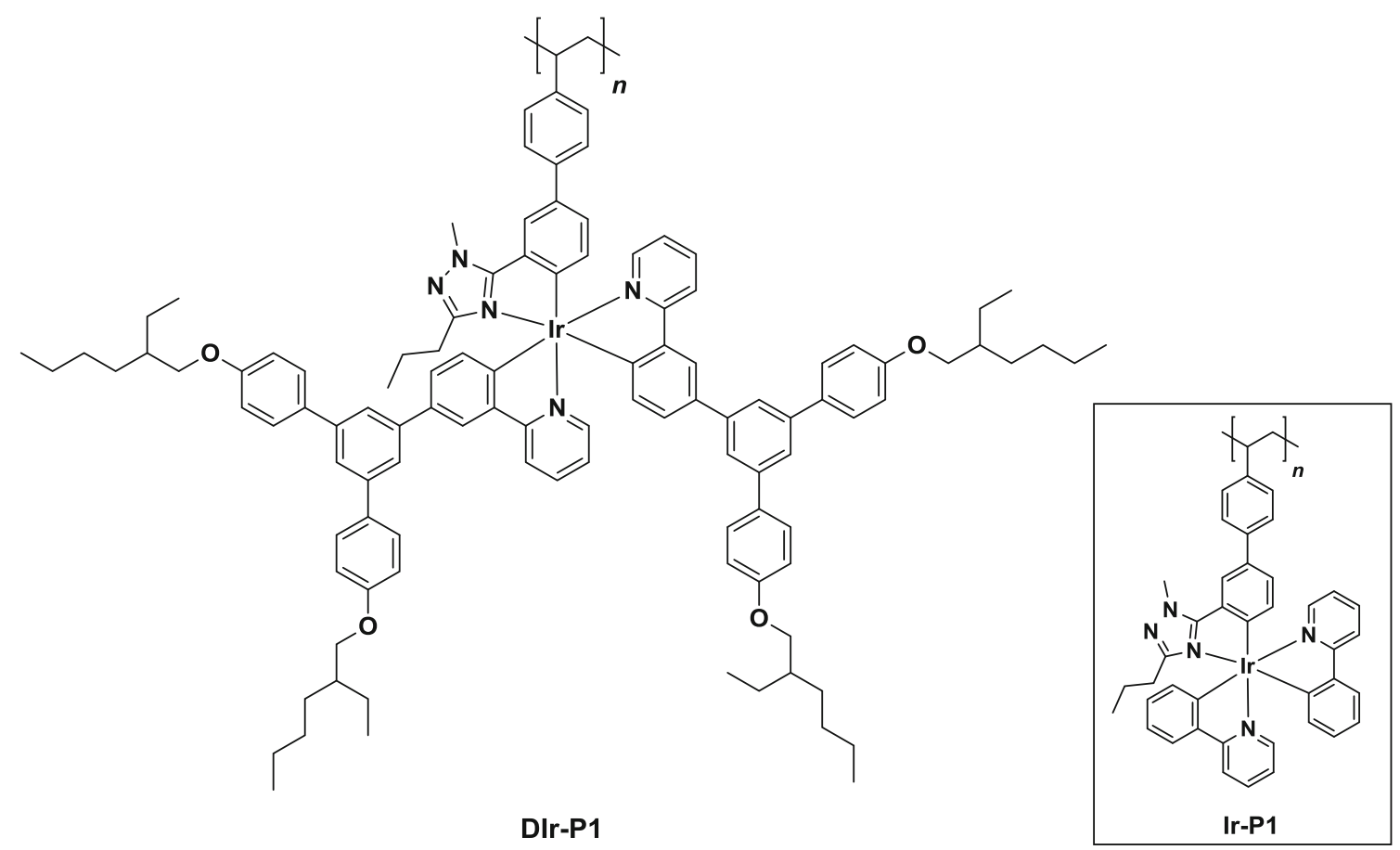

Fig. 3. Polystyrene containing pendant iridium(III) phosphor (DIr-P1) functionalized with bulky 1,3-bis(2-ethylhexyloxyphenyl)phenyl dendrons to suppress interchromophore interactions. Also shown in the inset is the non-dendronized reference polymer (Ir-P1).

former. DIr-P1 showed a green emission with $\lambda_{\mathrm{PL}}$ (emission maximum of photoluminescence) at $518 \mathrm{~nm}$ with a shoulder at $548 \mathrm{~nm}$ in degassed DCM, and its neat film emission spectrum was essentially identical. The device [ITO/20 wt.\% DIr-P1 in CBP/TPBI $(60 \mathrm{~nm}) / \mathrm{LiF} \quad(0.7 \mathrm{~nm}) / \mathrm{Al}$ $(>100 \mathrm{~nm})]$ (see Table SII for the chemical nomenclature and structures of OLED materials mentioned in this review) gave a green $\lambda_{\mathrm{EL}}$ (emission maximum of electroluminescence) at $520 \mathrm{~nm}$ with CIE at $(0.34,0.62)$. The maximum EQE of $7.5 \%$ was attained, when device emission became detectable, and the efficiency roll-off was small so that the EQE dropped slightly to $6.2 \%$ and $5.5 \%$ at luminance of 100 and $1000 \mathrm{~cd} \mathrm{~m}^{-2}$, respectively.

Levell and coworkers also reported a similar dendronized phosphorescent iridium(III) polymer (DIr-P2, Fig. 4) which had a 2-(2-pyridyl)-1,3,4triazole ligand and a norbornenyl polymer backbone instead of the 2-phenyl-1,3,4-triazole ligand and a polystyrene backbone in DIr-P1. ${ }^{27}$ DIr-P2 showed a green emission with $\lambda_{\mathrm{PL}}$ at $497 \mathrm{~nm}$ and a shoulder at $525 \mathrm{~nm}$ in degassed DCM. Its $\Phi_{\mathrm{PL}}$ of $37 \%$ was slightly lower than that of the reference compound (DIr-M2, $\Phi_{\mathrm{PL}}: 53 \%$ ), suggesting the presence of interchromophore interactions in the polymer due 


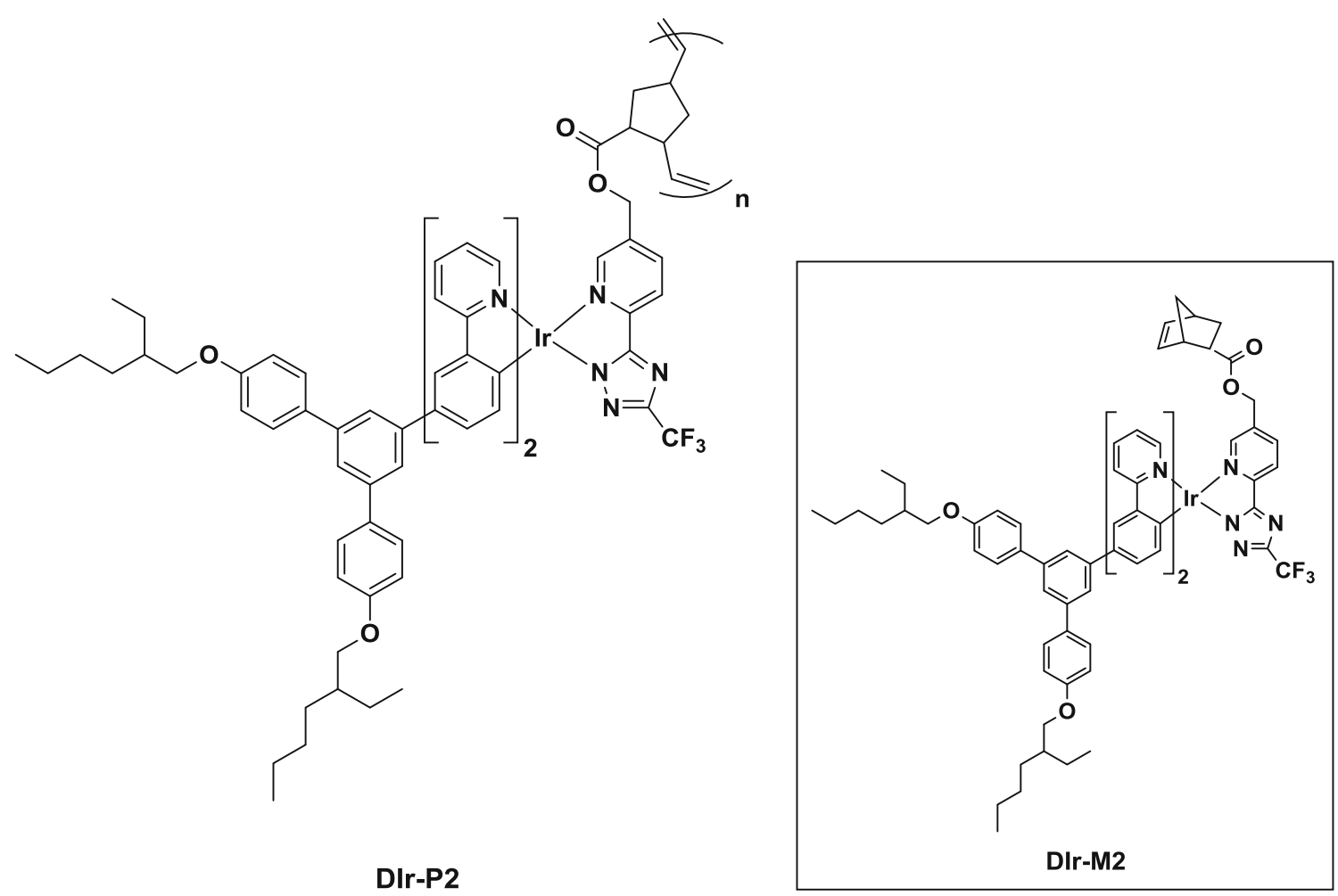

Fig. 4. Dendronized phosphorescent iridium(III) polymer (DIr-P2) based on norbornenyl backbone. Also shown in the inset is the monomer (DIrM2) as the reference emitter.

to the close proximity of iridium(III) phosphors along the polymer chain. Both DIr-P2 and DIr-M2 neat films exhibited emissions slightly red-shifted by $c a$. $5-10 \mathrm{~nm}$ compared with those in DCM and their $\Phi_{\mathrm{PL}}$ values were significantly lowered to $15 \%$ and $13 \%$, respectively. Yet, the $\Phi_{\mathrm{PL}}$ of neat DIr-P2 (15\%) was much better than that of the nondendronized analogue $(<1 \%)$ reported previously, ${ }^{28}$ thus proving the effectiveness of the dendrons. Given that DIr-P2 doped in CBP (20 wt.\%) showed a much improved $\Phi_{\mathrm{PL}}$ of $52 \%$ than the polymer neat film, it was employed as the emitting layer in the PLED device [ITO/20 wt.\% DIr-P2 in CBP $(\sim 100 \mathrm{~nm}) / \mathrm{TPBI}(60 \mathrm{~nm}) / \mathrm{LiF}(0.7 \mathrm{~nm}) / \mathrm{Al}(100 \mathrm{~nm})]$ which gave an EQE and a current efficiency of $5.1 \%$ and $16.4 \mathrm{~cd} \mathrm{~A}^{-1}$, respectively, at a brightness of $100 \mathrm{~cd} \mathrm{~m}^{-2}$ under an applied voltage of $15.8 \mathrm{~V}$. The emission was green with CIE coordinates at $(0.32$, $0.60)$.

Given that the aforementioned homopolymers DIr-P1 and DIr-P2 could not suppress interchromophore interactions completely, even though they were dendronized, Levell et al. then developed a copolymerization strategy as a resolution. ${ }^{29}$ They prepared a random copolymer (DIr-P1-co-S, Fig. 5) between DIr-P1 and polystyrene by free-radical copolymerization. According to nuclear magnetic resonance (NMR) integration, the molar ratio of styrene units to the dendronized iridium(III) chromophores was found to be 75:1. In DCM solution, DIr-P1-co-S had the same emission spectrum as
DIr-P1 with $\lambda_{\text {PL }}$ at $517 \mathrm{~nm}$, which suggested that the styrene units did not take part in the photophysical processes. In addition, DIr-P1-co-S had an excellent $\Phi_{\mathrm{PL}}$ of $94 \%$, which was comparable to that of the reference emitter (DIr-M3, $\Phi_{\mathrm{PL}}$ : 92\%) whereas the $\Phi_{\mathrm{PL}}$ of the homopolymer DIr-P1 was significantly lower (61\%). ${ }^{26}$ Furthermore, the doped film of DIr-P1-co-S (20 wt.\% in CBP) showed a much improved $\Phi_{\mathrm{PL}}$ of $67 \%$ compared with the DIr-P1 case $\left(\Phi_{\mathrm{PL}}: 42 \%\right)$. All these results proved that the copolymerization strategy succeeded in completely suppressing interchromophore interactions thanks to the styrene units as spacer. Despite the enhanced photophysical properties of the copolymer, device [ITO/20 wt.\% DIr-P1-co-S in CBP $(\sim 100 \mathrm{~nm}) / \mathrm{TPBI}(60 \mathrm{~nm}) / \mathrm{LiF}(0.7 \mathrm{~nm}) / \mathrm{Al}(>100 \mathrm{~nm})]$ offered an EQE of $6.7 \%$ at a luminance of $100 \mathrm{~cd} \mathrm{~m}^{-2}$ which was only comparable to that of the homopolymer DIr-P1 device (EQE: 6.2\%). Indeed, while styrene units in the copolymer were fully functional in diluting the phosphors, they were not electroactive, and; hence, the hole mobility of the copolymer suffered, followed by limited device performance.

Levell et al. then reported a follow-up study by replacing insulating styrene units with electroactive carbazole functionality to boost the hole mobility of the polymers, ${ }^{30}$ given poly $(N$-vinylcarbazole $)$ is a widely employed hole-transporting material. ${ }^{11}$ They prepared a series of random copolymers (Ir-P1-coVK, DIr-P1-co-VK and DDIr-P1-co-VK, Fig. 6) 


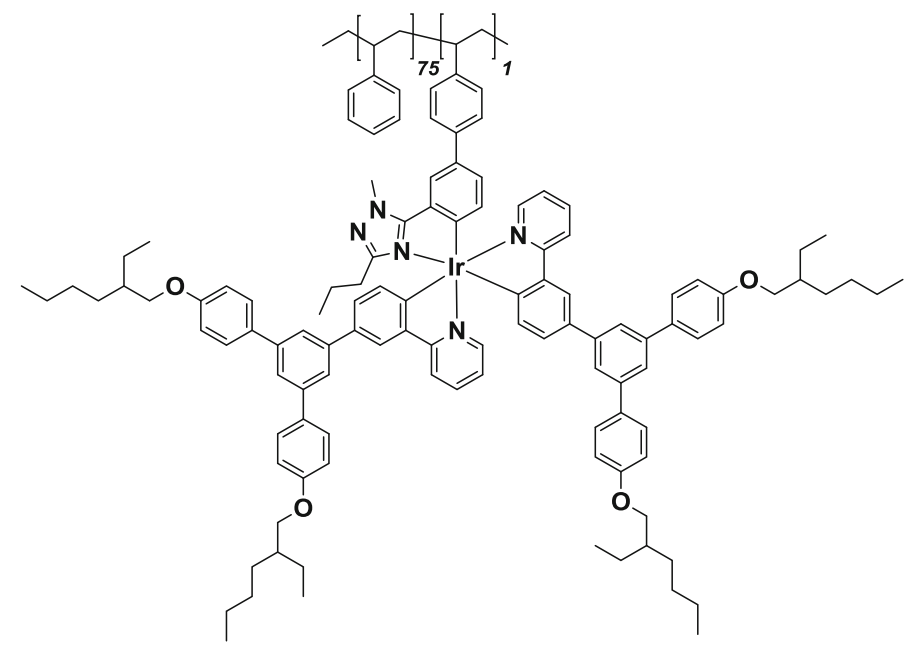

DIr-P1-co-S

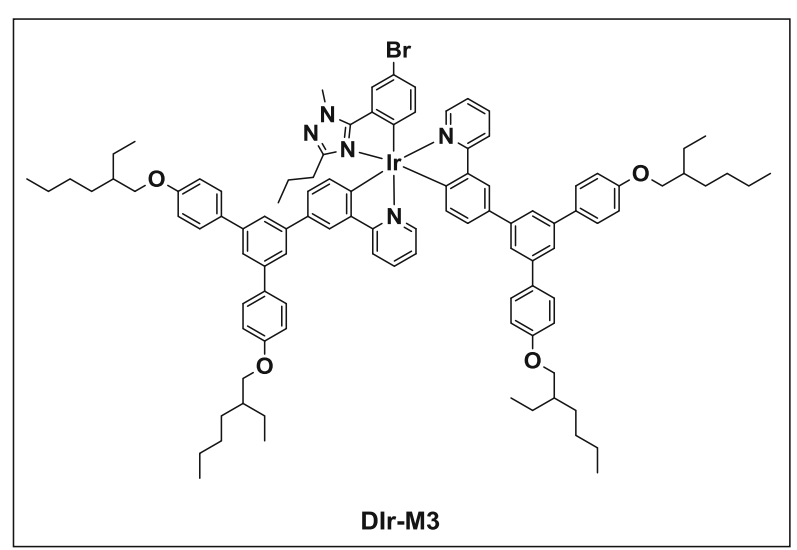

Fig. 5. A copolymer (DIr-P1-co-S) between polystyrene and DIr-P1 where the styrene units acted as spacer to prevent undesirable interchromophore interactions. Also shown in the inset is the reference emitter (DIr-M3).

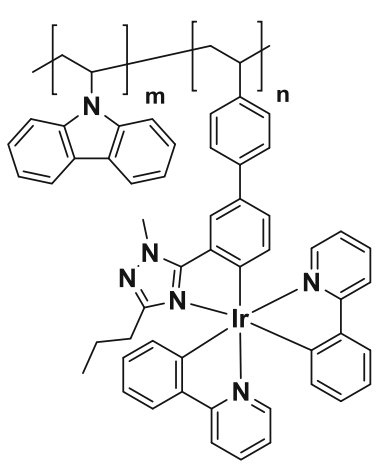

Ir-P1-co-VK

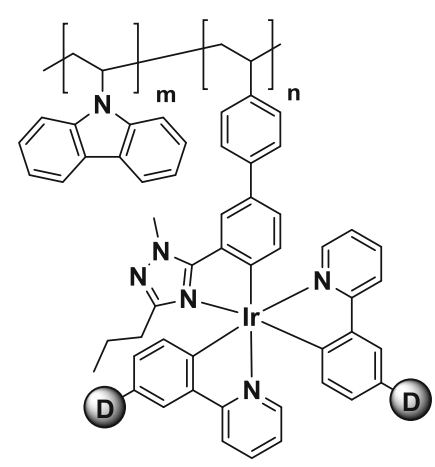

DIr-P1-co-VK

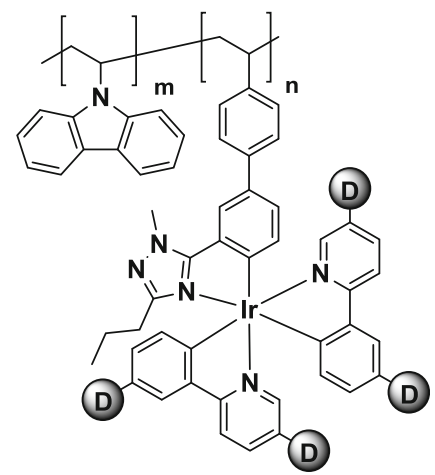

DDIr-P1-co-VK

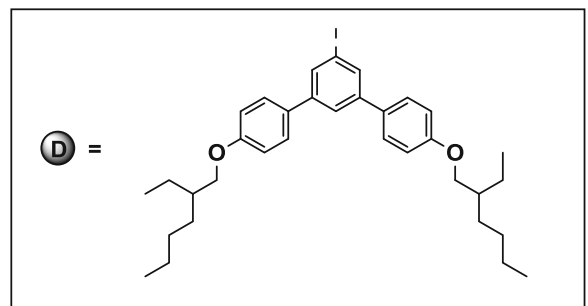

Fig. 6. Three copolymers between poly( $N$-vinylcarbazole) and polystyrene with pendant iridium(III) phosphors having none (Ir-P1-co-VK), one (DIr-P1-co-VK) and two (DDIr-P1-co-VK) dendrons on each ligand. Also shown in the inset is the 1,3-bis(2-ethylhexyloxyphenyl)phenyl dendron.

with carbazole to phosphor monomer feed ratios of 55-72 to 1 , but the authors could not obtain the monomer compositions in the resulting copolymers due to the broadness and significant overlap of NMR signals. In DCM solutions, Ir-P1-co-VK, DIr-P1co-VK and DDIr-P1-co-VK showed green $\lambda_{\mathrm{PL}}$ at $512 \mathrm{~nm}, 516 \mathrm{~nm}$ and $551 \mathrm{~nm}$, respectively, which were basically identical to those of the homopolymers (Ir-P1, DIr-P1 and DDIr-P1, Fig. 7, vide infra) ${ }^{31}$ implying efficient energy transfer from carbazole moieties to the phosphors. Their $\Phi_{\mathrm{PL}}$ values were found to be $69 \%, 64 \%$, and $64 \%$, respectively, which were lower than DIr-P1-co-S $\left(\Phi_{\mathrm{PL}}: 94 \%\right)^{29}$ due to back triplet energy transfer from the phosphors to the carbazole units $(\operatorname{poly}(N$ vinylcarbazole has a low triplet energy of $2.5 \mathrm{eV}$ ). 
<smiles></smiles>

Ir-P1

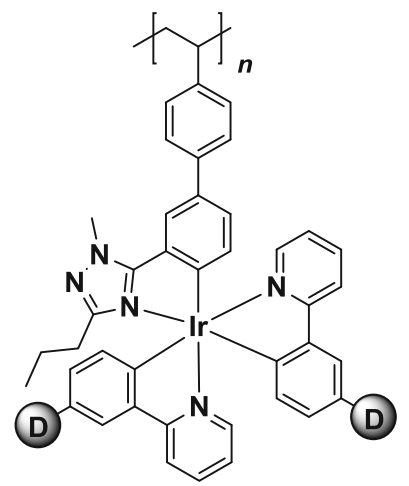

DIr-P1

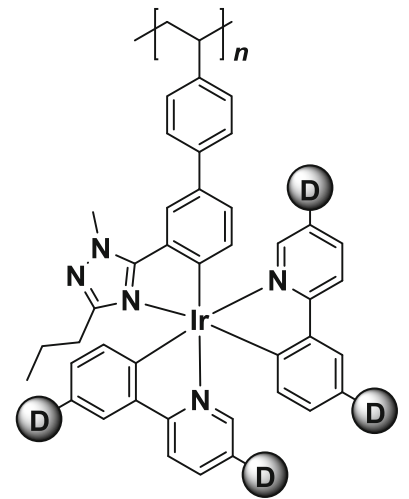

DDIr-P1

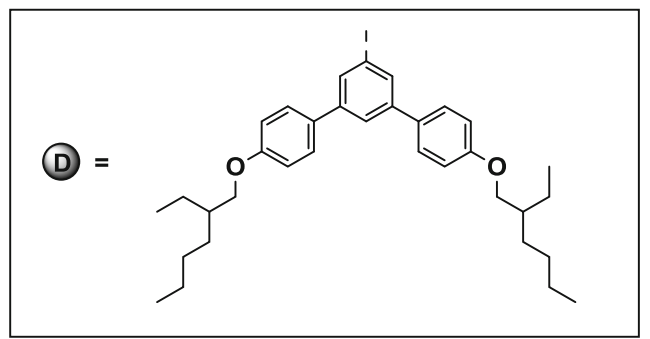

Fig. 7. Polystyrenes with pendant iridium(III) phosphors having none (Ir-P1), one (DIr-P1) and two (DDIr-P1) dendrons on each ligand. Also shown in the inset is the 1,3-bis(2-ethylhexyloxyphenyl)phenyl dendron.

The device [ITO/50 wt.\% DDIr-P1-co-VK in CBP (ca. $100 \mathrm{~nm}) / \mathrm{TPBI} \quad(60 \mathrm{~nm}) / \mathrm{LiF} \quad(0.7 \mathrm{~nm}) / \mathrm{Al}$ $(>100 \mathrm{~nm})]$ gave the best $\mathrm{EQE}$ of $14.7 \%$ at $100 \mathrm{~cd} \mathrm{~m}^{-2}$. Devices with the same architecture, while using neat Ir-P1-co-VK, DIr-P1-co-VK and DDIr-P1-co-VK as the emitting layers, were also fabricated, but lower EQEs $(10.0-11.0 \%)$ were obtained. Given that $\Phi_{\mathrm{PL}}$ of neat films of the copolymers (46-57\%) were considerably lower than that of 50 wt.\% DDIr-P1-co-VK doped in CBP film $\left(\Phi_{\mathrm{PL}}: 73 \%\right)$, it was concluded that the efficiencies of these devices were determined by the $\Phi_{\mathrm{PL}}$ values of the emitting layers.

In addition to copolymerization strategy, Lai and co-workers proposed a "double-dendron" approach to solve the interchromophore interaction problem. ${ }^{31}$ They contrasted three polymers Ir-P1, DIrP1 and DDIr-P1 (Fig. 7) to investigate how the number of dendrons on the central iridium(III) phosphor impacted the photophysical properties and device performances of the polymers. In the DCM solution, $\Phi_{\mathrm{PL}}$ of Ir-P1, DIr-P1 and DDIr-P1 were $23 \%, 61 \%$, and $67 \%$, respectively, while their neat films all showed diminished $\Phi_{\mathrm{PL}}$ of $<1 \%,{ }^{26}$ $13 \%$, and $47 \%$, respectively. These results demonstrated a clear trend that increasing the number of dendrons on the phosphor effectively suppressed interchromophore interactions in the polymers. It is worth noting that while Ir-P1 and DIr-P1 had very similar emission energies (DIr-P1 $\lambda_{\mathrm{PL}}: 518 \mathrm{~nm}$ ), the
$\lambda_{\mathrm{PL}}$ of DDIr-P1 was significantly red-shifted by $c a$. $30 \mathrm{~nm}$ to $551 \mathrm{~nm}$, as a result of effective conjugation length increase in the ligands. A PLED device [ITO/ DDIr-P1 $\quad(75 \mathrm{~nm}) / \mathrm{TPBI} \quad(60 \mathrm{~nm}) / \mathrm{LiF} \quad(0.7 \mathrm{~nm}) / \mathrm{Al}$ $(>100 \mathrm{~nm})$ ] gave a yellow emission with CIE at $(0.48,0.51)$. An EQE of $9.2 \%$ was achieved at $100 \mathrm{~cd} \mathrm{~m}^{-2}$ with a low efficiency roll-off so that the EQE dropped slightly to $8.4 \%$ at $1000 \mathrm{~cd} \mathrm{~m}^{-2}$. On the other hand, a device with same structure based on DIr-P1 gave a lower EQE of $6.2 \%$ at $100 \mathrm{~cd} \mathrm{~m}^{-2}$ even though the polymer was doped in CBP host (20 wt.\%), hence, proving the effectiveness of the dendrons.

Lai and co-workers also synthesized a series of similar polymers (Ir-P3, DIr-P3 and DDIr-P3, Fig. 8) whose backbone was derived from norbornene using ring-opening metathesis polymerization (ROMP). ${ }^{32}$ The key merit of these polymers was their narrower polydispersity index (PDI) of $c a .1 .4$ than those with polystyrene backbone (Ir-P1, DIrP1 and DDIr-P1 $)^{31}$ prepared by free-radical copolymerization (e.g., DDIr-P1 had a PDI as high as 4). PLED performances based on conjugated polymers have been found to depend on their PDIs. ${ }^{33,34}$ In line with the results obtained from polystyrene analogues (Ir-P1, DIr-P1 and DDIr-P1), ${ }^{31}$ it has been shown a clear positive correlation between the number of dendrons on the ligands and the $\Phi_{\mathrm{PL}}$ of the polymers both in solution and neat films. For example, $\Phi_{\mathrm{PL}}$ of Ir-P3, DIr-P3 and DDIr-P3 in 


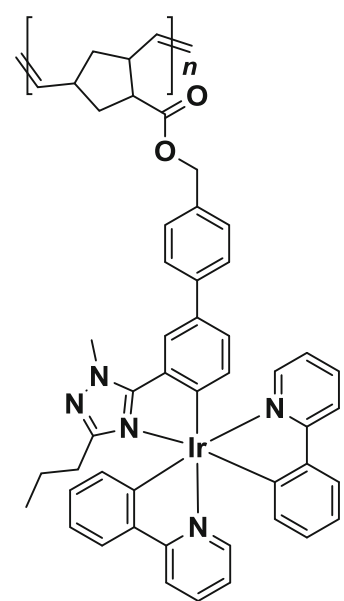

Ir-P3

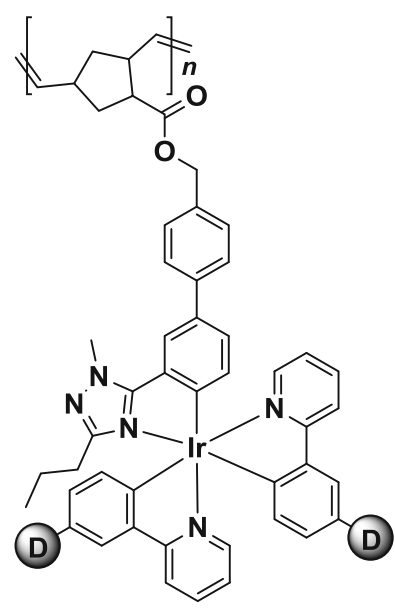

DIr-P3

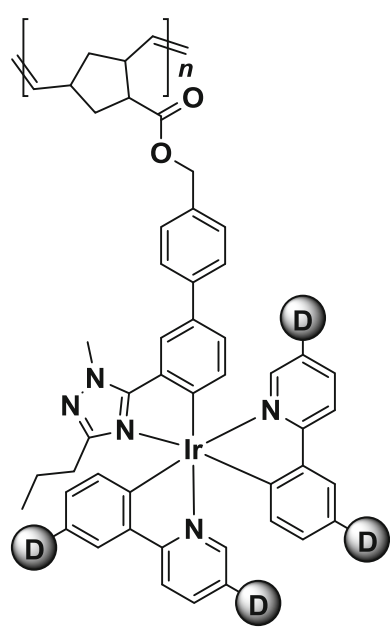

DDIr-P3

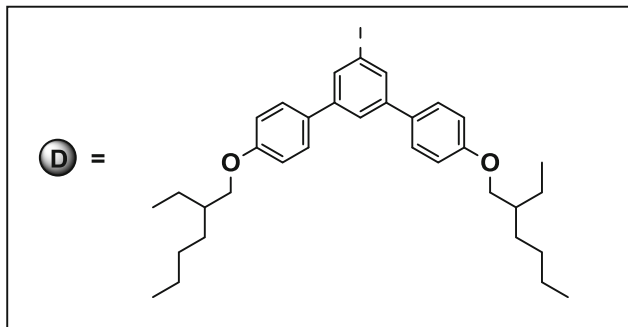

Fig. 8. Polymers with norbornene-derived backbone by ring-opening metathesis polymerization (ROMP) with pendant iridium(III) phosphors having none (Ir-P3), one (DIr-P3) and two (DDIr-P3) dendrons on each ligand. Also shown in the inset is the 1,3-bis(2-ethylhexyloxyphenyl)phenyl dendron.

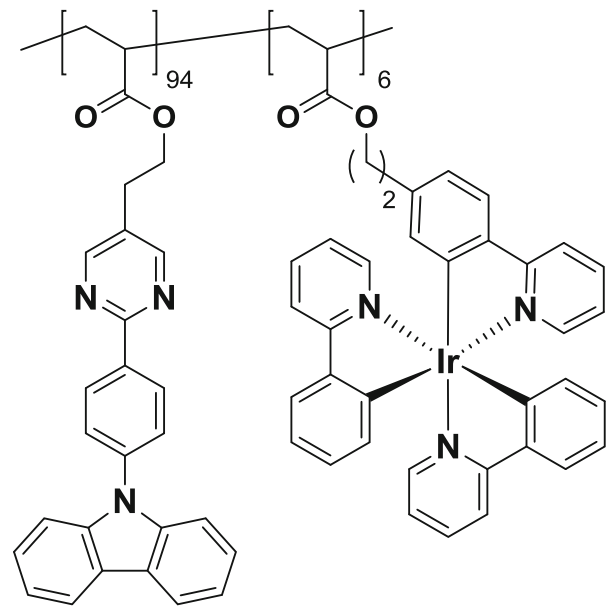

Poly(M6-MA-co-Ir-2C-MA)

Fig. 9. A random copolymer (Poly(M6-MA-co-Ir-2C-MA)) between carbazole-pyrimidine based host and pendant $\operatorname{Ir}(\mathrm{ppy})_{3}$ phosphor with a methyl methacrylate backbone for single-layer PLED applications.

DCM solutions were $48 \%, 65 \%$, and $71 \%$, respectively. In neat films, their values were lowered to $2, \% 44 \%$, and $58 \%$, respectively. However, no PLED devices were fabricated in this study.
Page et al. very recently reported a library of random copolymers consisting of a carbazole-pyrimidine bipolar host and a pendant $\operatorname{Ir}(\mathrm{ppy})_{3}$ phosphor for PLED applications (the best performing copolymer among the series, Poly(M6-MA-co-Ir-2C-MA), is shown in Fig. 9). ${ }^{35}$ They found that the PLQYs of the polymer neat films decreased with increasing $\operatorname{Ir}(\text { ppy })_{3}$ phosphor concentrations (0.5-29 mol.\%), suggesting the presence of undesirable interchromophore interactions in the film when the phosphor content became more concentrated, which is consistent with the observations reported in the aforementioned studies. ${ }^{27,29,31}$ Although the copolymer with 0.5 mol.\% $\operatorname{Ir}(\text { ppy })_{3}$ phosphor exhibited the best PLQY of $81 \%$ among the series, a minimum of 3 mol.\% phosphor was required to complete the energy transfer from the host to the dopant. Thanks to the bipolar characteristics of the host to facilitate both hole and electron injections and transport, a single-layered PLED [ITO/AQ1200/Poly(M6-MAco-Ir-2C-MA) $(\sim 30 \mathrm{~nm}) / \mathrm{LiQ}(2 \mathrm{~nm}) / \mathrm{Al}(100 \mathrm{~nm})]$ was fabricated, where a $6 \mathrm{~mol} \%$ phosphor was found to show the best compromise between PLQY and charge transport in the polymeric emitting layer. The device gave a green emission $\left(\lambda_{\mathrm{EL}}\right.$ : $\sim 520 \mathrm{~nm}$ ) with a maximum current efficiency of $3.6 \mathrm{~cd} \mathrm{~A}^{-1}$. 


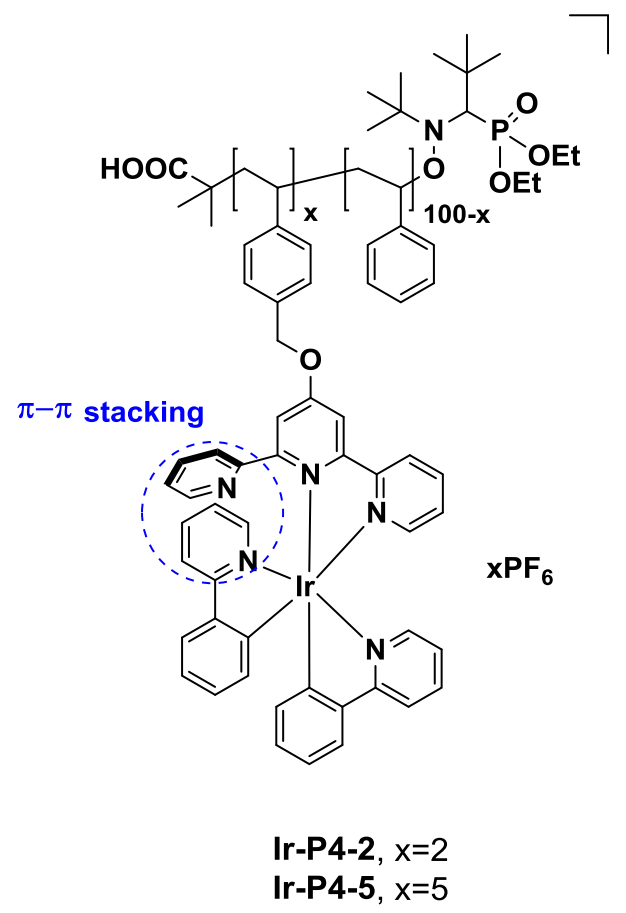

Fig. 10. Two random copolymers of styrene and a cationic iridium(III) phosphor with $\mathrm{PF}_{6}{ }^{-}$as the counter anion (Ir-P4-2 and Ir-P45). The $\pi-\pi$ stacking between the non-coordinating pyridine moiety of the terpyridine ligand and the pyridine ring of adjacent phenylpyridine ligand is highlighted in blue, which results in enhanced emitter stability.

Dumur and co-workers reported a series of two random copolymers of styrene and a cationic iridium(III) phosphor with $\mathrm{PF}_{6}{ }^{-}$as the counter anion (Ir-P4-2 and Ir-P4-5, Fig. 10, which contained $2 \mathrm{~mol} . \%$ and $5 \mathrm{~mol} . \%$ of phosphor, respectively). ${ }^{36}$ A distinct feature of the pendant iridium(III) complex was the strong $\pi-\pi$ stacking between the noncoordinating pyridine moiety of the terpyridine ligand and the pyridine ring of adjacent phenylpyridine ligand, hence, creating a steric bulk around the complex to decrease its accessibility to nucleophilic quenchers and increase its stability. ${ }^{37}$ Being ionic, Ir-P4-2 and Ir-P4-5 had the potential for light-emitting electrochemical cell (LEEC) applications. LEEC is an alternative to OLED as a lightemitting device, which enjoys a simpler device architecture and fabrication procedure, because it is usually single-layered and has the ionic emitting layer spun-coated on the anode substrate. ${ }^{38-41}$ Furthermore, air-stable cathodes (e.g., $\mathrm{Al}^{40}$ and $\mathrm{Ag}^{41}$ ) can be employed for LEEC devices to reduce device encapsulation cost. Ir-P4-2 and Ir-P4-5 were synthesized by nitroxide mediated polymerization (NMP) so that they had low PDIs of 1.16 and 1.17, respectively. Ir-P4-2 and Ir-P4-5 neat films gave green $\lambda_{\mathrm{PL}}$ at $539 \mathrm{~nm}$ and $553 \mathrm{~nm}$, respectively, suggesting more prominent chromophore aggregation in the latter due to its higher phosphor concentration. Blend films of Ir-P4-2 and Ir-P4-5 with $\operatorname{poly}(N$-vinylcarbazole) $(w / w=1: 1)$ resulted in slightly blue-shifted $\lambda_{\mathrm{PL}}$ at $526 \mathrm{~nm}$ and $532 \mathrm{~nm}$, respectively. However, no $\Phi_{\mathrm{PL}}$ data were reported. It was found that only Ir-P4-5 was able to function in light-emitting devices, whereas Ir-P4-2 failed to give any emissions because the concentration of insulating styrene units was too large for efficient charge hopping in the polymer. LEEC device [ITO/ PEDOT:PSS (40 nm)/PVK/Ir-P4-5/Ca $\quad(300 \mathrm{~nm})]$ offered a luminance of $70 \mathrm{~cd} \mathrm{~m}^{-2}$ under high voltage of $24 \mathrm{~V}$. On the other hand, an OLED device [ITO/ PEDOT:PSS $(40 \mathrm{~nm}) / 50$ wt.\% Ir-P4-5 blend with $\mathrm{PVK} / \mathrm{Ca}(300 \mathrm{~nm})]$ gave a poor luminance of $5 \mathrm{~cd} \mathrm{~m}^{-2}$ at $30 \mathrm{~V}$.

Shao and co-workers prepared a series of polymer (Ir-P5-x, Fig. 11) based on a fluorinated poly(arylene ether phosphine oxide) backbone with varying concentrations of pendant yellow phosphor (fbi) ${ }_{2} \operatorname{Ir}(-$ acac) (1-4 mol.\%). ${ }^{42}$ The key merit of the polymer backbone is its bipolar characteristics with the highest occupied molecular orbital (HOMO) and the lowest unoccupied molecular orbital (LUMO) levels at $-5.7 \mathrm{eV}$ and $-2.3 \mathrm{eV}$, respectively, due to the presence of carbazole donor and triphenylphosphine oxide acceptor moieties, yet maintaining a high triplet energy $\left(\mathrm{E}_{\mathrm{T}}\right)$ of $2.96 \mathrm{eV}$. The authors attributed the high triplet energy to the electronic isolation effect of the oxygen atoms. A series of polymers were prepared with varying compositions of (fbi) $)_{2} \operatorname{Ir}($ acac) (1-4 mol.\%). In photoluminescence measurements, it was found that a minimum concentration of $4 \mathrm{wt} \%$ (fbi) $)_{2} \operatorname{Ir}(\mathrm{acac})$ in the polymer was required to attain almost complete Forster energy transfer from the host to the phosphor. However, a lower amount of 2 wt.\% of (fbi) ${ }_{2} \operatorname{Ir}$ (acac) was required in electroluminescence to achieve this due to charge trapping by the yellow phosphor, given its shallower HOMO level $(-5.1 \mathrm{eV})$ and deeper LUMO level $(-2.7 \mathrm{eV})$ than those of the host. The best PLED device [ITO/PEDOT:PSS $(40 \mathrm{~nm}) / \mathbf{I r}-\mathbf{P 5 - 0 . 0 3} \quad(40 \mathrm{~nm}) / \mathrm{TPCz} \quad(50 \mathrm{~nm}) / \mathrm{LiF}$ $(1 \mathrm{~nm}) / \mathrm{Al}(100 \mathrm{~nm})]$ offered $\lambda_{\mathrm{EL}}$ at $566 \mathrm{~nm}$ and CIE at $(0.53,0.46)$ with an $\mathrm{EQE}$ of $4.1 \%$ and a current efficiency of $10.4 \mathrm{~cd} \mathrm{~A}^{-1}$. The group also simultaneously reported an identical polymer system with pendant blue phosphor (FIrpic) whose device [ITO/ PEDOT:PSS $\quad(40 \mathrm{~nm}) /$ polymer $\quad(40 \mathrm{~nm}) / \mathrm{TPCz}$ $(50 \mathrm{~nm}) / \mathrm{LiF}(1 \mathrm{~nm}) / \mathrm{Al}(100 \mathrm{~nm})]$ achieved a decent EQE of $9.0 \%{ }^{43}$

The group then extended the work by combining the blue and yellow phosphors to prepare a bichromophoic polymer for white PLED applications (Ir-P5-x-y, Fig. 12). By carefully tuning the relative compositions of the blue (x mol.\%) and yellow (y mol.\%) phosphors, white emission could be obtained. ${ }^{44}$ The high triplet energy of the host $(2.96 \mathrm{eV})$ was particularly important to prevent back energy transfer from the blue phosphors $\left(\mathrm{E}_{\mathrm{T}}\right.$ : $2.65 \mathrm{eV})$. The best white PLED [ITO/PEDOT:PSS $(40 \mathrm{~nm}) / \mathbf{I r}-\mathbf{P 5 - 0 . 0 7 5 - 0 . 0 0 7}(40 \mathrm{~nm}) / \mathrm{TPCz}(50 \mathrm{~nm}) /$ $\mathrm{LiF}(1 \mathrm{~nm}) / \mathrm{Al}(100 \mathrm{~nm})]$ attained an EQE and a 


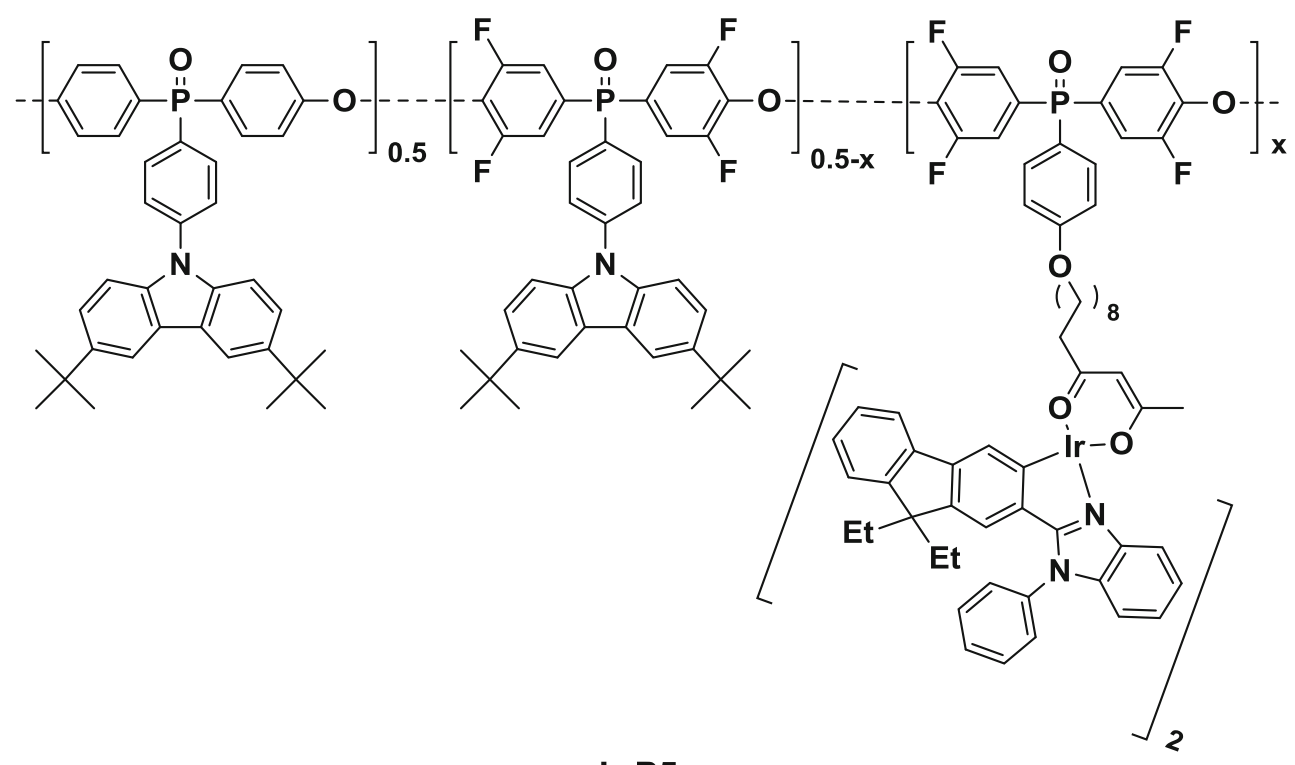

Ir-P5-X

Fig. 11. A polymer based on a fluorinated poly(arylene ether phosphine oxide) backbone with varying concentrations of pendant yellow phosphor (Ir-P5-x, x: 0.01-0.04).

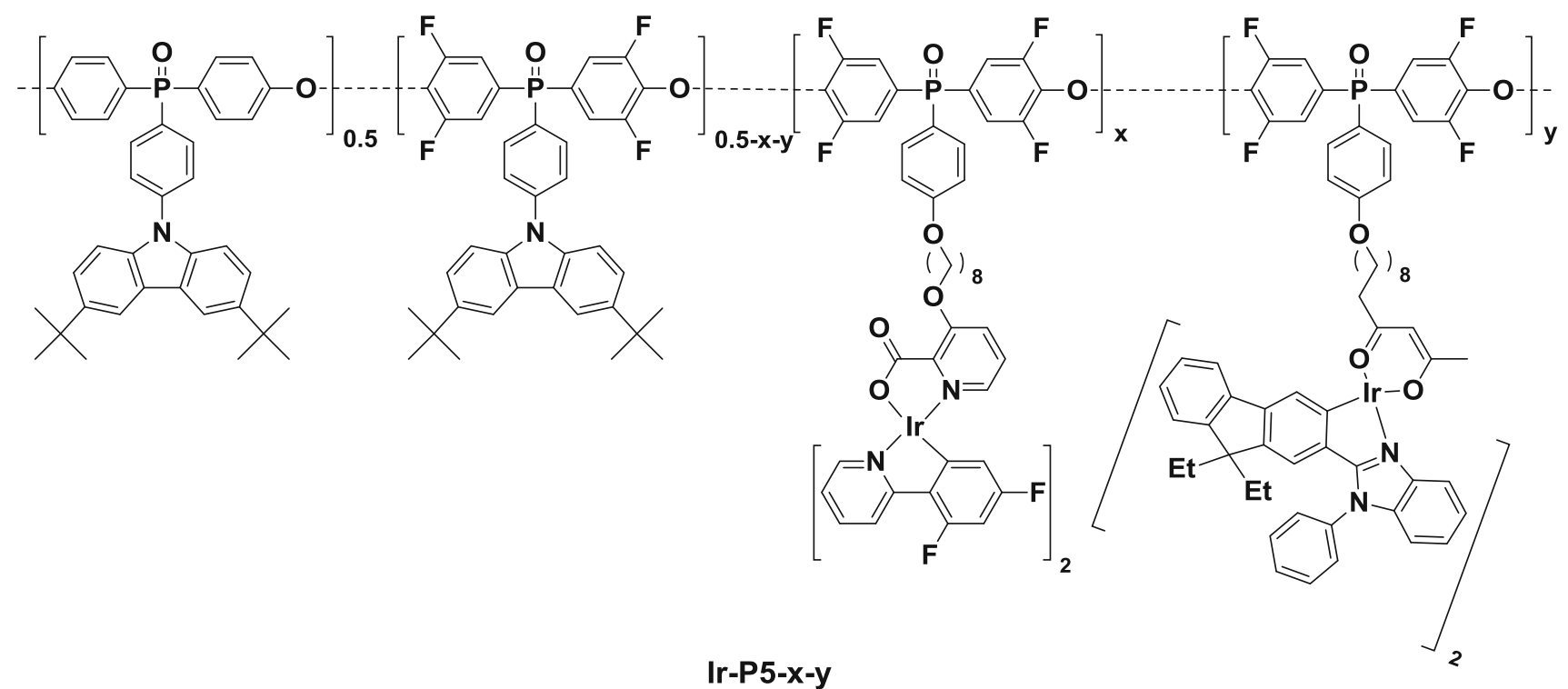

Fig. 12. A bichromophoic polymer (Ir-P5-x-y) containing $\mathbf{x}$ mol.\% and $\mathbf{y}$ mol.\% of blue and yellow phosphors for white PLED applications.

current efficiency of $7.1 \%$ and $18.4 \mathrm{~cd} \mathrm{~A}^{-1}$, respectively, with CIE at $(0.31,0.43)$.

Park and co-workers developed a series of blue (Ir-P6(mCP-co-B)), green (Ir-P6(CBP-co-G)) and red (Ir-P6(CBP-co-R)) phosphorescent copolymers for PLED applications (Fig. 13). ${ }^{45}$ The copolymers consisted mainly of host with a small amount of respective phosphors [mCP for blue FIracac; CBP for both green (ppy) $)_{2} \operatorname{Ir}\left(\right.$ acac) and red (btp) ${ }_{2} \operatorname{Ir}($ acac) $]$. Phosphor compositions: 1.7-13.9 mol.\%. Vinyl addition polymerization of norbornene-functionalized monomers using $\mathrm{Pd}(\mathrm{II})$ catalysis produced high molecular weight polymers $\left(M_{\mathrm{w}}: 151-457 \mathrm{kDa}\right)$.
The copolymers demonstrated excellent thermal stabilities $\left(T_{\mathrm{g}} \mathrm{S}>330^{\circ} \mathrm{C}\right)$. In solutions, all the copolymers showed both high-energy emissions (ca. 350-400 nm) from the hosts and low-energy emissions from the phosphors. However, the emission spectra of the copolymer neat films were mainly contributed by the phosphors. These results indicated that energy transfer from host to the phosphor was much more efficient in neat film compared with that in solutions. All the copolymers were tested for PLED performances with the device structure: ITO/PEDOT:PSS $(40 \mathrm{~nm}) /$ copolymer/(40 nm)/TPBI $(15 \mathrm{~nm}) / \mathrm{Bphen}(35 \mathrm{~nm}) / \mathrm{LiF}(1 \mathrm{~nm}) / \mathrm{Al}(100 \mathrm{~nm})$. The 

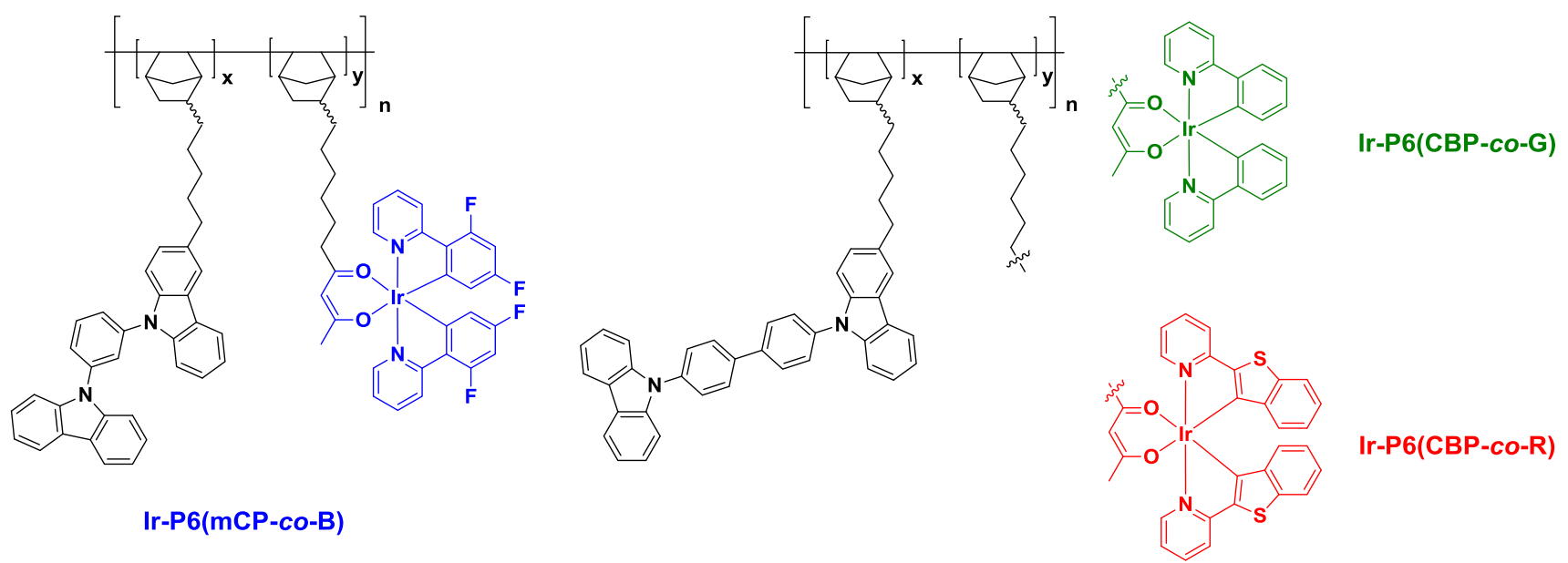

Fig. 13. Three series of blue (Ir-P6(mCP-co-B)), green (Ir-P6(CBP-co-G)) and red (Ir-P6(CBP-co-R)) phosphorescent copolymers of host monomers and respective phosphors.

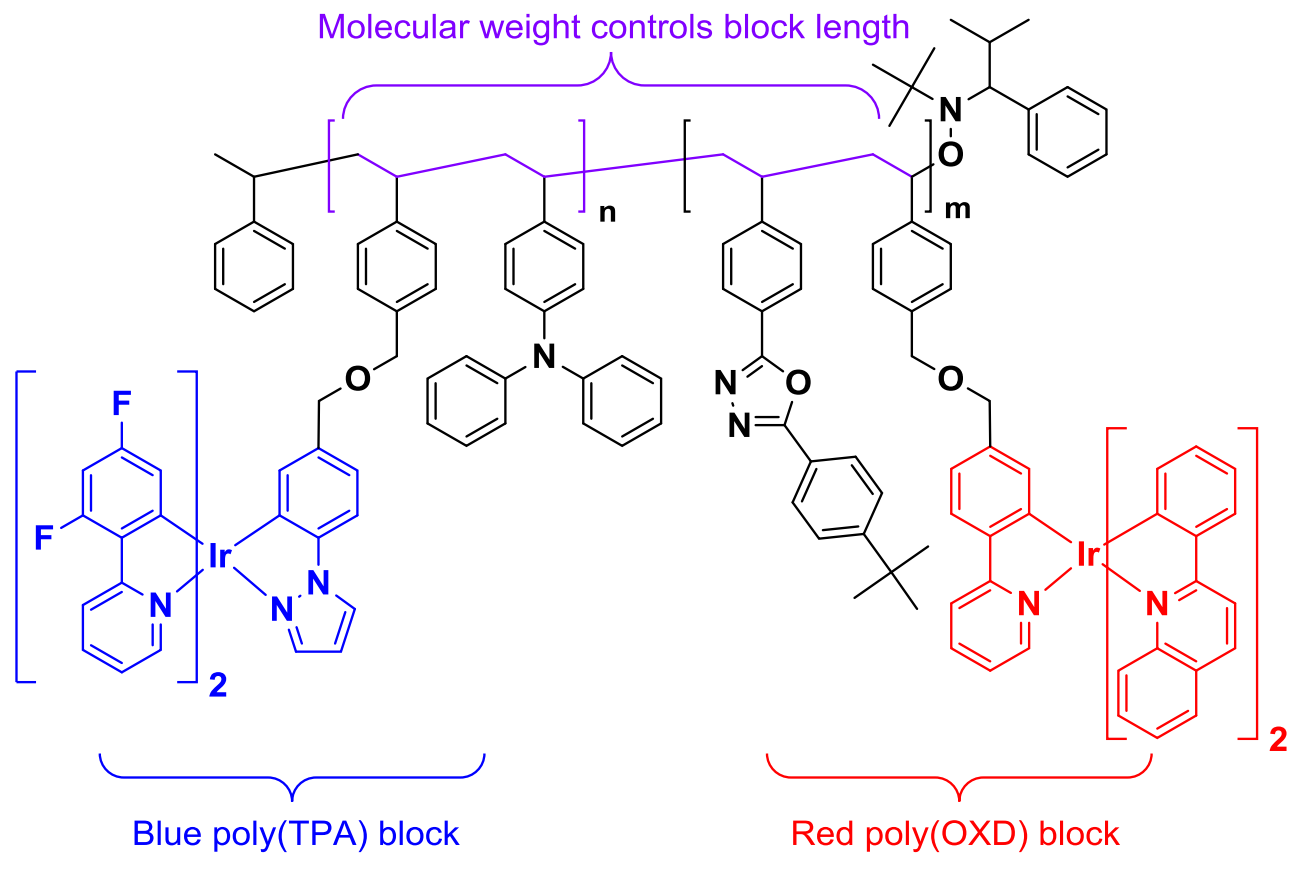

\section{Ir-P7(10B-co-xR-MW)}

Fig. 14. A biphasic white-emitting block copolymer, Ir-P7(10B-co-xR-MW), consisting of poly(TPA) copolymerized with blue phosphor (always 10 wt.\%) and poly(OXD) with varying amount of red phosphors $(x=0.1-2 \mathrm{wt} . \%)$. The molecular weight of the polymer is the key factor for successful site isolation.

best blue device was offered by the polymer with $10.5 \mathrm{~mol} \%$ phosphor, which gave $\lambda_{\mathrm{EL}}$ at $488 \mathrm{~nm}$ with an EQE of $8.8 \%$. On the other hand, the best green and red devices were fabricated with polymers with $5.3 \mathrm{~mol} . \%$ and $13.9 \mathrm{~mol} . \%$ phosphors, respectively, which showed $\lambda_{\mathrm{EL}}$ at $522 \mathrm{~nm}$ and $619 \mathrm{~nm}$ with EQEs of $13.3 \%$ and $5.1 \%$, respectively.

Poulsen et al. employed a strategy of biphasic block copolymer (Ir-P7(10B-co-xR-MW), Fig. 14) to achieve site isolation in which energy transfer from the high-energy phosphor to the low-energy one could be controlled so that white emission could be generated. ${ }^{46}$ The first block consisted of poly(TPA) randomly copolymerized with a small amount of blue phosphor (10 wt.\%) while the second block contained poly (OXD) randomly copolymerized with an even smaller amount of red phosphor (0.12 wt.\%). The two blocks were always of the same length to allow systematic study of how block length impacted the morphological properties of the polymer. It was found that the molecular weight of the polymer (i.e., block length) was critical to the 


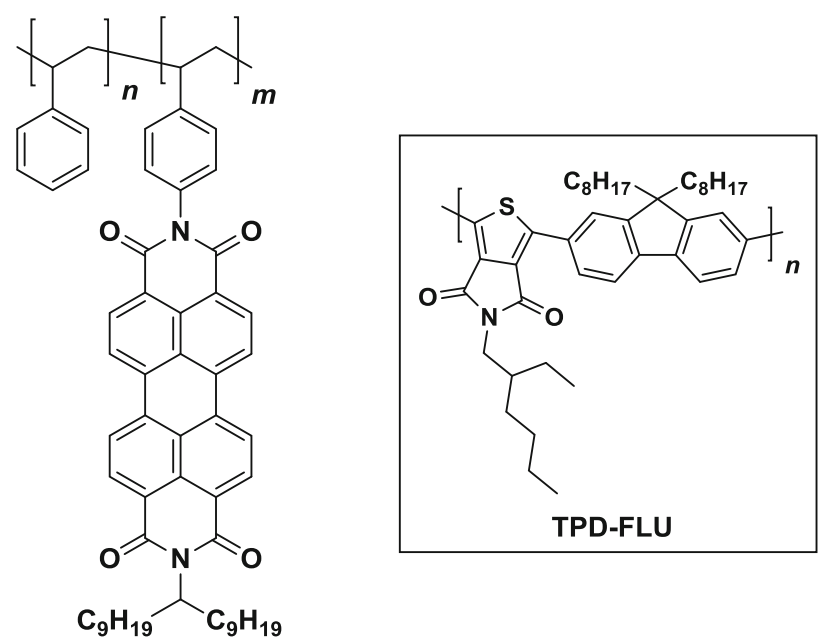

PS-PERY-8: $n / m=24$

PS-PERY-16: $n / m=76$

Fig. 15. Two copolymers of styrene and a red-emitting PDI chromophore, PS-PERY-8 and PS-PERY-16 with 4 mol. $\%$ and $1.3 \mathrm{~mol} . \%$ of PDI units in a polymer chain, respectively. Also shown in the inset is a green-emitting polymer TPD-FLU.

success of site isolation. For example, a copolymer with a low number average molecular weight $\left(M_{\mathrm{n}}\right)$ of $30 \mathrm{kDa}$ did not show any phase separation under the examination of transmission electron microscopy (TEM). However, copolymers with higher $M_{\mathrm{n}}$ from $100 \mathrm{kDa}$ to $150 \mathrm{kDa}$ demonstrated well-separated domains with clear nano-sized lamellar morphology. A single-layer white PLED [ITO/IrP7(10B-co-1R-100)/LiF (1 nm)/Al (100 nm)] using a copolymer of $100 \mathrm{kDa}$ molecular weight with blue to red phosphor ratio of $10 \%$ to $1 \%$ gave the best $\mathrm{EQE}$ of $1.5 \%$. Consistent with the TEM results, for a given ratio of blue to red phosphor (10\% to $1 \%$ or $10 \%$ to $0.5 \%$ ), the contribution of red emission fell when the molecular weight of the polymers increased. Yet, no CIE coordinates of the emissions were reported.

From the phosphorescent polymers discussed, it can be observed that both dendrimer and copolymerization approaches managed to reduce interchromophore interactions along the polymer chain to improve the photophysical properties of the polymers, and a combined use of these two strategies helped to create the optimal device. For example, the highest EQE obtained by DDIr-P1-co-VK copolymer was $14.7 \%,{ }^{30}$ nearly $50 \%$ higher than that of DDIr-P1 homopolymer (EQE: 9.2\%). ${ }^{31}$ One likely reason is that the 1,3-bis(2-ethylhexyloxyphenyl)phenyl dendron was neither a $p$-type nor a $n$-type moiety, and; hence, charge transport in the emitting layer was hampered. A similar phenomenon has been observed in DIr-P1-co-S in which the insulating styrene units limited the device efficiency as a result of compromised charge mobility. ${ }^{29}$ Two strategies for white PLED have been discussed: biphasic Ir-P7(10B-co-xR-MW) for chromophore isolation ${ }^{46}$ and concentration control of the high-energy and low-energy phosphors in (Ir-P5-x-y) for mutual emission. ${ }^{4}$ The achieved EQEs were $1.5 \%$ and $7.1 \%$, respectively. Another strategy for site isolation is to employ dendritic structure in the polymer ${ }^{47,48}$ which is worth a future research effort.

\section{Fluorescent Polymers}

Fluorescent emitters are typically made of light elements ( $\mathrm{C}, \mathrm{H}, \mathrm{O}, \mathrm{N}$, etc.), and; therefore, the vast majority of them are organic materials. Unlike phosphorescent organometallic complexes, most fluorescent emitters have very slow intersystem-crossing (ISC) rates, and; hence, only the singlet excitons can emit. As a result, the maximum IQE achievable is 25\%. Assuming lambertian emission, which results in an outcoupling efficiency of about $20 \%$, the maximum EQE of fluorescence devices will be $25 \% \times 20 \%=5 \% .{ }^{49}$ However, the main advantage of fluorescent emitters over phosphorescent counterparts is the employment of economical organic materials instead of expensive rare metal complexes.

Perylene diimide is an ideal red chromophore with excellent quantum efficiency in dilute solution and supreme photochemical stability. ${ }^{50}$ However, due to its largely planar structure, intermolecular face-to-face stacking results in severe aggregationcaused quenching (ACQ). ${ }^{51}$ Therefore, Kozma et al. prepared two random copolymers of styrene and a red perylene diimide chromophore (PS-PERY-8 and PS-PERY-16, Fig. 15) by nitroxide mediated radical polymerization (NMP) in which the styrene units acted as an inter-chromophore spacer. ${ }^{51}$ PSPERY-8 and PS-PERY-16 contained 4 mol.\% and $1.3 \mathrm{~mol} . \%$ of perylene diimide units respectively in a polymer chain. Both copolymer neat films showed a broad emission from $500 \mathrm{~nm}$ to $700 \mathrm{~nm}$, but PSPERY-16 exhibited a better $\Phi_{\mathrm{PL}}$ of $83 \%$ than PSPERY-8 ( $\Phi_{\mathrm{PL}}: 68 \%$ ) which can be explained by more effective suppression of aggregation-caused quenching (ACQ) in PS-PERY-16 due to its higher styrene content. This was further evidenced by the much lower $\Phi_{\mathrm{PL}}$ of $23 \%$ when polystyrene film was blended with the corresponding amount $(4 \mathrm{~mol} . \%$ or $1.3 \mathrm{~mol} . \%$ ) of perylene diimide vinyl monomer. Instead of a PLED device, a hybrid one was fabricated, where a commercial blue light-emitting diode (Osram) was employed to provide blue light and to act as the excitation light source for a known green polymer (TPD-FLU), and the aforementioned red polymer PS-PERY-16, resulting in a white light device with an EQE and power efficiency of 5\% and $28 \mathrm{~lm} \mathrm{~W}^{-1}$, respectively. The CIE coordinates were $(0.31,0.34)$ and the color-rendering index $(\mathrm{CRI})$ was 83.

Wang and Leung reported two novel blue fluorescent polymers $\mathbf{P}(\mathbf{2 A D N})$ and $\mathbf{P}(\mathbf{3 A D Q})^{52}$ where the 
<smiles>CC(C)C(C)(C)c1ccc2c(-c3ccc4ccccc4c3)c3ccccc3c(-c3ccc4ccccc4c3)c2c1</smiles>

$\mathrm{P}(2 \mathrm{ADN})$<smiles>CC(C)(C)C(c1ccc2c(-c3cnc4ccccc4c3)c3ccccc3c(-c3cnc4ccccc4c3)c2c1)C(C)(C)C</smiles>

$P(3 A D Q)$

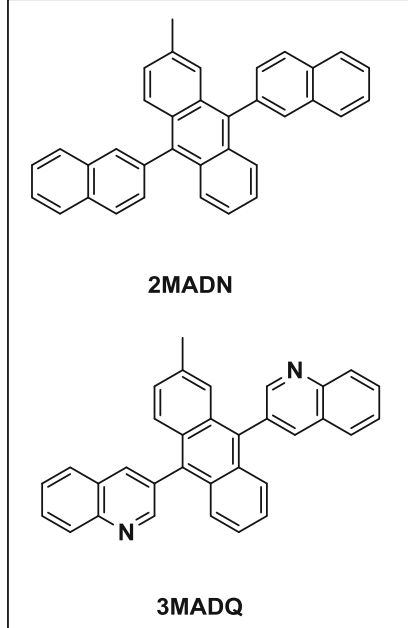

3MADQ<smiles>CC(C)(C)C(c1ccc2c(-c3ccccc3)c3ccccc3c(-c3ccccc3)c2c1)C(C)(C)C</smiles>

$\mathrm{P}(\mathrm{ADN})$<smiles>CC(C)(C)CC(C)(C)C(C)(C)C(c1ccccc1)C(C)(C)C</smiles>

P(ADN-co-S)<smiles></smiles>

P(ADN-co-VK)

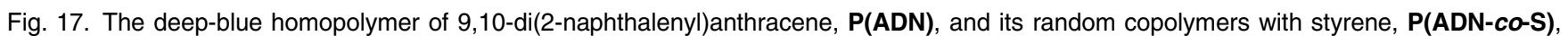
and carbazole, P(ADN-co-VK).

former was derived from the well-noted blue emitter 2MADN $^{53}$ (Fig. 16). P(2ADN) and P(3ADQ) exhibited very high glass-transition temperatures $\left(T_{\mathrm{g}} \mathrm{s}\right)$ of $343^{\circ} \mathrm{C}$ and $298^{\circ} \mathrm{C}$, respectively. Interestingly, P(3ADQ) could be dissolved in ethanol/water mixture $(v: v=1: 1)$ despite its high composition of hydrophobic aromatic rings and alkyl side chain, which was likely the result of extensive hydrogenbonding between the pyridine-type nitrogen atoms and the protic solvents. P(2ADN) and P(3ADQ) showed $\lambda_{\mathrm{PL}}$ at $443 \mathrm{~nm}$ and $452 \mathrm{~nm}$ in THF, respectively, both slightly red-shifted compared with their reference compounds (2MADN: $\lambda_{\text {PL }}$ at $426 \mathrm{~nm}$ and 3MADQ: $\lambda_{\text {PL }}$ at $436 \mathrm{~nm}$ ) which was attributed to the enhanced aggregation of chromophore brought into close proximity by the polymer side chains. In addition, $\mathbf{P}(\mathbf{2 A D N})$ and $\mathbf{P}(\mathbf{3 A D Q})$ exhibited significantly lower $\Phi_{\mathrm{PL}}$ of $43 \%$ and $24 \%$, respectively, than their reference compounds $(80 \%$ and $41 \%$, respectively), further suggesting the presence of chromophore aggregation in the polymer. Neat films of $\mathbf{P}(\mathbf{2 A D N})$ and $\mathbf{P}(\mathbf{3 A D Q})$ emitted in deep-blue regions with $\lambda_{\mathrm{PL}}$ at $448 \mathrm{~nm}$ and $453 \mathrm{~nm}$, respectively. PLED devices (ITO/ $\mathrm{MoO}_{3} / \mathbf{P}(\mathbf{2 A D N})$ or
P(3ADQ)/LiF/Al) were fabricated, but the performances were poor and no device data were reported. The authors attributed the poor efficiency to very low hole mobilities of the polymers, which were in the order of $10^{-7}$ and $10^{-8} \mathrm{~cm}^{2} \mathrm{~V}^{-1} \mathrm{~s}^{-1}$.

Wang et al. then reported a homopolymer $\mathbf{P}(\mathbf{A D N})^{54}$ (Fig. 17) based on a known deep-blue emitter, 9,10-di(2-naphthalenyl)anthracene ${ }^{55}$ and a series of random copolymers with styrene $\mathbf{P}(\mathbf{A D N}-$ co-S) or carbazole $\mathbf{P}(\mathbf{A D N}-\mathbf{c o}-\mathbf{V K})$ (Fig. 17). All the polymers had high $T_{\mathrm{gs}}\left(203-237^{\circ} \mathrm{C}\right)$ which did not change significantly with monomer composition. The homopolymer P(ADN) exhibited a deep-blue emission in tetrahydrofuran (THF) with $\lambda_{\mathrm{PL}}$ at $423 \mathrm{~nm}$ and $442 \mathrm{~nm}$ and a decent $\Phi_{\mathrm{PL}}$ of $40 \%$. When the compositions of styrene or carbazole increased in $\mathbf{P}(\mathbf{A D N}-\mathbf{c o}-\mathbf{S})$ and $\mathbf{P}(\mathbf{A D N}-\mathbf{c o}-\mathbf{V K})$, respectively, their emission profiles became slightly blue-shifted by $c a .5-10 \mathrm{~nm}$, suggesting the presence of chromophore aggregation in the homopolymer P(ADN), similar to the aforementioned $\mathbf{P}(\mathbf{2 A D N})$ and P(3ADQ $)^{52}$ (Fig. 16). This was further evidenced by the gradual $\Phi_{\mathrm{PL}}$ increase of P(AND-co-S) from $40 \%$ to $58 \%$, when the composition of styrene 
<smiles>CC(C)(C)C(C)(C)c1ccc2ccc3cccc4ccc1c2c34</smiles><smiles>CC(C)(C)C(C)(C)C(C)(C)C(C)(C)C</smiles>

P(PyPA)

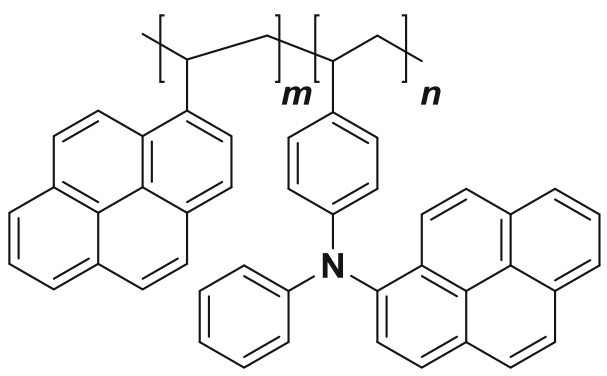

P(PyPA-co-VPy)

Fig. 18. Homopolymers based on pyrene, P(VPy), and 1-(N,N-diphenylamino)pyrene, P(PyPA), and their copolymers, P(PyPA-co-VPy).

increased, which acted as a spacer and effectively prevented chromophore aggregation. However, the opposite was observed for P(AND-co-VK), probably due to the stacking of the carbazole units with ADN chromophores. Indeed, pendant carbazole groups in $\operatorname{poly}(N$-vinylcarbazole $)$ can interact with each other in the excited state and give excimer emissions. ${ }^{56}$ Unfortunately, the PLED device $\left[\mathrm{ITO} / \mathrm{MoO}_{3}\right.$ $(20 \mathrm{~nm}) / \mathbf{P}(\mathbf{A D N}) / \mathrm{LiF} \quad(1 \mathrm{~nm}) / \mathrm{Al} \quad(100 \mathrm{~nm})]$ performed poorly with luminance at only ca. 30$50 \mathrm{~cd} \mathrm{~m}^{-2}$ even at applied voltage as high as $18 \mathrm{~V}$. The authors attributed the poor performance to the low hole mobility $\left(4.7 \times 10^{-8} \mathrm{~cm}^{2} \mathrm{~V}^{-1} \mathrm{~s}^{-1}\right)$ of P(ADN).

Although pyrene is an efficient deep-blue emitter and has been frequently employed in OLED applications, the largely planar aromatic hydrocarbon is very prone to undesirable excimer formation. ${ }^{57-60}$ As a result, even in very dilute solution poly (1-vinylpyrene) (P(VPy), Fig. 18) shows an exclusively green emission with $\lambda_{\mathrm{PL}}$ at $491 \mathrm{~nm}$ and a low $\Phi_{\mathrm{PL}}$ of $13 \%$ due to excimer emission of pyrene moieties brought into a close distance by the polymer side chain. ${ }^{61}$ In order to solve this problem, Wang et al. prepared a novel polymer P(PyPA) (Fig. 18) where the propeller structure of diphenylamino group was used to induce steric hindrance around the pyrene moiety to suppress excimer formation. ${ }^{61}$ This strategy proved to be successful so that P(PyPA) showed a slightly red-shifted $\lambda_{\mathrm{PL}}$ at $475 \mathrm{~nm}$ in THF compared with the reference compound 1-( $N, N$-diphenylamino)pyrene (PyPA, $\left.\lambda_{\mathrm{PL}}: 460 \mathrm{~nm}\right)$. The $\Phi_{\mathrm{PL}}$ of P(PyPA) $(48 \%)$ was also comparable to that of PyPA ( $\left.\Phi_{\mathrm{PL}}: 61 \%\right)$. A series of copolymers of pyrene and PyPA, P(PyPA-co-VPy) (Fig. 18), were also synthesized, and it was found that increasing pyrene content gradually redshifted the emission, suggesting more prominent excimer formation of the pyrene moieties in the polymer. Interestingly, all the copolymers had the same $\Phi_{\mathrm{PL}}$ of $51 \%$. They all showed very similar $T_{\mathrm{g}} \mathrm{s}$ $\left(190-197^{\circ} \mathrm{C}\right)$ too. PLED devices [CFx-treated ITÖ/ P(PyPA) or P(VPy) or P(PyPA-co-VPy) (50$60 \mathrm{~nm}) / \mathrm{TPBI}(20 \mathrm{~nm}) / \mathrm{LiF}(1 \mathrm{~nm}) / \mathrm{Al}(100 \mathrm{~nm})]$ were fabricated and P(PyPA) gave the best current

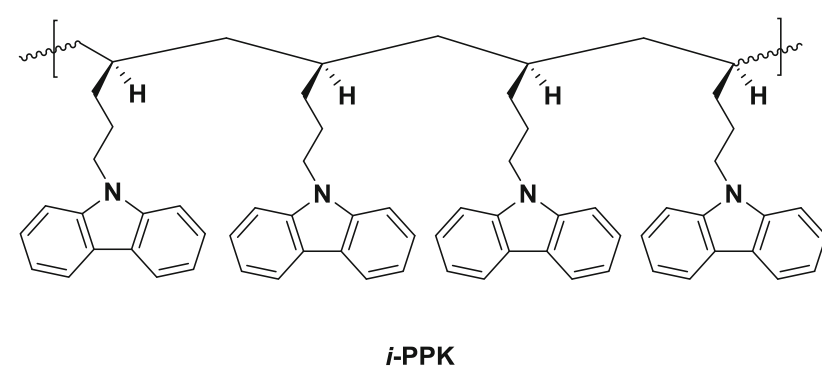

Fig. 19. Isotactic poly( $N$-pentyl-carbazole) (i-PPK) for white PLED application.

efficiency of $1.1 \mathrm{~cd} \mathrm{~A} \mathrm{~A}^{-1}$, but with a green $\lambda_{\mathrm{EL}}$ at $c a$. $521 \mathrm{~nm}$.

Tacticity controls the stereoregularity of the polymer and its interchain stacking behaviours and, hence, can be important in PLED. For example, syndiotactic poly(diphenylaminostyrene) was found to exhibit higher hole drift mobility than isotactic ones. ${ }^{62}$ Botta and co-workers prepared an isotactic $\operatorname{poly}(N$-pentyl-carbazole) (i-PPK, Fig. 19) by a homogeneous Ziegler-Natta catalytic system of rac- $\left.\left[\left(\mathrm{CH}_{3}\right)_{2} \mathrm{Si} \text { (indenyl }\right)_{2}\right] \mathrm{ZrCl}_{2}$ and methylallumoxane (MAO) in toluene at $20^{\circ} \mathrm{C} .^{63}$ Interestingly, $\boldsymbol{i}$ PPK film showed a broad emission spectrum from $350 \mathrm{~nm}$ to $600 \mathrm{~nm}$, probably due to the presence of singlet and triplet excimers similar to the case of poly $(N$-vinylcarbazole $){ }^{56}$ Given the broad emission, $\boldsymbol{i}$-PPK was an ideal candidate for white PLED device [ITO/PEDOT:PSS $(40 \mathrm{~nm}) / \boldsymbol{i}$-PPK $(70 \mathrm{~nm}) /$ $\left.\mathrm{BCP}(10 \mathrm{~nm}) / \mathrm{Alq}_{3}(10 \mathrm{~nm}) / \mathrm{Ca}(30 \mathrm{~nm}) / \mathrm{Al}(70 \mathrm{~nm})\right]$ which gave a broad electroluminescence spectrum covering from $400 \mathrm{~nm}$ to $800 \mathrm{~nm}$ with three peaks at $420 \mathrm{~nm}, 520 \mathrm{~nm}$, and $620 \mathrm{~nm}$. However, the efficiency was low and no numerical data were reported.

Cappelli et al. reported two interesting $\pi$-stacked polybenzofulvenes decorated with triphenylamine donor for PLED applications (Poly-6-TPA-BF3 k and Poly-4'-TPA-6-MO-BF3 k, Fig. 20). ${ }^{64}$ Other similar $\pi$-stacked polymers include poly(dibenzofulvene) $s^{65-67}$ and polyvinylsilafluorene ${ }^{68}$ which have been applied in organic field-effect transistor and 


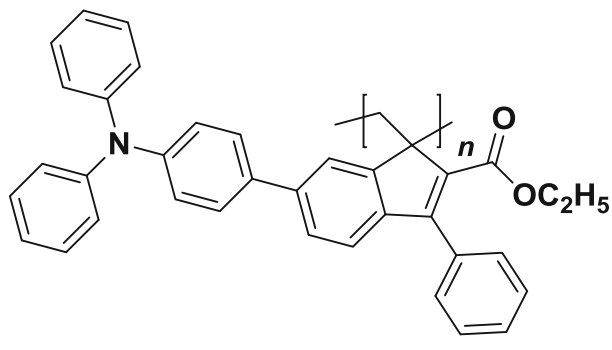

Poly-6-TPA-BF3k

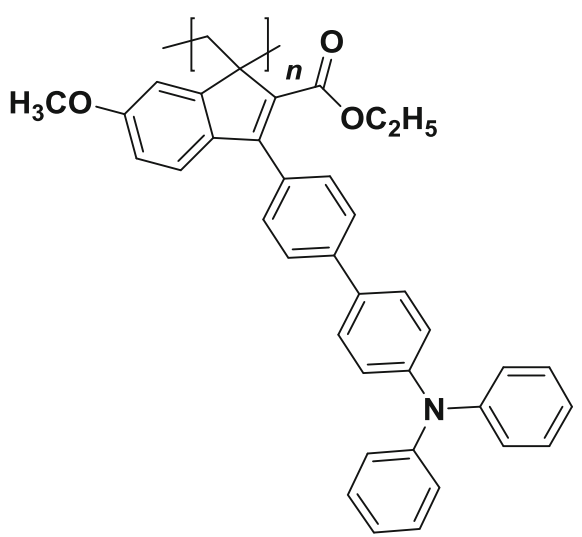

Poly-4'-TPA-6-MO-BF3k

Fig. 20. Two $\pi$-stacked polybenzofulvenes decorated with triphenylamine donor (Poly-6-TPA-BF3 k and Poly-4'-TPA-6-MO-BF3 k) for PLED applications.

nanofuse applications, respectively, but not in PLEDs. An unusual spontaneous polymerization (repeated concentration of monomer solutions in chloroform under reduced pressure for five times, then precipitation in ethanol) was employed to produce Poly-6-TPA-BF3 k and Poly-4'-TPA-6MO-BF3 k which had high $M_{\mathrm{n}}$ of $233 \mathrm{kDa}$ and $353 \mathrm{kDa}$ as well as PDI of 2.6 and 2.7 , respectively. Neat films of Poly-6-TPA-BF3 k and Poly-4'-TPA6-MO-BF3 k showed $\lambda_{\mathrm{PL}}$ at $542 \mathrm{~nm}$ and $478 \mathrm{~nm}$ with $\Phi_{\mathrm{PL}}$ of $23 \%$ and $9 \%$, respectively. PLED devices [ITO/PEDOT:PSS $(50 \mathrm{~nm}) /$ Poly-6-TPABF3 k $(210 \mathrm{~nm})$ or Poly-4'-TPA-6-MO-BF3 k $(214 \mathrm{~nm}) / \mathrm{Ba}(8 \mathrm{~nm}) / \mathrm{Al}(70 \mathrm{~nm})]$ gave poor EQEs of $0.008 \%$ and $0.0015 \%$, respectively.

Most of the non-conjugated fluorescent polymers in this survey performed poorly in PLED devices. One main reason is their inability to utilize dark triplet excitons in the device, which constitute as large as $75 \%$ of total excitons. Thanks to the recent advances of thermally activated delayed fluorescence (TADF) mechanism ${ }^{69-72}$ (vide infra) which allow purely organic materials to recruit dark triplets and ,hence, achieve 100\% IQE, it is expected that the 1st generation fluorescent emitters will soon fade.

\section{Thermally Activated Delayed Fluorescence (TADF) Polymers}

TADF is the third generation OLED mechanism, which utilizes the dark triplet excitons by thermally up-converting them to emissive singlet excitons via reverse intersystem-crossing (RISC) as a result of a vanishingly small energy gap $\left(\Delta \mathrm{E}_{\mathrm{ST}}\right)$ between the lowest singlet state $\left(S_{1}\right)$ and the lowest triplet state $\left(T_{1}\right){ }^{69-72}$ The key merit of the TADF mechanism is to allow purely organic emitters made of light elements $(\mathrm{C}, \mathrm{H}, \mathrm{O}, \mathrm{N}$ etc.) to achieve comparable EQE (20-30\%) to the expensive second generation phosphorescent emitters made of rare heavy metals

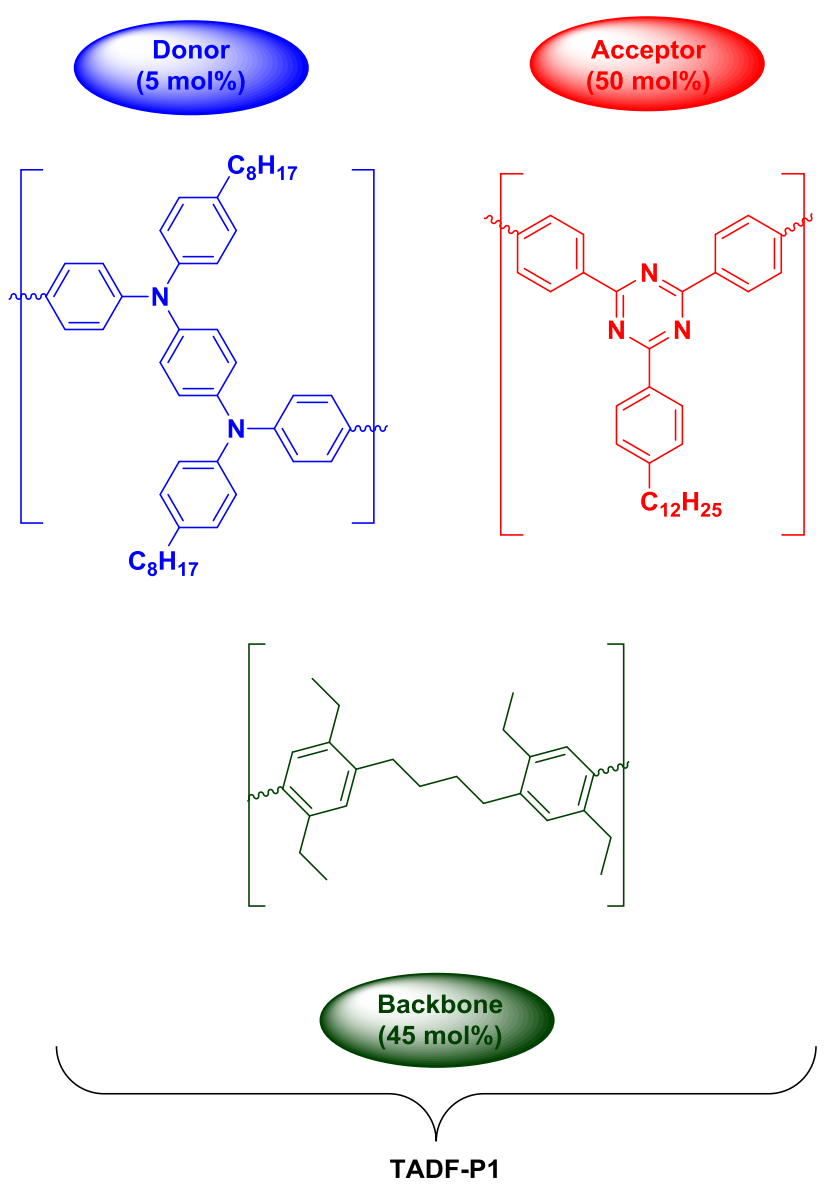

Fig. 21. Composition of the first TADF polymer (TADF-P1) which consists of $5 \mathrm{~mol} . \%$ triphenylamine donor, 50 mol.\% 1,3,5-triazine acceptor and a 45 mol.\% backbone with an insulating $n$-butyl linkage. Adapted with permission from Ref. 77 . Copyrighted by Wiley.

such iridium and platinum. ${ }^{69,70,72}$ Currently, the vast majority of TADF emitters are small molecules with devices that were fabricated by the costly 


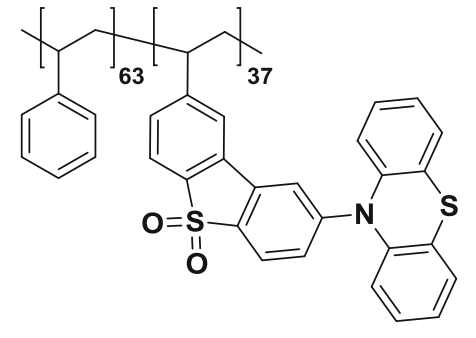

TADF-P2

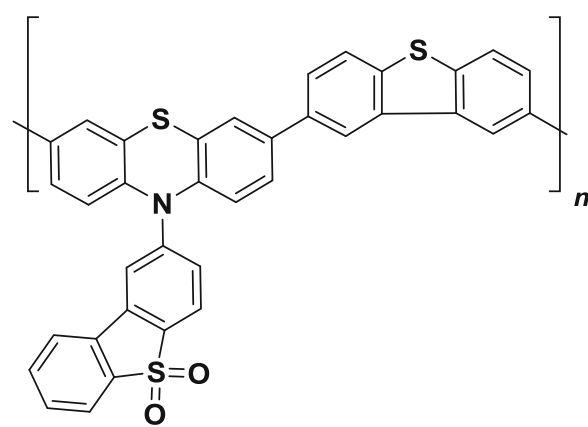

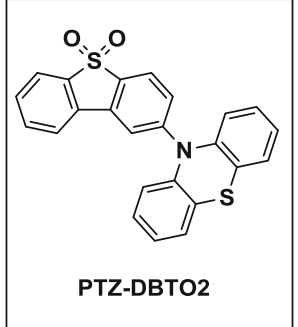

TADF-P3

Fig. 22. Chemical structures of non-conjugated and conjugated TADF copolymers (TADF-P2 and TADF-P3, respectively) reported by Nobuyasu and co-workers. Also shown in the inset is the prototypical TADF emitter PTZ-DBTO2. Adapted with permission from Refs. 21 and 80. Copyrighted by the American Chemical Society and Wiley.

vacuum thermal evaporation technique ${ }^{69,70,72}$ with a few exceptions. ${ }^{73-75}$ Polymeric emitters, on the other hand, are solution-processable and enjoy more facile device fabrication procedure.

Unexpectedly, it took 4 years after the pioneering study of the organic TADF emitter in $2011^{76}$ for the first TADF polymer to be reported by Nikolaenko and co-workers who prepared TADF-P1 ${ }^{77}$ (Fig. 21) with a TADF chromophore that is very similar to that of DPA-TRZ ${ }^{78}$ reported by Shizu and coworkers. The polymer consists of $5 \mathrm{~mol} . \%$ triphenylamine donor, $50 \mathrm{~mol} . \%$ 1,3,5-triazine acceptor and a $45 \mathrm{~mol} . \%$ backbone unit with an insulating $n$-butyl linkage. The much higher composition of the 1,3,5-triazine acceptor serves to balance the hole and electron mobilities of the polymer so that the recombination zone could be located near the center of the polymeric emitting layer. The insulating $n$ butyl linkage in the backbone unit is important because it limits conjugation length to avoid generating triplet traps in the polymer. ${ }^{79}$ The polymer neat film showed $\lambda_{\mathrm{PL}}$ at $540 \mathrm{~nm}$ and $\Phi_{\mathrm{PL}}$ of $44 \%$, with a considerably small $\Delta \mathrm{E}_{\mathrm{ST}}$ of $0.22 \mathrm{eV}$. PLED device [ITO (45 nm)/PEDOT:PSS (65 nm)/interlayer $(40 \mathrm{~nm}) / \mathbf{T A D F}-\mathbf{P 1}(80 \mathrm{~nm}) / \mathrm{NaF}(2 \mathrm{~nm}) / \mathrm{Al}(100 \mathrm{~nm}) /$ $\mathrm{Ag}(100 \mathrm{~nm})]$ gave a green $\lambda_{\mathrm{EL}}$ at $\sim 530 \mathrm{~nm}$ and CIE at $(0.32,0.58)$ with an EQE of $10.0 \%$. Yet, the authors did not report any characterization data (nuclear magnetic resonance (NMR) spectroscopy, infrared (IR) spectroscopy, gel-permeation chromatography (GPC), etc.) of their polymer.

Nobuyasu et al. designed a novel TADF emitter PTZ-DBTO2 (Fig. 22) whose crystal structure showed a nearly perpendicular arrangement between the phenothiazine donor and the dibenzosulfone acceptor moieties. ${ }^{80}$ As a result, the HOMO and LUMO are largely separated, resulting in a $\Delta \mathrm{E}_{\mathrm{ST}}$ as small as $0.018 \mathrm{eV}$. Two different types of copolymers, non-conjugated TADF-P2 (copolymerized with styrene, Fig. 22) and conjugated TADF-P3 (copolymerized with dibenzothiophene, Fig. 22), containing the PTZ-DBTO2 chromophore, were synthesized. Both
TADF-P2 and TADF-P3 neat films showed $\lambda_{\mathrm{PL}}$ at $565 \mathrm{~nm}$ but the authors did not report any $\Phi_{\mathrm{PL}}$ data of PTZ-DBTO2 and the two copolymers. Indeed, the absorption of PTZ-DBTO2 in toluene showed little sign of intramolecular charge-transfer (ICT) contribution, suggesting very limited overlap between the frontier molecular orbitals, which should result in a small transition dipole moment and, hence, a slow radiative rate constant $\left(k_{r}\right)^{78,81}$ TADF-P2 was applied as a dopant in the small-molecule CBP host (10 wt.\%) while TADF-P3 also doped in PBD and PVK at a weight ratio of 1:4:5. Devices of TADF-P2 [ITO/PEDOT:PSS $(40 \mathrm{~nm}) / 10 \mathrm{wt} \%$ TADF-P2 in CBP $(25 \mathrm{~nm}) / \mathrm{TPBi}(50 \mathrm{~nm}) / \mathrm{LiF}(1 \mathrm{~nm}) / \mathrm{Al}(100 \mathrm{~nm})]$ and TADF-P3 [ITO/PEDOT:PSS $(40 \mathrm{~nm}) / 10 \mathrm{wt} . \%$ TADF-P3 and $40 \mathrm{wt} . \%$ PBD in PVK $(25 \mathrm{~nm}) / \mathrm{TPBi}$ $(50 \mathrm{~nm}) / \mathrm{LiF}(1 \mathrm{~nm}) / \mathrm{Al}(100 \mathrm{~nm})]$ gave EQEs of $2.3 \%$ and $11.1 \%$, respectively, but no information about the emission colors was given.

A follow-up study by the same group investigated the impact of styrene content in a series of copolymers of styrene and PTZ-DBTO2 chromophore on their photophysical properties and device performance. ${ }^{21}$ A homopolymer of PTZ-DBTO2 was also synthesized and studied. It was found that, with increasing styrene composition in the polymers, the contribution of the delayed fluorescence became more significant due to suppressed triplet-triplet annihilation (TTA) because the concentration of PTZ-DBTO2 chromophore in the polymer was diluted. Polymer with the lowest PTZ-DBTO2 composition (37 mol.\%, i.e., TADF-P2) exhibited the smallest $\Delta \mathrm{E}_{\mathrm{ST}}$ of $0.35 \mathrm{eV}$, while other polymers (46 mol.\%, $67 \mathrm{~mol} . \%$, and $100 \mathrm{~mol} . \%$ PTZ-DBTO2) had larger values $(0.40-0.46 \mathrm{eV})$. Again, no $\Phi_{\mathrm{PL}}$ data were reported. Similar to their previous study ${ }^{80}$ all the polymers were doped in a smallmolecule host $(10 \mathrm{wt} . \%)$ but this time $\mathrm{mCP}$ was employed due to its much higher triplet energy $(2.9 \mathrm{eV})$ than that of CBP $(2.56 \mathrm{eV})$ in order to confine triplet excitons on the PTZ-DBTO2 chromophore so that undesirable TTA and host 
<smiles>C=CC(=O)OCCOC(=O)CCC(=O)OC(C)c1ccc(-c2ccc(N(c3ccc(C=C(C#N)C#N)cc3)c3ccc(-c4ccc(C(C)OC(=O)CCC(=O)OCCOC(=O)C=C)cc4)cc3)cc2)cc1</smiles><smiles>CC(C)(C)c1ccc(-c2ccc(N(c3ccc(C=C(C#N)C#N)cc3)c3ccc(-c4ccc(C(C)(C)C)cc4)cc3)cc2)cc1</smiles>

FVIN

FVIN-A

Fig. 23. Chemical structures of cross-linkable orange-red emitter FVIN-A and its noncross-linkable reference FVIN.

quenching could be minimized. Device (ITO/PEDOT:PSS $(40 \mathrm{~nm}) / 10 \mathrm{wt} . \%$ TADF-P2 in $\mathrm{mCP}$ $(45 \mathrm{~nm}) / \mathrm{TPBi} \quad(30 \mathrm{~nm}) / \mathrm{LiF} \quad(1 \mathrm{~nm}) / \mathrm{Al} \quad(100 \mathrm{~nm})$ exhibited the highest EQE of $20.1 \%$ among all polymers, which was far better than using CBP as host (EQE: $2.3 \%){ }^{80}$ As expected, the device EQEs showed a clear positive correlation with styrene content. For example, the homopolymer of PTZDBTO2 chromophore gave a low EQE of $1.4 \%$ only.

The best performing non-conjugated TADF polymer in this review is TADF-P2 with a device that gave an EQE of $20.1 \%,{ }^{21}$ yet it should be noted that the polymer was doped in a large amount (90 wt.\%) of small-molecule mCP host as the emitting layer. On the other hand, neat TADF-P1 as the emitting layer gave a decent EQE of $10 \%{ }^{77}$ Intuitively, TADF polymers should be based on a non-conjugated backbone to prevent triplet trap formation as triplet energy has been known to decrease rapidly with increasing effective conjugation length. ${ }^{79,82}$ However, there have been several reports of conjugated TADF polymers with chromophores either grafted ${ }^{83,84}$ or built-in along the polymer main-chain ${ }^{85-87}$, and most of them performed nicely in PLED devices (EQE: 2.2-16.1\%). Wei et al. recently demonstrated how a TADF-inactive carbazole-based monomer could be turned into a TADF-active macromolecule (macrocycle or polymer). ${ }^{88}$ These results suggest that TADF polymers can be constructed with either conjugated or nonconjugated backbones, and they perform equally well.

\section{Cross-Linked Polymers}

Much research effort has been devoted to allsolution-processed devices (i.e., every organic layer in the device is deposited by a wet process) to significantly reduce fabrication cost. ${ }^{89,90}$ However, the main obstacle is the dissolution of the previous organic layer by the solvent used for the deposition of the current layer. One resolution is to first spincast cross-linkable materials on the substrate followed by thermal- ${ }^{91}$ or photo-induced ${ }^{92,93}$ crosslinking so as to transform them into an insoluble polymeric layer. The main advantage of the crosslinking approach over other methods such as use of orthogonal solvent $^{94}$ and polyelectrolyte route ${ }^{95}$ is that the intractable cross-linked layer is resistant to all organic solvents. On the other hand, in some cases thermal- or photo-induced cross-linking can cause damage to the organic materials of the device. ${ }^{92}$

Derue et al. prepared a cross-linkable orange-red emitter FVIN-A (Fig. 23) which generated an excellent film after ultraviolet irradiation with a $R_{\mathrm{q}}$ (rootmean-square surface roughness) as low as $0.7 \mathrm{~nm} .{ }^{92}$ The film showed a $\lambda_{\mathrm{PL}}$ at $635 \mathrm{~nm}$ with a high $\Phi_{\mathrm{PL}}$ of $37 \%$. An all-solution-processed device [ITO/PEDOT:PSS $(40 \mathrm{~nm}) / \mathrm{QUPD}(35 \mathrm{~nm}) / \mathbf{F V I N}-\mathbf{A}(25 \mathrm{~nm}) /$ TPBI $(50 \mathrm{~nm}) / \mathrm{LiF}(1 \mathrm{~nm}) / \mathrm{Al}(100 \mathrm{~nm})]$ showed $\lambda_{\mathrm{EL}}$ and $\mathrm{CIE}$ at $600 \mathrm{~nm}$ and $(0.54,0.45)$, respectively, where QUPD is a commercial cross-linkable holetransporting material first reported by Yang and coworkers. ${ }^{96} \mathrm{~A}$ rather weak EQE of $0.30 \%$ was obtained, which is attributed to low density of electroactive content in the cross-linked FVIN-A film due to its incomplete photopolymerization, and; therefore, charge transport in the film was seriously hampered. A reference device with thermally deposited FVIN and TPBI layers with identical device architecture and thickness showed similar 
<smiles>CCC1(COCC(C)(C)COCC2(CC)COC2)COC1</smiles>

X-H1

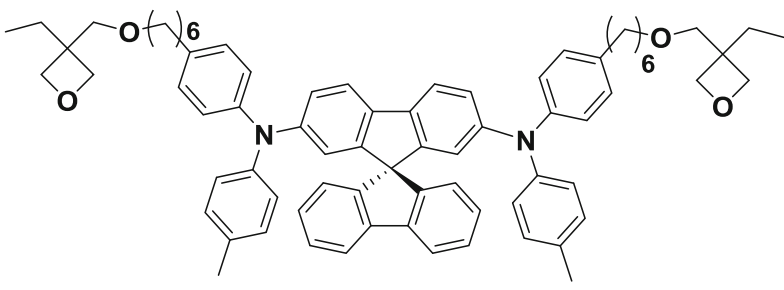

$X-\mathrm{H} 2$

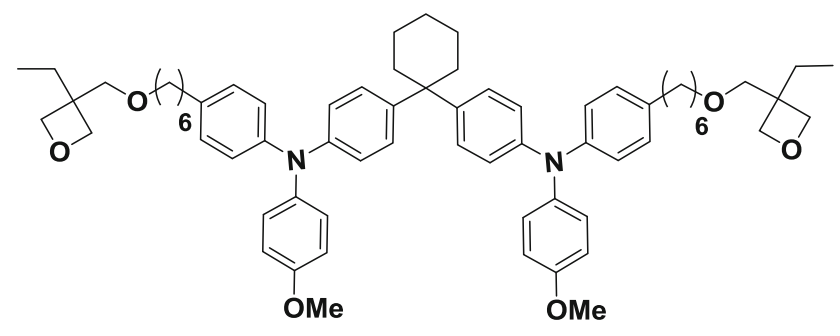

X-TAPC

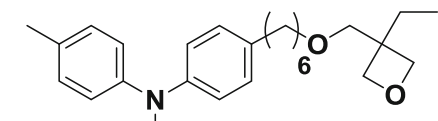

X-IrG3

Fig. 24. Chemical structures of X-H1, X-H2, X-TAPC and X-IrG3.

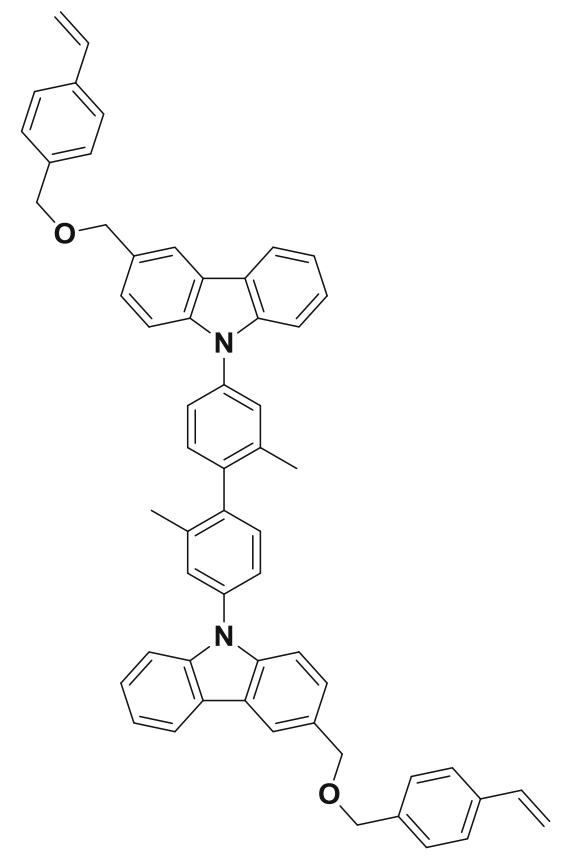

DV-CDBP
$\Longrightarrow$<smiles>C=CC(=O)S(=O)(=O)c1ccc(-n2c3ccccc3c3cc(O)ccc32)cc1</smiles>

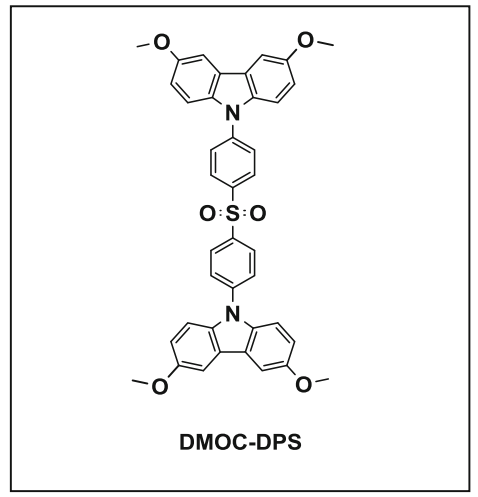

o<smiles>C=Cc1ccc(C)cc1</smiles>

DV-MOC-DPS

Fig. 25. Chemical structures of cross-linkable monomers DV-CDBP (as host) and DV-MOS-DPS (as TADF chromophore). Also shown in the inset is the DMCO-DPS prototype. ${ }^{97}$ Adapted with permission from Refs. 91 and 97 . Copyrighted by the Royal Society of Chemistry.

efficiency (EQE: 0.37\%) to the all-solution-processed analogue.

Liaptsis and co-workers applied the "doubleemission layers" (DEL) strategy in their all-solution-processed phosphorescent device. ${ }^{93}$ In DEL design, two emitting layers with different hosts are fabricated adjacent to each other so that charge carriers can be confined at their interface in order to prevent exciton leakage into other undoped layers. Two cross-linkable hosts (X-H1 and X-H2, Fig. 24) 
<smiles>C=Cc1ccc(N(c2ccccc2)c2ccccc2)cc1</smiles>

TPA<smiles>C=Cc1ccc(-c2nnc(-c3ccc(C(C)(C)C)cc3)o2)cc1</smiles>

OXD<smiles></smiles>

Miniemulsion $\stackrel{\text { polymerization }}{\longrightarrow} \because \because \bullet)$

polymeric nanoparticles for spincasting

Ir-R

Fig. 26. The preparation of blue and red phosphorescent polymeric particles by miniemulsion copolymerization to achieve site isolation for white OLED application.

and phosphor (X-IrG3, Fig. 24) functionalized with oxetane groups were prepared. Doped films of $\mathbf{X}$ IrG3 (8 wt.\%) in X-H1 and X-H2 showed excellent $\Phi_{\mathrm{PL}}$ of $86 \%$ and $90 \%$, respectively, under excitation at $355 \mathrm{~nm}$. All-solution-processed device [ITO/PEDOT:PSS $(35 \mathrm{~nm}) / \mathrm{X}$-TAPC $(10 \mathrm{~nm}) / 8$ wt.\% X-IrG3:XH2 $(20 \mathrm{~nm}) / 8$ wt.\% X-IrG3:X-H1 $(20 \mathrm{~nm}) / \mathrm{TPBI}$ $(40 \mathrm{~nm}) / \mathrm{CsF}(2 \mathrm{~nm}) / \mathrm{Al}(100 \mathrm{~nm})]$ gave a green-yellow $\lambda_{\mathrm{EL}}$ at $530 \mathrm{~nm}$ and a shoulder at $c a .570 \mathrm{~nm}$ with a maximum current efficiency of $33.5 \mathrm{~cd} \mathrm{~A}^{-1}$. Devices employing a single emission layer with X-H1 and X-H2 as hosts gave comparable maximum current efficiencies of $29.1 \mathrm{~cd} \mathrm{~A}^{-1}$ and $34.4 \mathrm{~cd} \mathrm{~A}^{-1}$ respectively.

Sun et al. prepared a cross-linkable deep-blue thermally activated delayed fluorescence (TADF) emitter DV-MOC-DPS ${ }^{91}$ derived from the DMOCDPS $^{97}$ prototype reported by Adachi's group (Fig. 25). A cross-linkable host DV-CDBP with a high triplet energy of $2.95 \mathrm{eV}$ to prevent back energy transfer from the deep-blue dopant was also synthesized. It was found that cross-linked film of 9 wt.\% DV-MOC-DPS:DV-CDBP exhibited the highest $\Phi_{\mathrm{PL}}$ of $71 \%$ among other ratios $(6 \mathrm{wt} . \%$ and $12 \mathrm{wt} . \%$ ) and the film also showed an excellent surface quality with a small $R_{\mathrm{q}}$ of $0.6-0.7 \mathrm{~nm}$. The
PLED device [ITO/PEDOT:PSS (30 nm)/9 wt.\% DVMOC-DPS:DV-CDBP $(50 \mathrm{~nm}) / \mathrm{TPBI} \quad(40 \mathrm{~nm}) /$ $\left.\mathrm{CsCO}_{3}(2 \mathrm{~nm}) / \mathrm{Al} \quad(100 \mathrm{~nm})\right]$ exhibited $\lambda_{\mathrm{EL}}$ at $444 \mathrm{~nm}$ with an EQE of $2.0 \%$.

Gao and co-workers achieved emitter site isolation for white phosphorescent OLED by cross-linked nanoparticles to suppress undesirable energy transfer from blue to red phosphor. ${ }^{98}$ An important advantage of cross-linked nanoparticles over noncross-linked ones is that the former can be stored in a dry state without losing particle shape, which is not possible for the latter that must be stored in aqueous dispersion to preserve the shape. Freeradical copolymerization of TPA, OXD, Ir-B or Ir-G and divinylbenzene cross-linker at a weight ratio of $1: 1: 10 \%: 8 \%$ in a miniemulsion system afforded the blue- and red-emitting polymeric nanoparticles (Fig. 26). An emitting layer consisting of blue and red nanoparticles together with a linear co-polymer $\mathrm{P}$ (TPA-co-OXD) at a weight ratio of $3: 1: 4$ offered a near white device [ITO/PEDOT-PSS $(40 \mathrm{~nm}) / \mathrm{emit}$ ting layer $(65 \mathrm{~nm}) / \mathrm{BCP} \quad(40 \mathrm{~nm}) / \mathrm{LiF} \quad(1 \mathrm{~nm}) / \mathrm{Al}$ $(100 \mathrm{~nm})]$ with CIE at $(0.40,0.42)$ and an EQE of $\sim 1 \%$.

Wettach and co-workers fabricated an all-solution-processed deep-blue OLED using cross-linkable 


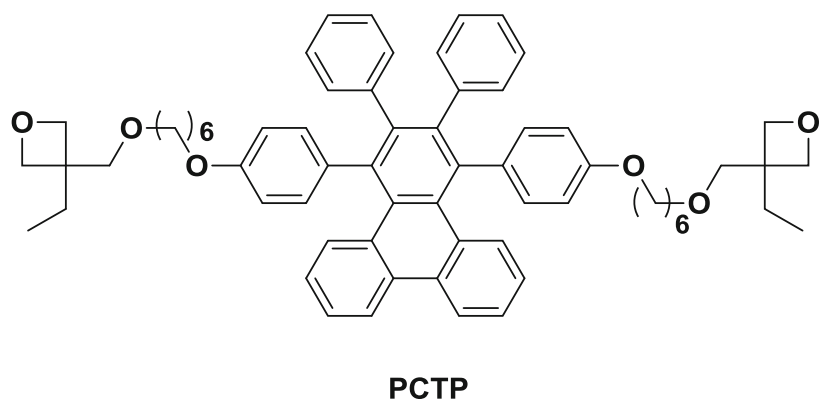

Fig. 27. Chemical structure of cross-linkable deep-blue emitter based on triphenylene moiety (PCTP).

emitter based on triphenylene chromophore (PCTP, Fig. 27) ${ }^{99}$ The device [ITO/PEDOT:PSS $(35 \mathrm{~nm}) /$ QUPD $(20 \mathrm{~nm}) / \mathrm{OTPD}(10 \mathrm{~nm}) / \mathbf{P C T P}(80 \mathrm{~nm}) / \mathrm{Ba}$ $(4 \mathrm{~nm}) / \mathrm{Al}(150 \mathrm{~nm})]$ exhibited $\lambda_{\mathrm{EL}}$ at $456 \mathrm{~nm}$, but the blue emission was contaminated by a broad lowenergy emission extended up to $800 \mathrm{~nm}$ with peaks at $\sim 600 \mathrm{~nm}$ and $\sim 750 \mathrm{~nm}$, which is attributed to exciton leakage to the adjacent OTPD layer (a crosslinkable hole-transporting material reported by Yang and co-workers). ${ }^{96}$ The efficiency of the device was poor, which reached a current efficiency of $\sim 0.2 \mathrm{~cd} \mathrm{~A}^{-1}$ at most, probably due to the low emission capability of the PCTP emitter $\left(\Phi_{\mathrm{PL}}: 3 \%\right.$ in DCM).

While cross-linkable materials enable all-solution-processed devices to reduce fabrication cost, most devices based on these materials showed poorer performance than their polymer analogues. For example, a device based on cross-linked phosphor X-IrG3 gave a current efficiency of $34.4 \mathrm{~cd} \mathrm{~A} \mathrm{~A}^{-1}$ in the green-yellow region ${ }^{93}$ and that using crosslinked phosphorescent nanoparticles Ir-B and Ir-G resulted in a low EQE of $\sim 1 \%,{ }^{98}$ those efficiencies being lower than the best EQE obtained from the phosphorescent copolymer DDIr-P1-co-VK ${ }^{30}$ (EQE: $14.7 \%)$.* In addition, the device based on crosslinked DV-CDBP (as host) and DV-MOS-DPS (as TADF chromophore) gave an EQE of $2.0 \%$ whereas TADF polymer TADF-P2 offered a much higher EQE of $20.1 \% .^{21}$ One possible reason for the lower device efficiency is the very limited characterization and purification available for the resulting intractable cross-linked polymer film.

\section{CONTRASTING CONJUGATED POLYMERS WITH NON-CONJUGATED COUNTERPARTS FOR PLED APPLICATIONS}

Polymers employed in PLED applications can be constructed with either conjugated or non-conjugated backbones. Both of them have been widely employed, but a systematic comparison between

\footnotetext{
*In general, current efficiency in the green-yellow region can be roughly approximated into EQE by dividing by a factor of 3 to 4 . See Refs. 85 and 100-102.
}

these two classes of materials is rarely attempted. An understanding on the similarities and differences between conjugated polymers and non-conjugated counterparts is essential to the workers in the field when it comes to design of the desired polymers for PLED applications. Moreover, knowledge about structure-property relationship PLED polymers can be reinforced.

\section{Conjugated versus Non-conjugated Polymers: Material Preparations}

There are several important parameters for the synthesis of polymers. Polymerization yield is obviously the integral factor for the economy of the polymer. The number-average molecular weight $\left(M_{\mathrm{n}}\right)$ is a critical property that impacts the practical applications of the polymer. According to the wellknown Mark-Houwink equation ${ }^{123}$ :

$$
\mu=K \times M_{\mathrm{w}}^{a},
$$

where $\mu$ and $M_{\mathrm{w}}$ refer to viscosity of the polymer solution and weight-average molecular weight of the polymer, respectively. $K$ and $a$ are both constants, where the former is related to polymer species, temperature as well as solvent and the latter to polymer conformation. A high molecular weight is important to attain sufficient viscosity of the polymer solution for generating high-quality thin film. ${ }^{32}$ Conjugated polymers with higher molecular weight are shown to have better charge mobility because long polymer chains serve as interconnections between ordered phases of the polymer film. ${ }^{124}$ In addition, high-molecular-weight alternating copolymer of fluorene and $\mathrm{MeH}-\mathrm{PPV}$ showed a much higher $\Phi_{\mathrm{PL}}$ of $61.2 \%$ than the low molecular weight analogue $\left(\Phi_{\mathrm{PL}}: 26.8 \%\right)$ whose short polymer chains were more rod-like, which resulted in more pronounced $\pi$ - $\pi$ stacking and hence greater energy transfer to the quenching site. ${ }^{123}$ Under certain circumstances, a high-molecularweight polymer is not necessarily superior to a low-molecular-weight one, but workers can make a wise use of their different physical properties. For instance, Al-Attar and Monkman fabricated an allsolution processed OLED device, in which a lowmolecular-weight poly( $N$-vinylcarbazole $)$ doped with $\operatorname{Ir}(\text { ppy })_{3}$ as the emitting layer, was spun-coated on a high-molecular-weight poly( $N$-vinylcarbazole) which functioned as the hole transport electron blocking layer. ${ }^{125}$ Undesirable interlayer mixing during the fabrication of the low-molecular-weight $\operatorname{poly}(N$-vinylcarbazole) was prevented because the dissolution of the high-molecular-weight $\operatorname{poly}(N$ vinylcarbazole) in toluene (spin-coating solvent) was very slow. Polydispersity index (PDI) has a significant impact on the effective conjugation length homogeneity of the polymer chains which in turn affects the emission colors, formation of undesirable charge traps and interchain packing in the polymer. ${ }^{33,126,127}$ 
Table I. Summary of polymerization method, yield, $M_{\mathrm{n}}$ and PDI of the non-conjugated polymers reported recently (2010-present)

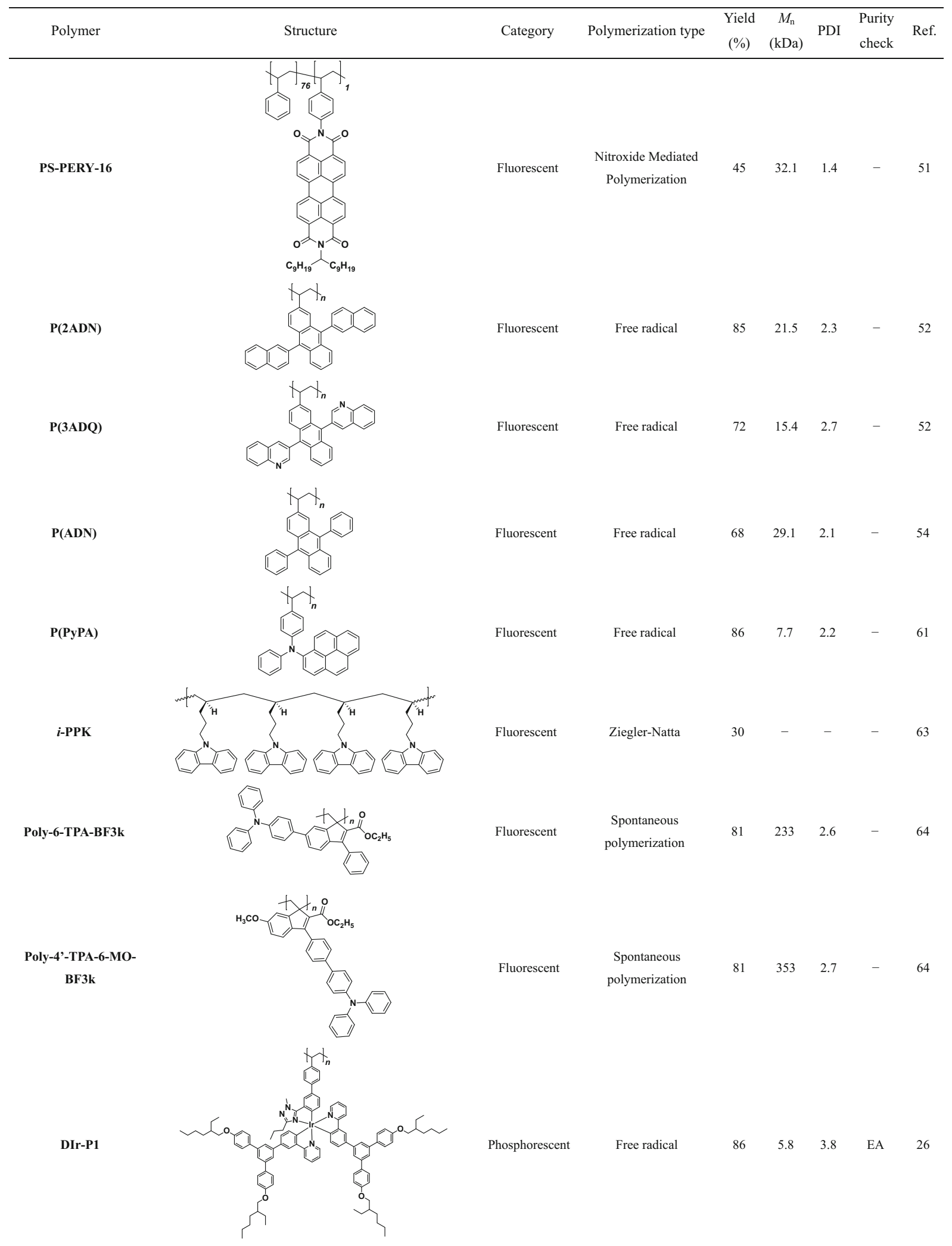




\section{Table I. continued}

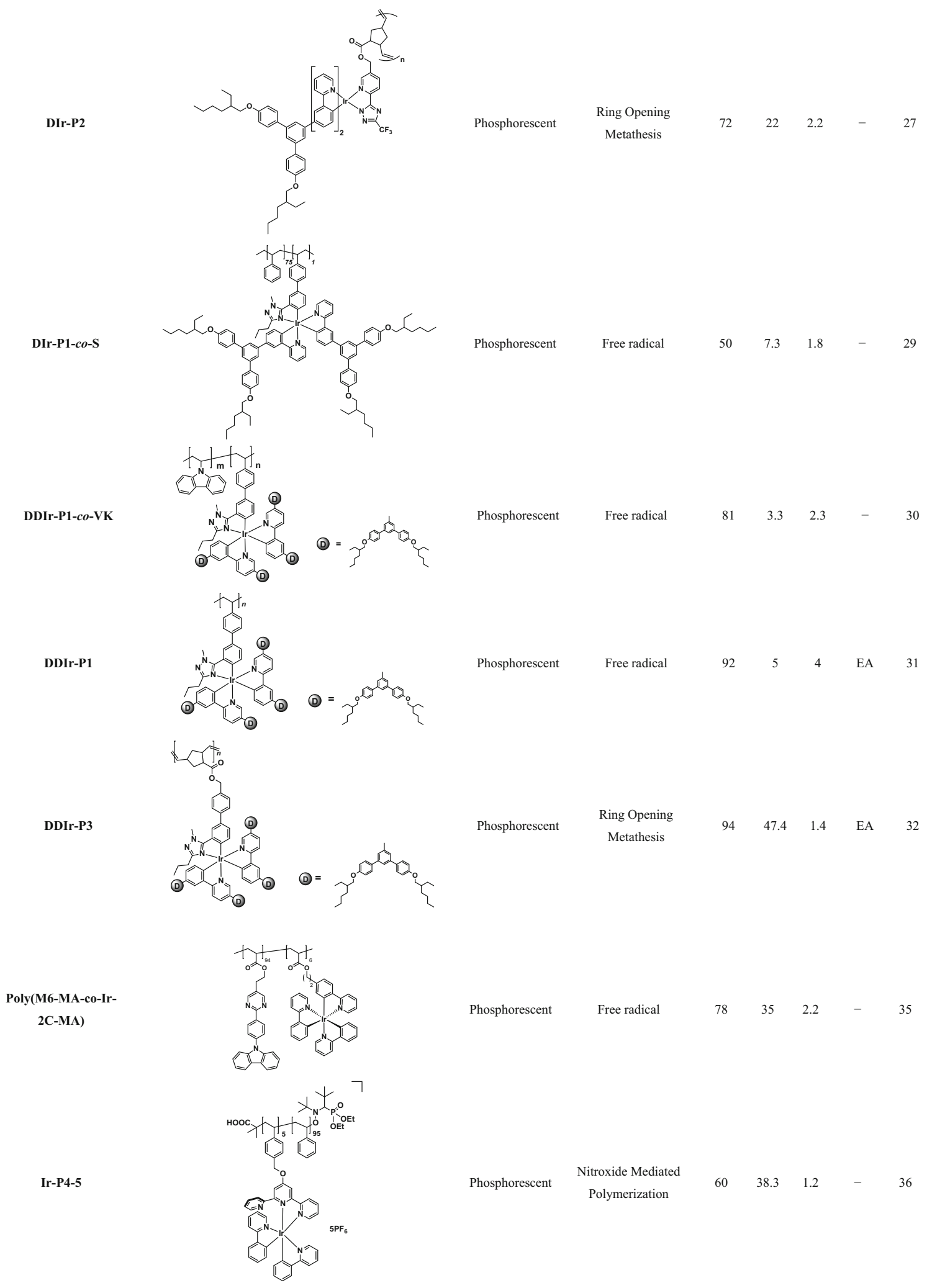


6268

Wong

Table I. continued

Ir-P5-0.03

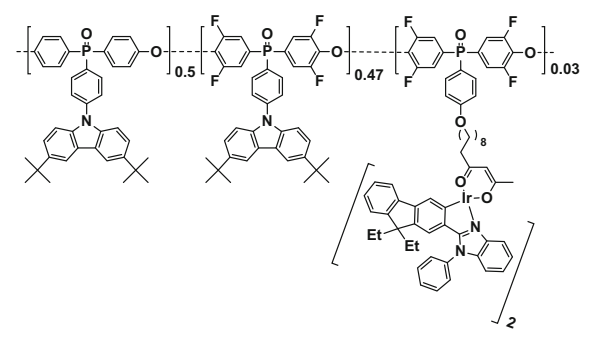

Ir-P5-0.075-0.007

Ir-P6(mCP-co-B)

Ir-P7(10B-co-1R100)

TADF-P1
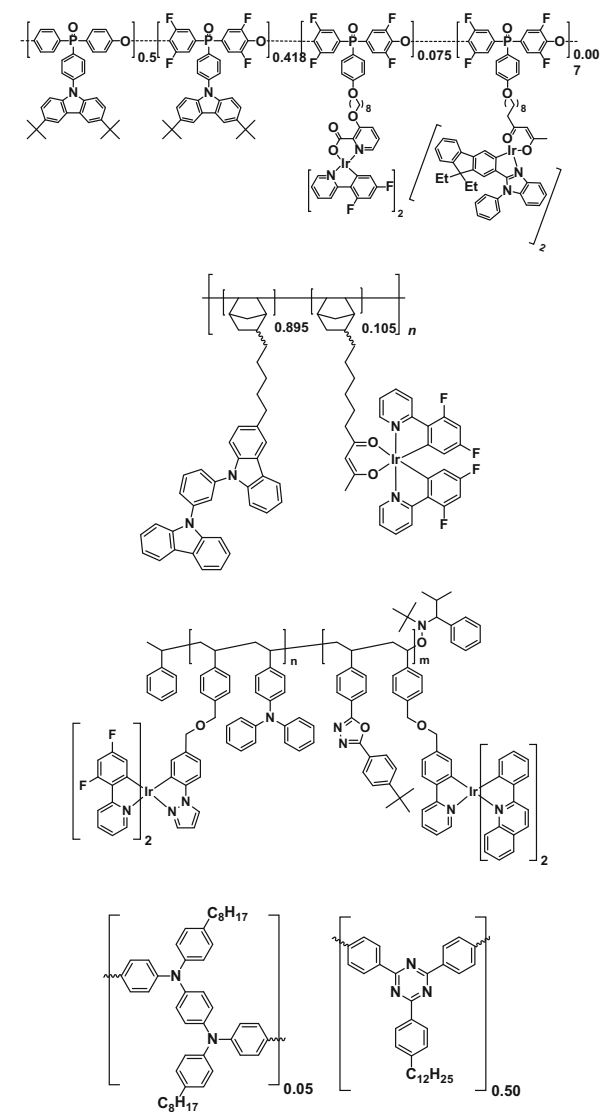

Nucleophilic aromatic substitution $\begin{array}{cc}\text { Phosphorescent } & \begin{array}{c}\text { Nucleophilic aromatic } \\ \text { substitution }\end{array}\end{array}$

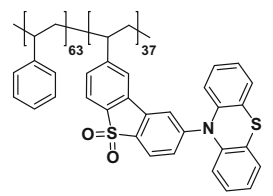

55

6.9

1.5

42

44
Phosphorescent

Vinyl addition

Phosphorescent

Nitroxide Mediated Polymerization

TAD

Suzuki coupling

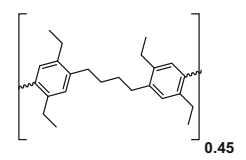

37

163

2.8

45

46

TAD F

TAD

Free radical

85

6.8

$\begin{array}{lll}1.7- & -\quad 80\end{array}$ 
Table II. Summary of polymerization method, yield, $M_{n}$ and PDI of the conjugated polymers reported recently (2011-present)

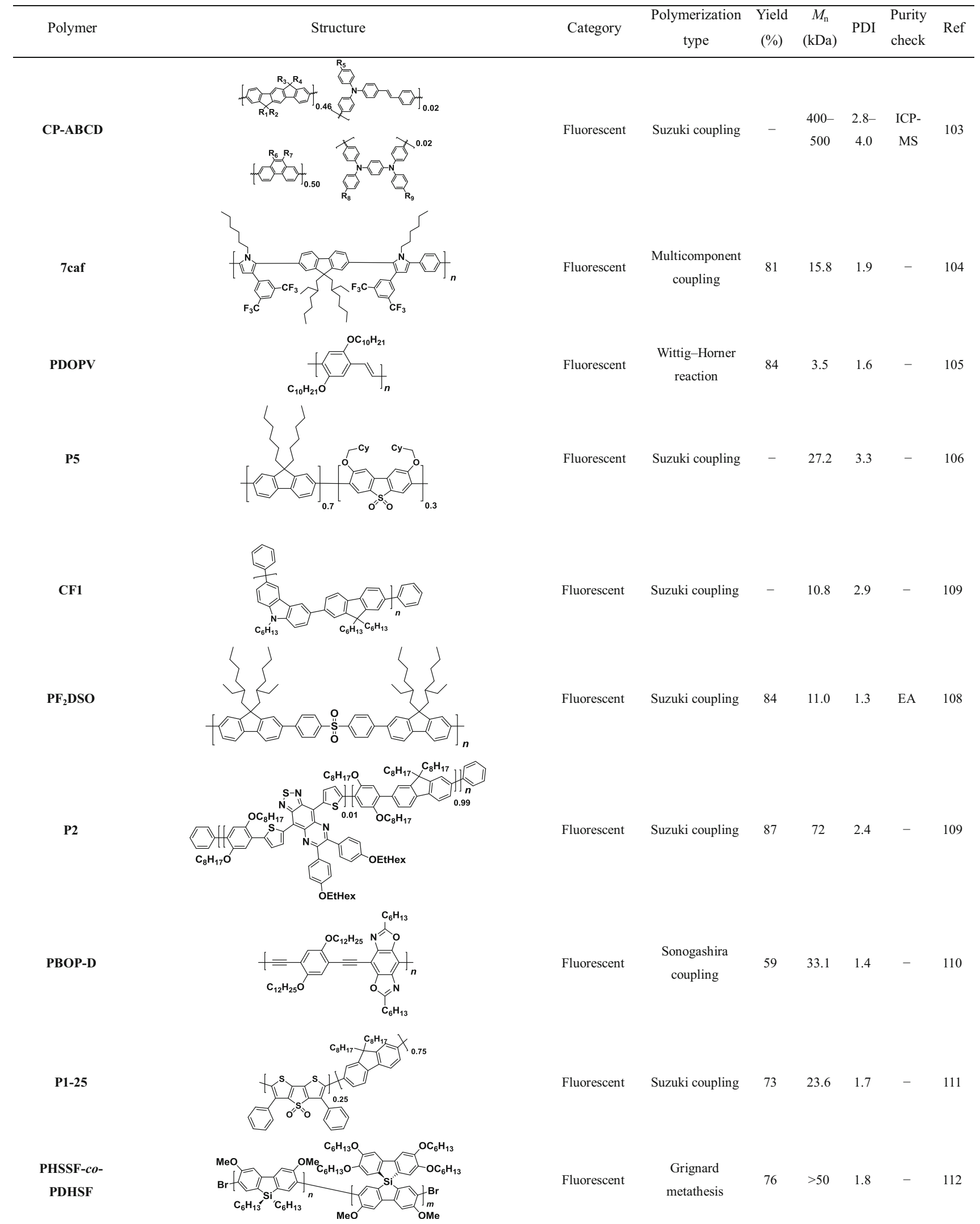


Table II. continued

PFO-TFP

PF-IrNiq1

PF-

$\operatorname{Ir}(\text { ppy })_{2}(\text { pytzph })_{5^{-}}$ $\operatorname{Ir}(\text { piq })_{2}(\text { pytzph })_{5}$

P-R-3

PCz6G0

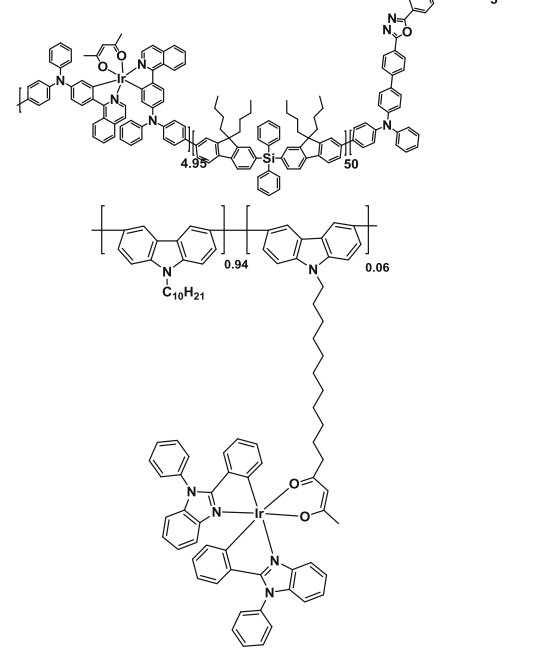

$\begin{array}{lllllll} & \text { Suzuki coupling } & 74 & 16.5 & 2.2 & \text { EA } & 113 \\ \text { Fluorescent } & \text { Direct arylation } & 81 & 31.5 & 3.5 & - & 114\end{array}$

$\begin{array}{lllllll}\text { Phosphorescent } & \text { Suzuki coupling } & 82 & 51.7 & 2.3 & - & 115\end{array}$ $\begin{array}{lllllll}\text { Phosphorescent } & \text { Suzuki coupling } & 64 & 10.4 & 2.1 & \ldots & 117\end{array}$

$\begin{array}{llllllll}\text { Phosphorescent } & \text { Suzuki coupling } & 84 & 31 & 2.0 & - & 118\end{array}$ 


\section{Table II. continued}

P3

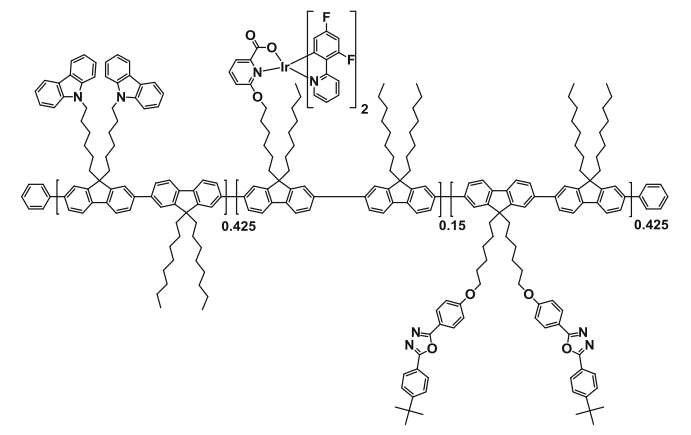

pAcBP

PCzDP-10

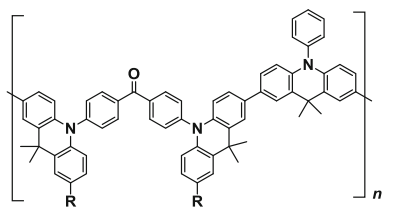

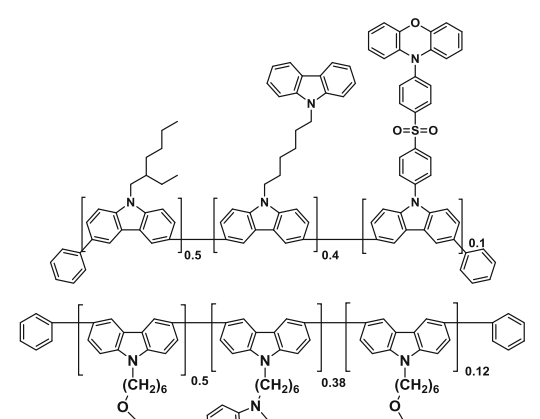

TADF

Suzuki coupling

TADF

Suzuki coupling

87

7.4

1.2

EA

85<smiles>C1CCCOCC1</smiles><smiles></smiles>

P12

PAPTC

FCP 2.5<smiles>[Te][Te]</smiles><smiles>[C]1[C+]CC1</smiles><smiles>[CH]1CC1</smiles><smiles>C1CCOC1</smiles>

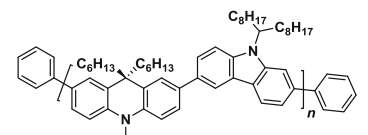<smiles>[C]1C=CC=C1</smiles>

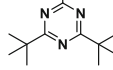

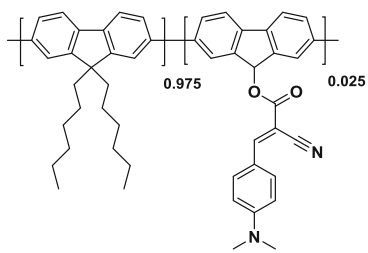

$$
\text { . }
$$

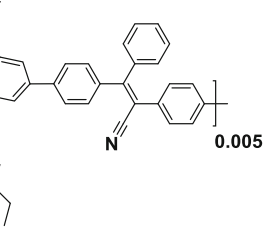

TADF

Suzuki coupling

47

3.3

1.8

EA $\quad 84$

TADF

Suzuki coupling

84

22.0

3.0

86

AIE

Suzuki coupling

83

21

2.3

121

FBPAN 0.5

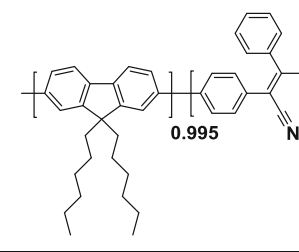


6272

Wong

Table III. Summary of PLED performances based on non-conjugated polymers, their PLQY ( $\Phi_{P L}$ ), glasstransition temperature $\left(T_{\mathrm{g}}\right)$ and film surface roughness $\left(R\right.$, where $R_{\mathrm{a}}$ and $\boldsymbol{R}_{\mathrm{q}}$ refer to average and root-meansquared roughness, respectively)

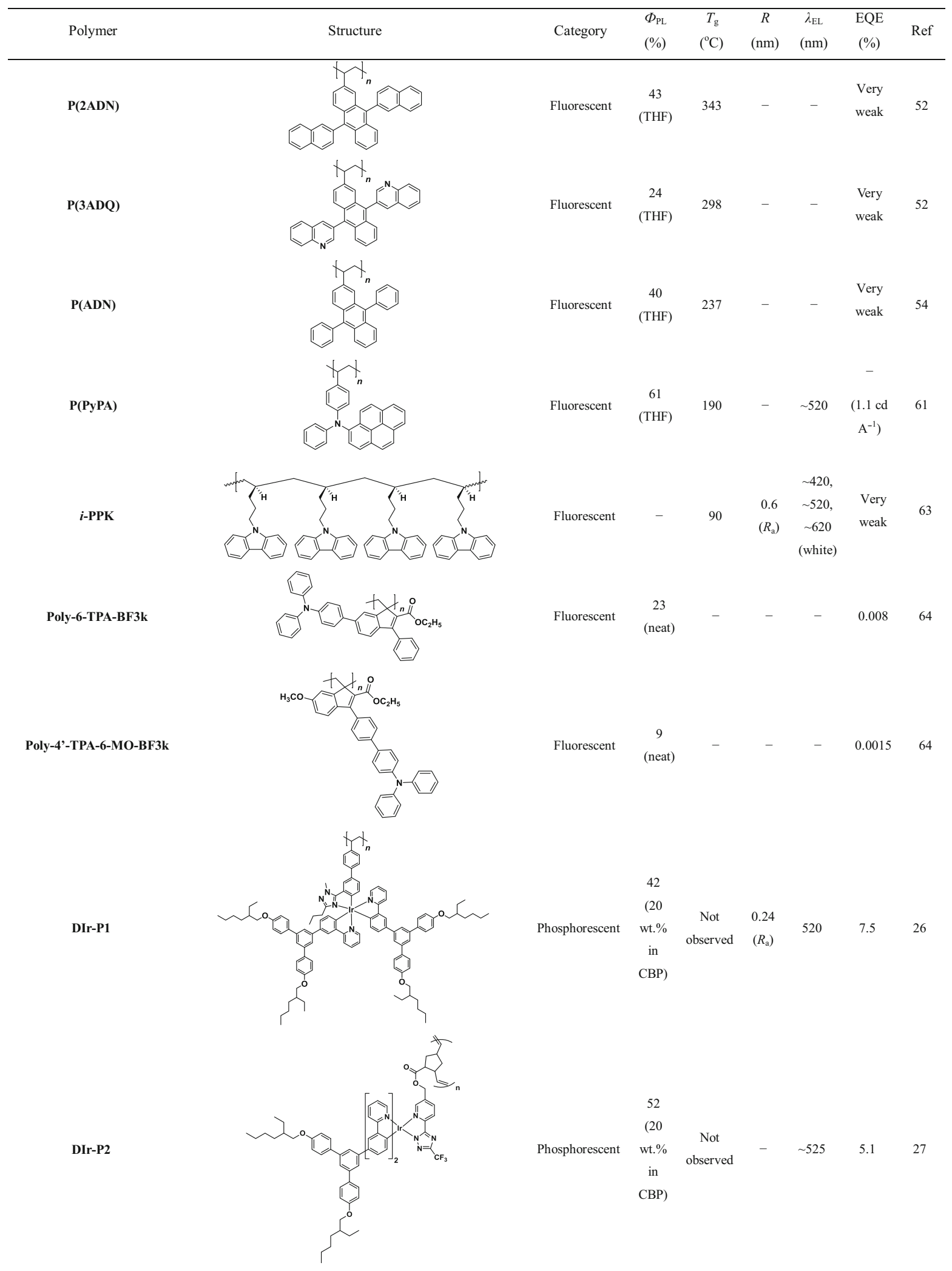




\section{Table III. continued}

DIr-P1-co-S

DDIr-P1

Poly(M6-MA-co-Ir-2C-

MA)

Ir-P4-5

Ir-P5-0.03

DDIr-P1-co-VK

Ir-P4-5

Ir-P5-0.075-0.007
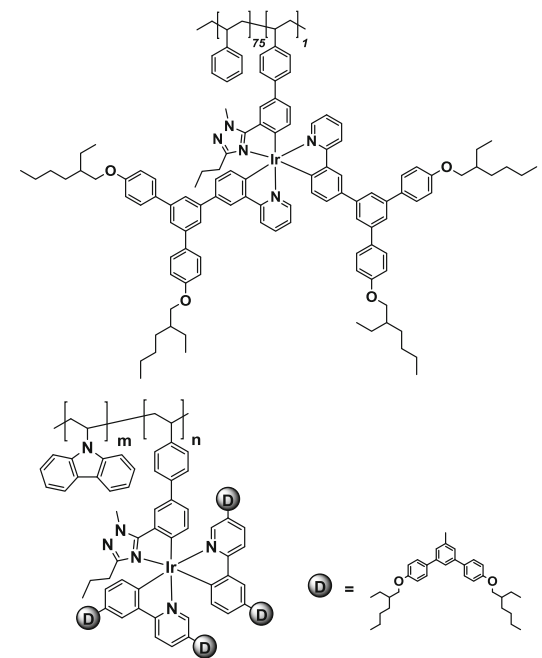

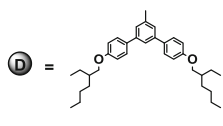

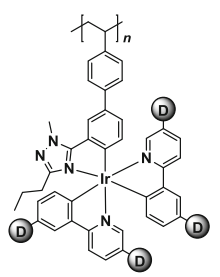

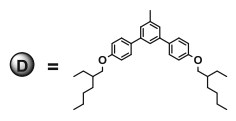

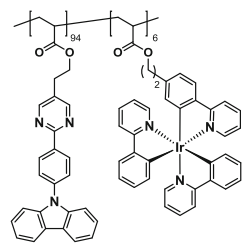

Phosphorescent

Phosphorescent

65
(neat)

$\sim 520$

(3.6 cd

$\mathrm{A}^{-1}$ )

29

in

CBP)

73

$(50$

Phosphorescent

$$
\text { in }
$$

CBP)

Phosphorescent

47
(neat)

$\sim 550$,

(sh)

9.2

31

Phosphorescent

(max. 5

36

$\mathrm{cd} \mathrm{m}^{-2}$ )

Phosphorescent
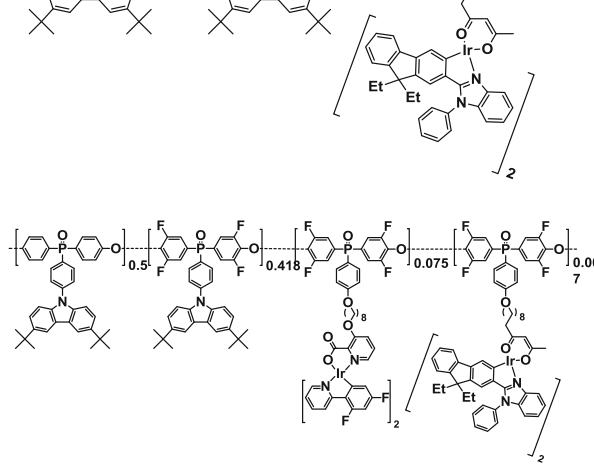

Phosphorescent 
Table III. continued

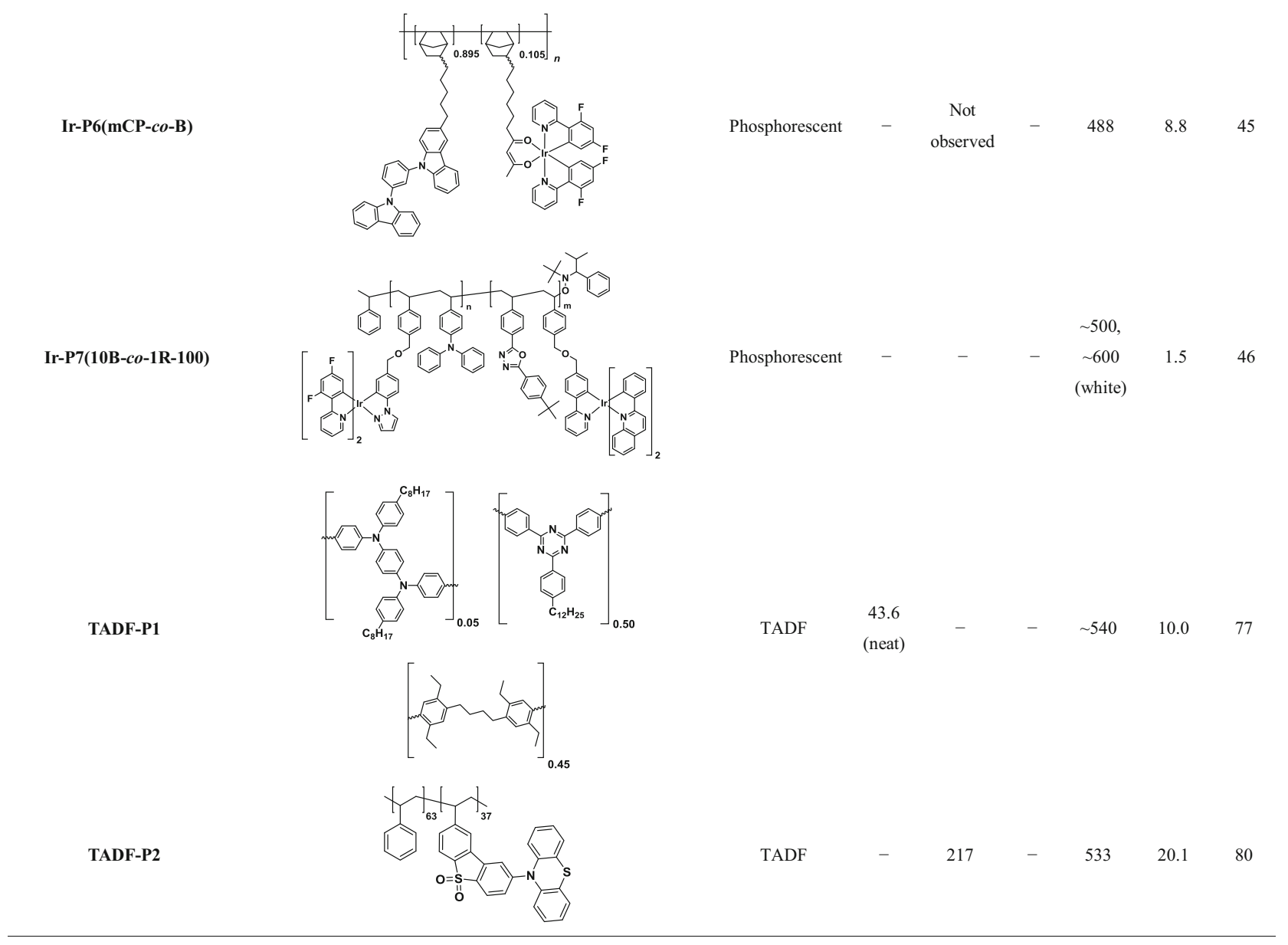

Table I summarizes the polymerization method, yield, number-average molecular weight $\left(M_{\mathrm{n}}\right)$ and polydispersity index (PDI) of the non-conjugated polymers introduced in this review. For comparison, the same information for the vast majority of conjugated polymers reported in the recent years (2011-present) is also presented in Table II. Among the 22 non-conjugated polymers, free-radical polymerization is the most widely used polymerization method, which amounts to $45.5 \%$ of all polymers synthesized due to its well-established chemistry and high functional group tolerance. ${ }^{128,129}$ The average yields, $M_{\mathrm{n}}$ and PDI of polymers generated via free-radical polymerization are $78.3 \%, 14.3 \mathrm{kDa}$ and 2.5 , respectively. The more advanced living radical polymerization such as nitroxide-mediated polymerization (NMP) allows polymers with much lower PDIs (1.2-1.4) to be synthesized. ${ }^{36,46,51}$ Nucleophilic aromatic substitution (SNAr) polycondensation resulted in a low $M_{\mathrm{n}}$ of $6.9 \mathrm{kDa}$ yet with a decent PDI of 1.5 in a $55 \%$ yield $^{42}$ but the success of this polymerization method strongly depends on the degree of activation of the electrophilic carbon to be attacked, and; hence, its generality can be limited. ${ }^{43}$ Vinyl addition polymerization of norbornene-based monomer offered a very high $M_{\mathrm{n}}$ of $163 \mathrm{kDa}$, but suffered from a low yield of $37 \%$ and a high PDI of 2.8. ${ }^{45}$

Among the 23 conjugated polymers, Suzuki coupling has dominated the polymerization method, which amounts to $79.2 \%$ of all polymers synthesized due to its well-established chemistry and employment of more environmentally benign reagents (e.g., Stille coupling is notoriously known for the toxic organotin reagents). The average yields, $M_{\mathrm{n}}$ and PDI of polymers synthesized via this method are $72.1 \%, 45.4 \mathrm{kDa}$ and 2.2 , respectively. Direct arylation polymerization (DAP) has recently attracted intense research attention, because it is more economical (fewer synthetic steps) and environmentally friendly (less organometallic by-products) than the traditional C-C bond formation chemistry. ${ }^{130,131}$ PFO-TFP synthesized via DAP had a $M_{\mathrm{n}}$ and PDI of $31.5 \mathrm{kDa}$ and 3.5 , respectively, in an $81 \%$ yield, ${ }^{114}$ 
Recent Advances in Polymer Organic Light-Emitting Diodes (PLED) Using Non-conjugated

6275

Polymers as the Emitting Layer and Contrasting Them with Conjugated Counterparts

Table IV. Summary of PLED performances based on conjugated polymers, their PLQY ( $\left.\Phi_{\mathrm{PL}}\right)$, glass-transition temperature $\left(T_{\mathrm{g}}\right)$ and film surface roughness $\left(R\right.$, where $R_{\mathrm{a}}$ and $R_{\mathrm{q}}$ refer to average and root-mean-squared roughness, respectively)

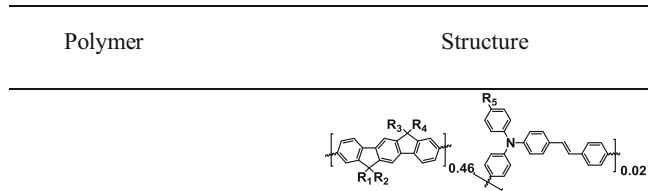

CP-ABCD

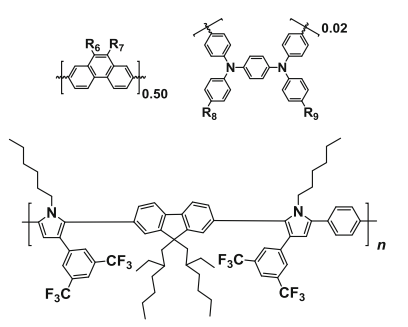

PDOPV

P5

CF

$\mathrm{PF}_{2} \mathrm{DSO}$

P2

PBOP-D

P1-25

PHSSF-coPDHSF

PFO-TFP
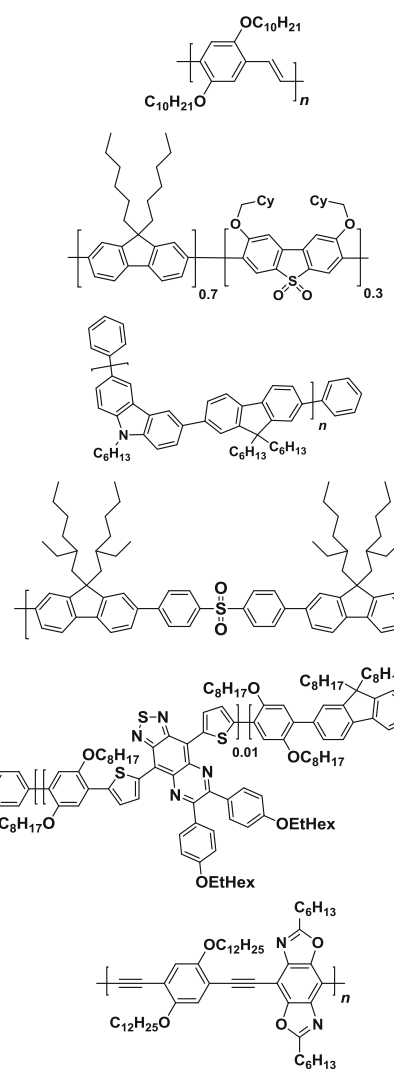

Fluorescent
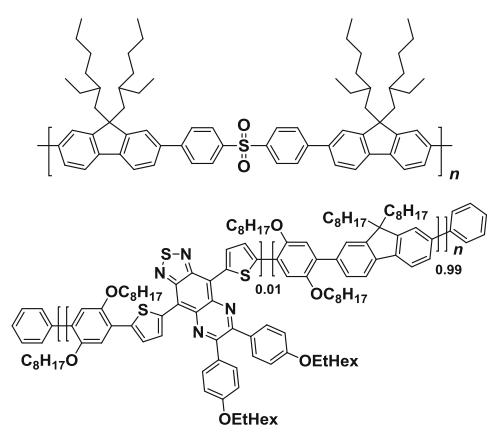$$
(\%)
$$

$\left({ }^{\circ} \mathrm{C}\right)$

$R$

$\lambda_{\mathrm{EL}}$

EQ

(nim)

(

$(\%)$

Ref
Fluorescent

Fluorescent

Fluorescent

Fluorescent

Fluorescent

Fluorescent

62 (neat) $\quad-\quad \quad-\quad-\quad \sim 450 \quad 3.2$

20 (neat)

$\begin{array}{llll}134 & - & 409 & 2.1\end{array}$

Fluorescent

Fluorescent

$<1$ (neat)

$12(\mathrm{EtOH})$

85 (neat)

68 (neat)

Fluorescent

$<1$

A

Fluorescent
459 ,

480

(9.7 cd

(sh) $\quad \mathrm{A}^{-1}$ )

103
104

$\mathrm{A}^{-1}$ )

$0.73 \mathrm{~cd}$

105

06

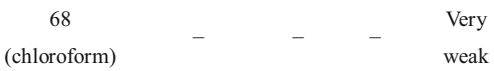

108

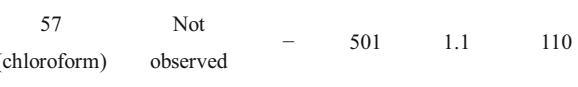

$\begin{array}{ccccc}\begin{array}{c}\text { Not } \\ \text { observed }\end{array} & - & 410 & 2.9 & 112 \\ \text { Not } & 1.2 & & & \\ \text { observed } & \left(R_{\mathrm{q}}\right) & 405 & 5.02 & 113\end{array}$

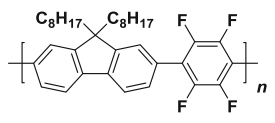

66

Not

(Chloroform)

observed
109

10

11

2

113

114 
6276

Wong

Table IV. continued
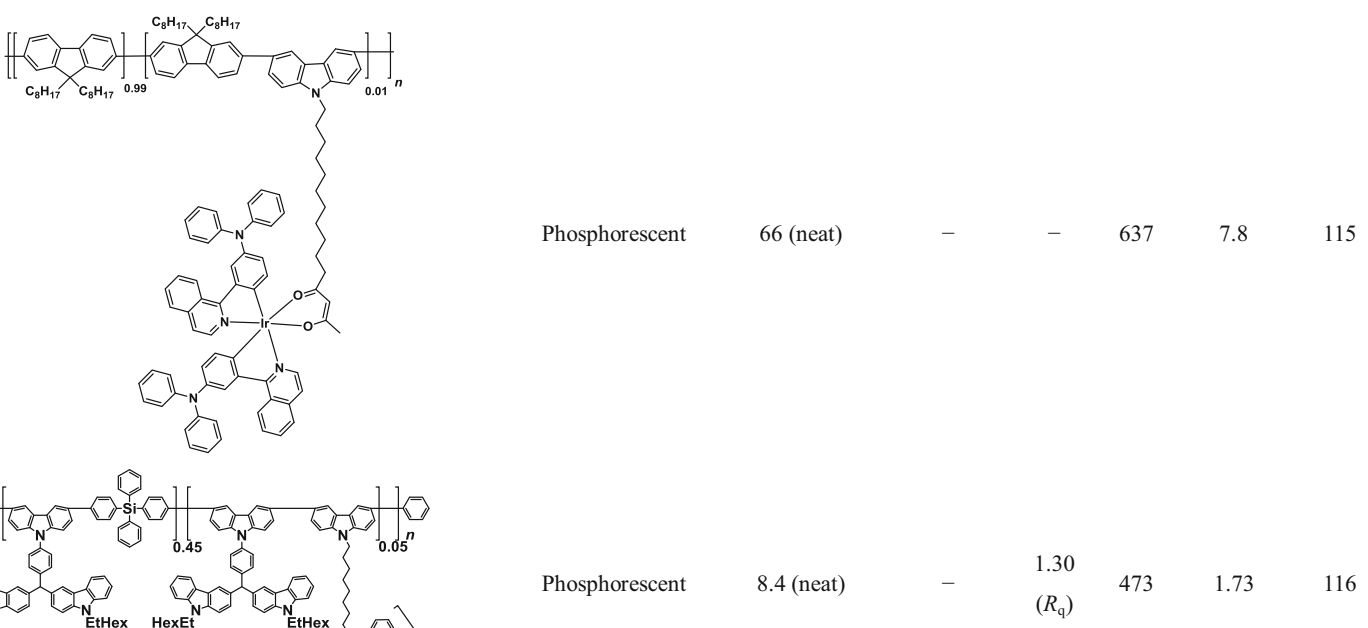

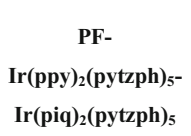

P-R-3 PCz6G0

P3

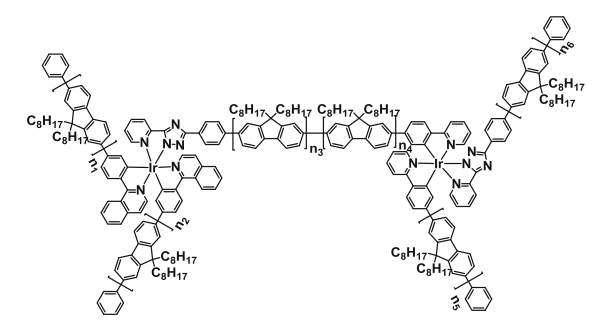

Phosphorescent

19 (neat)

133

Phosphorescent

Phosphorescent

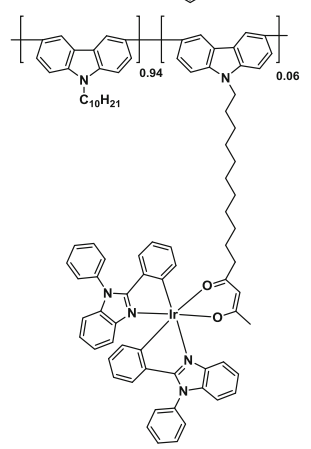

77 (LCM)

79 $\begin{array}{ccc}1.79 & \text { White } & - \\ \left(R_{\mathrm{q}}\right) & (0.32, & (11.49 \mathrm{~cd} \\ & 0.34) & \left.\mathrm{A}^{-1}\right)\end{array}$

117

118

119

$(2.90 \mathrm{~cd}$

120 


\section{Table IV. continued}

pAcBP

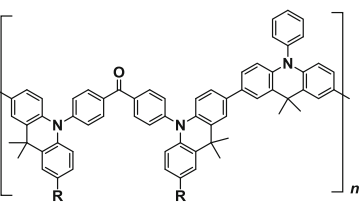<smiles>[GeH2]O[GeH2]OC1CO1</smiles>

PCzDP-10

P12

PAPTC
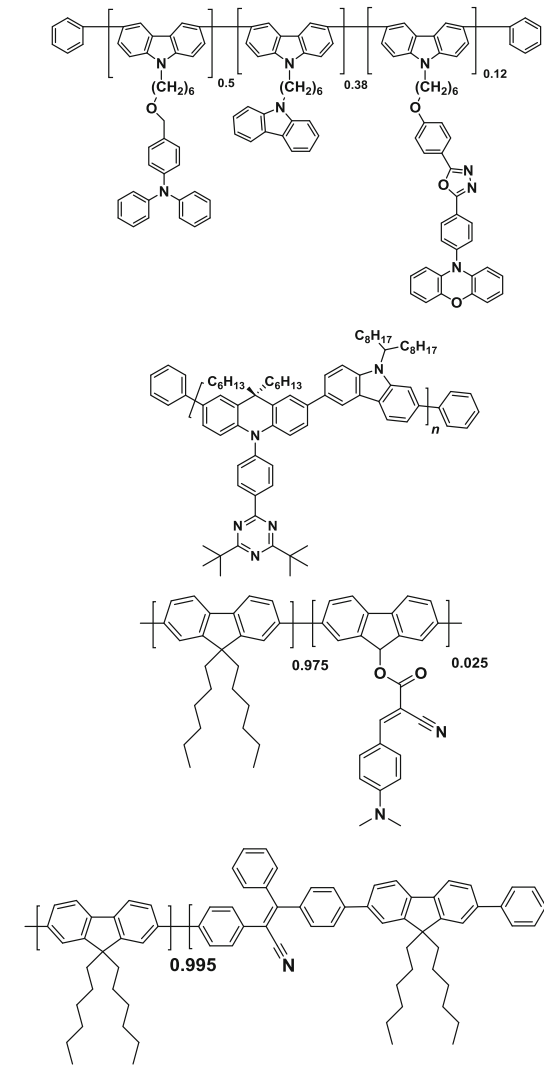

TADF

28 (neat)

TADF
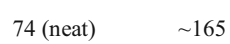

TADF

33.7 (neat)

126

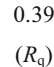

506

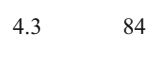

AIE

71.5 (neat)

White

(0.33, $\quad(6.34 \mathrm{~cd}$

0.34) $\left.\quad \mathrm{A}^{-1}\right)$

80.2 (neat)

White

(0.32, (7.56 cd 122

0.31) $\left.\quad \mathrm{A}^{-1}\right)$ whereas the same polymer synthesized via Suzuki coupling showed a $M_{\mathrm{n}}$ and PDI of $16.5 \mathrm{kDa}$ and 2.2 , respectively, in a $74 \%$ yield. ${ }^{113}$

Both conjugated and non-conjugated polymers are economical because the majority of the two classes of polymers were obtained with $>70 \%$ yields. A direct comparison of $M_{\mathrm{n}}$ and PDI between the two classes of polymers may be inappropriate, because they were not prepared by a single polymerization method. As mentioned previously, the most popular polymerization methods for conjugated and nonconjugated polymers are Suzuki coupling and freeradical polymerization, respectively, where the average $M_{\mathrm{n}}$ and PDI are $45.4 \mathrm{kDa}$ and 2.2 for the conjugated polymers as well as $12.0 \mathrm{kDa}$ and 2.5 for the non-conjugated polymers. While Suzuki coupling polycondensation seems to give polymers with better $M_{\mathrm{n}}$ and PDI than those produced via freeradical polymerization, it cannot be concluded that non-conjugated polymers are inferior in terms of $M_{\mathrm{n}}$ and PDI parameters. Indeed, living radical polymerization, in principle, is able to give any $M_{\mathrm{n}}$ desired based on the monomer to initiator ratio along with a very low PDI (e.g., <1.2). The analogous polymerization for conjugated polymers is the Grignard metathesis polymerization (GRIM) which 
shows quasi-living characters and is commonly used for preparing regioregular poly(3-hexylthiophene) (P3HT) ${ }^{132}$ Both of these polymerization methods are able to produce block copolymers. ${ }^{4,133}$ However, strongly nucleophilic organomagnesium species is inevitably present in GRIM, which severely limit the scope of monomers that can be polymerized, whereas radical polymerization is well known to have high functional group tolerance. ${ }^{128,129}$ Interestingly, block copolymers are unpopular in PLED applications: only one non-conjugated block copolymer was reported recently ${ }^{46}$ and conjugated block copolymer was absent. ${ }^{134,135}$

A critical parameter of OLED materials is purity because impurities can act as charge trapping sites and quenchers during device operation. ${ }^{136}$ However, among the 45 polymers (conjugated and non-conjugated) presented in this review, only ten of them had their purities verified (see "purity check" column in Tables I and II). This was done by elemental analysis (EA) techniques, and the results were essentially all based on CHN elemental compositions with only a few exceptions. For example, conjugated polymer CP-ABCD was examined by inductively coupled plasma mass spectrometry (ICP-MS) to detect trace elements like bromine, boron, phosphorus and palladium with concentrations that were found to be $\leq 50 \mathrm{ppm}, \leq 20 \mathrm{ppm}, \leq 200 \mathrm{ppm}$, and $\leq 15 \mathrm{ppm}$, respectively. ${ }^{103}$ Giovanella et al., along with CHN analysis, performed mass spectrometry analysis to conclude the absence of residual bromine and borolane groups in their PFO-TFP polymer. ${ }^{113}$ In addition to being unable to detect trace elements like halogens and transition metals, CHN analysis has a serious limitation, when it comes to random copolymers whose exact monomer compositions cannot be confirmed due to the broadness and overlap of aromatic peaks in the ${ }^{1} \mathrm{H}$ NMR spectra. ${ }^{30,45,116}$ Halogenated impurities have been shown to be detrimental to the PLED device lifetime due to radical chain type degradation. ${ }^{137}$ In addition, palladium black formed during polycondensation can be hard to remove completely. ${ }^{132}$ Given that the vast majority of conjugated polymers are generated by transition-metal catalyzed coupling in which monomers containing aryl bromide are frequently employed, non-conjugated polymers, which are mainly synthesized by free- or living-radical polymerizations where no transition metals and halogens are involved, may have an advantage over the conjugated counterparts in this regard.

\section{Conjugated versus Non-conjugated Polymers: PLED Performances}

The PLED performance ( $\lambda_{\mathrm{EL}}$ and EQE) based on non-conjugated and conjugated polymers are summarized in Tables III and IV, respectively, which also list the related determining parameters, such as the polymers' PLQY $\left(\Phi_{\mathrm{PL}}\right)$, glass-transition temperature $\left(T_{\mathrm{g}}\right)$ and film surface roughness $(R)$.
Among the phosphorescent PLEDs, the best performing non-conjugated polymer (DDIr-P1-co-VK) exhibited an EQE of $14.7 \%$ with a green emission $\left(\lambda_{\text {EL }} \text { at } 545 \mathrm{~nm}\right)^{30}$ while the conjugated counterpart (P-R-3) exhibited an EQE of $16.1 \%$ with a red emission $\left(\lambda_{\mathrm{EL}}\right.$ at $\left.640 \mathrm{~nm}\right){ }^{118}$ On the other hand, the best non-conjugated TADF polymer (TADF-P2) offered a green PLED ( $\lambda_{\text {EL }}$ at $533 \mathrm{~nm}$ ) with an EQE of $20.1 \%^{21}$, whereas the conjugated counterpart (PCzDP-10) gave a PLED with a blue emission at $496 \mathrm{~nm}$ and an EQE of $16.1 \%{ }^{83}$ Therefore, it is reasonable to conclude that for these two classes of polymers (phosphorescent and TADF), the nature of the polymer backbone has minimal impact on the PLED performance.

However, this is not the case for the fluorescent PLEDs, where non-conjugated and conjugated polymers show a significant difference in their PLED efficiencies. For example, while the best conjugated fluorescent polymers (P5 ${ }^{106}$ and CP-ABCD ${ }^{103}$, respectively) offered some decent PLED efficiencies such as an EQE of $3.2 \%$ and a current efficiency of $9.7 \mathrm{~cd} \mathrm{~A}^{-1}$ (both in the sky-blue region), all nonconjugated fluorescent polymers exhibited much poorer PLED performance $\left(<1 \mathrm{~cd} \mathrm{~A}{ }^{-1}\right)$. This remarkable difference in PLED efficiencies should not be explained by differing determining factors such as PLQY, surface roughness, and charge carrier balance of the emitting polymer layer brought about by the nature of the polymer backbone, because the difference in the PLED efficiencies are only observed in fluorescent PLEDs but not in phosphorescent and TADF PLEDs. Indeed, the PLQYs of non-conjugated fluorescent polymers are competitive (up to $61 \%$ in THF $)^{61}$ and the surface roughness seems to not depend on the nature of the polymer backbone $\left(R_{\mathrm{a}}<1 \mathrm{~nm}\right) .{ }^{26,63}$ Considering the key difference between fluorescent polymers and phosphorescent/TADF analogues is the utilization of triplet excitons for emission in the latter two types of materials, one might wonder if the nature of the polymer backbone affected the exciton utilization efficiency $\left(\eta_{\mathrm{S}}\right)$, hence, resulting in the remarkably different PLED efficiencies demonstrated by non-conjugated and conjugated fluorescent polymers. The internal quantum efficiency (IQE) of PLED is strongly related to $\eta_{\mathrm{S}}$ according to the following expression ${ }^{138}$ :

$$
\mathrm{IQE}=\Phi_{\mathrm{PL}} \times \eta_{\mathrm{rec}} \times \eta_{\mathrm{S}}
$$

where $\eta_{\text {rec }}$ and $\eta_{\mathrm{S}}$ refer to charge recombination and exciton utilization efficiencies, respectively. In phosphorescent and TADF materials, both singlet and triplet excitons can contribute to emission and, hence, $\eta_{\mathrm{S}}$ equals 1 . On the other hand, fluorescent materials, in principle, have their emission contributed only by singlet excitons, and; hence, $\eta_{\mathrm{S}}$ equals merely 0.25 according to spin statistics. However, one must be aware that in practical OLED operation, triplet excitons can also contribute 
to emission in fluorescent materials due to the presence of triplet-triplet annihilation (TTA) in which two dark triplet excitons merge to form an emissive singlet exciton. Indeed, this process can be surprisingly efficient and contribute as a major emission mechanism in fluorescent PLED devices (up to $20-60 \%$ of total emission). ${ }^{139,140}$ It follows that fluorescent polymers with a conjugated polymer backbone might undergo a more efficient TTA process than those with a non-conjugated backbone and, hence, show better PLED efficiencies. It could be that the extensive charge delocalization in the conjugated polymers may significantly lower the triplet energy level $\left(\mathrm{T}_{1}\right)^{79}$, and; hence, the tripletpolaron annihilation (TPA) and TTA processes would not be able to produce excessive energy that causes structural disruption of the emitting species, where the former has been regarded as the major degradation cause for the blue phosphorescent materials. ${ }^{141}$ Moreover, the conjugated backbone might result in better intrachain or interchain bimolecular triplet exciton communication to allow a more efficient TTA process. Of course, it could also be that the currently reported PLED efficiencies of fluorescent polymers with non-conjugated backbone have not yet reflected the true potential of this class of materials. However, given the explosive development of TADF OLED materials in the recent years, ${ }^{69,70,72}$ the research interest in fluorescent materials has been sharply diminished.

\section{CONCLUSIONS}

In this review, recent advances in the development of non-conjugated polymers for PLED applications have been discussed. While fluorescent nonconjugated polymers performed poorly in PLEDs, phosphorescent and TADF polymers offered much more competitive PLED devices where the efficiencies of these two classes of materials have been comparable. Based on the comparison with recently reported PLED devices using conjugated polymers, it can be concluded that phosphorescent and TADF PLED performances do not depend on whether the polymer backbone is conjugated, whereas conjugated fluorescent PLED exhibited much higher efficiencies than the non-conjugated counterparts. This might be because the conjugated polymer backbone allows better triplet exciton recruitment via the triplet-triplet annihilation (TTA) process, or because the true potential of non-conjugated fluorescent PLED has just not yet been revealed.

Further research efforts in some areas are still required. For example, the effects of molecular weight and polydispersity of the polymers on the PLED performance are still underexplored. Although a few previous studies were conducted, ${ }^{33,34,126,127}$ much more work has to be done to gain conclusions of enhanced generalities and also to obtain more solid understanding on the structure-property relationships in PLED materials. In addition, the purity of polymers for PLED applications should always be verified to establish a reliable link between device performances with the structure of the polymer employed in the device. However, a survey conducted in this review shows that only ten out of 45 PLED polymers had their purity verified.

As to the outlook of PLED materials, it is expected that TADF polymers will receive escalating research attention and efforts due to their lower costs and ability to utilize triplet excitons in the device. Currently, the TADF polymers reported so far were all used as the primary emitting species for the devices. In principle, TADF polymers can also be used as host materials for conventional fluorescent dyes. ${ }^{69}$ In this setting, the host is responsible for upconversion of dark triplet excitons, which then transfers its energy to the fluorescent dopant dye which has key merits of high PLQY and much narrower emission spectrum (i.e., enhanced color purity). TADF polymers for white light emission still remain as a challenge. While the current progress of PLED materials has been very fruitful and encouraging, further research efforts are still required.

\section{OPEN ACCESS}

This article is distributed under the terms of the Creative Commons Attribution 4.0 International License (http://creativecommons.org/licenses/by/4.0/), which permits unrestricted use, distribution, and reproduction in any medium, provided you give appropriate credit to the original author(s) and the source, provide a link to the Creative Commons license, and indicate if changes were made.

\section{ELECTRONIC SUPPLEMENTARY MATERIAL}

The online version of this article (doi: 10.1007/s11664-017-5702-7) contains supplementary material, which is available to authorized users.

\section{REFERENCES}

1. C.W. Tang and S.A. VanSlyke, Appl. Phys. Lett. 51, 913 (1987).

2. T.-A. Lin, T. Chatterjee, W.-L. Tsai, W.-K. Lee, M.-J. Wu, M. Jiao, K.-C. Pan, C.-L. Yi, C.-L. Chung, K.-T. Wong, and C.-C. Wu, Adv. Mater. 28, 6976 (2016).

3. H. Kaji, H. Suzuki, T. Fukushima, K. Shizu, K. Suzuki, S. Kubo, T. Komino, H. Oiwa, F. Suzuki, A. Wakamiya, Y. Murata, and C. Adachi, Nat. Commun. 6, 8476 (2015).

4. D.R. Lee, B.S. Kim, C.W. Lee, Y. Im, K.S. Yook, S.-H. Hwang, and J.Y. Lee, ACS Appl. Mater. Interfaces 7, 9625 (2015)

5. C.H. Lee and J.Y. Lee, Adv. Mater. 25, 5450 (2013).

6. H. Sasabe and J. Kido, Eur. J. Org. Chem. 2013, 7653 (2013).

7. J.-H. Jou, Y.-T. Su, S.-H. Liu, Z.-K. He, S. Sahoo, H.-H. Yu, S.-Z. Chen, C.-W. Wang, and J.-R. Lee, J. Mater. Chem. C 4, 6070 (2016).

8. C. Sekine, Y. Tsubata, T. Yamada, M. Kitano, and S. Doi, Sci. Technol. Adv. Mater. 15, 034203 (2014).

9. F. Xua, H.U. Kima, J.-H. Kima, B.J. Jung, A.C. Grimsdale, and D.-H. Hwang, Prog. Polym. Sci. 47, 92 (2015). 
10. C.A. Zuniga, S. Barlow, and S.R. Marder, Chem. Mater. 23, 658 (2011).

11. F. Dumur, Org. Electron. 25, 345 (2015).

12. J.H. Burroughes, D.D.C. Bradley, A.R. Brown, R.N. Marks, K. Mackay, R.H. Friend, R.L. Burns, and A.B. Holmes, Nature 347, 539 (1990).

13. G. Gustafsson, Y. Cao, G.M. Treacy, F. Klavetter, N. Colaner, and A.J. Heeger, Nature 357, 477 (1992).

14. S.-A. Chen, H.-H. Lu, and C.-W. Huang, Polyfluorenes, ed. U. Scherf and D. Neher (Berlin: Springer, 2008), p. 49.

15. M. Leclerc, J. Poly. Sci. Part A Poly. Chem. 39, 2867 (2001).

16. C. Zhu, L. Liu, Q. Yang, F. Lv, and S. Wang, Chem. Rev. 112,4687 (2012)

17. Z. Ma, J. Ding, B. Zhang, C. Mei, Y. Cheng, Z. Xie, L. Wang, X. Jing, and F. Wang, Adv. Funct. Mater. 20, 138 (2010).

18. Z. Ma, J. Ding, Y. Cheng, Z. Xie, L. Wang, X. Jing, and F. Wang, Polymer 52, 2189 (2011).

19. D. Sun, X. Zhou, J. Liu, X. Sun, H. Li, Z. Ren, D. Ma, M.R. Bryce, and S. Yan, ACS Appl. Mater. Interfaces 7, 27989 (2015).

20. X. He, D. Cai, D.-Y. Kang, W. Haske, Y. Zhang, C.A. Zuniga, B.H. Wunsch, S. Barlow, J. Leisen, D. Bucknall, B. Kippelen, and S.R. Marder, J. Mater. Chem. C 2, 6743 (2014).

21. Z. Ren, R.S. Nobuyasu, F.B. Dias, A.P. Monkman, S. Yan, and M.R. Bryce, Macromolecules 49, 5452 (2016).

22. M.A. Baldo, D.F. O'Brien, Y. You, A. Shoustikov, S. Sible, M.E. Thompson, and S.R. Forrest, Nature 395, 151 (1998),

23. Y. Tao, C. Yang, and J. Qin, Chem. Soc. Rev. 40, 2943 (2011).

24. B. Minaev, G. Baryshnikov, and H. Agren, Phys. Chem. Chem. Phys. 16, 1719 (2014).

25. K.-H. Kim, S. Lee, C.-K. Moon, S.-Y. Kim, Y.-S. Park, J.-H. Lee, J.W. Lee, J. Huh, Y. You, and J.-J. Kim, Nat. Commun. 5, 4769 (2014).

26. W.Y. Lai, J.W. Levell, A.C. Jackson, S.-C. Lo, P.V. Bernhardt, I.D.W. Samuel, and P.L. Burn, Macromolecules 43, 6986 (2010).

27. J.W. Levell, J.P. Gunning, P.L. Burn, J. Robertson, and I.D.W. Samuel, Org. Electron. 11, 1561 (2010).

28. W.Y. Lai, J.W. Levell, P.L. Burn, S.-C. Lo, and I.D.W. Samuel, J. Mater. Chem. 19, 4952 (2009).

29. J.W. Levell, W.Y. Lai, R.J. Borthwick, S.-C. Lo, P.L. Burn, and I.D.W. Samuel, J. Phys. Chem. C 115, 25464 (2011).

30. J.W. Levell, W.-Y. Lai, R.J. Borthwick, P.L. Burn, S.-C. Lo, and I.D.W. Samuel, New J. Chem. 36, 407 (2012).

31. W.-Y. Lai, J.W. Levell, M.N. Balfour, P.L. Burn, S.-C. Lo, and I.D.W. Samuel, Polym. Chem. 3, 734 (2012).

32. W.-Y. Lai, M.N. Balfour, J.W. Levell, A.K. Bansal, P.L. Burn, S.-C. Lo, and I.D.W. Samuel, Macromolecules 45, $2963(2012)$

33. A. Menon, H. Dong, Z.I. Niazimbetova, L.J. Rothberg, and M.E. Galvin, Chem. Mater. 14, 3668 (2002).

34. S.J. Konezny, L.J. Rothberg, M.E. Galvin, and D.L. Smith, Appl. Phys. Lett. 97, 143305 (2010).

35. Z.A. Page, C.-Y. Chiu, B. Narupai, D.S. Laitar, S. Mukhopadhyay, A. Sokolov, Z.M. Hudson, R.B. Zerdan, A.J. McGrath, J.W. Kramer, B.E. Barton, and C.J. Hawker, ACS Photonics 4, 631 (2017).

36. F. Dumur, Y. Guillaneuf, A. Guerlin, G. Wantz, D. Bertin, F. Miomandre, G. Clavier, D. Gigmes, and C.R. Mayer, Macromol. Chem. Phys. 212, 1616 (2011).

37. R.D. Costa, E. Ortí, H.J. Bolink, S. Graber, C.E. Housecroft, and E.C. Constable, J. Am. Chem. Soc. 132, 5978 (2010).

38. R.D. Costa, E. Ortí, H.J. Bolink, F. Monti, G. Accorsi, and N. Armaroli, Angew. Chem. Int. Ed. 51, 8178 (2012).

39. S.B. Meier, D. Tordera, A. Pertegás, C. Roldán-Carmon, E. Ortí, and H.J. Bolink, Mater. Today 17, 217 (2014).

40. M.Y. Wong, M.-G. La-Placa, A. Pertegás, H.J. Bolink, and E. Zysman-Colman, J. Mater. Chem. C 5, 1699 (2017).

41. N. Armaroli, G. Accorsi, M. Holler, O. Moudam, J.-F. Nierengarten, Z. Zhou, R.T. Wegh, and R. Welter, Adv. Mater. 18, 1313 (2006).
42. S. Shao, J. Ding, L. Wang, X. Jinga, and F. Wang, J. Mater. Chem. 22, 24848 (2012).

43. S. Shao, J. Ding, L. Wang, X. Jinga, and F. Wang, J. Am. Chem. Soc. 134, 15189 (2012)

44. S. Shao, J. Ding, L. Wang, X. Jinga, and F. Wang, J. Am. Chem. Soc. 134, 20290 (2012).

45. J.H. Park, T.-W. Koh, J. Chung, S.H. Park, M. Eo, Y. Do, S. Yoo, and M.H. Lee, Macromolecules 46, 674 (2013).

46. D.A. Poulsen, B.J. Kim, B. Ma, C.S. Zonte, and J.M.J. Fréchet, Adv. Mater. 22, 77 (2010).

47. S.-C. Lo and P.L. Burn, Chem. Rev. 107, 1097 (2007).

48. P.L. Burn, S.-C. Lo, and I.D.W. Samuel, Adv. Mater. 19, 1675 (2007).

49. D.Y. Kondakov, Dig. Tech. Pap. Soc. Inf. Disp. Int. Symp. 39, 617 (2008).

50. E. Kozma, W. Mróz, F. Villafiorita-Monteleone, F. Galeotti, A. Andicsová-Eckstein, M. Catellania, and C. Botta, RSC Adv. 6, 61175 (2016).

51. E. Kozma, W. Mróz, and F. Galeotti, Dyes Pigments 114, 138 (2015).

52. J. Wang and L.M. Leung, Dyes Pigments 99, 105 (2013).

53. M.-H. Ho, M.-T. Hsieh, K.-H. Lin, T.-M. Chen, J.-F. Chen, and C.-H. Chen, Appl. Phys. Lett. 94, 023306 (2009).

54. J. Wang, L.M. Leung, S.-K. So, and C.Y.H. Chan, Polym. Int. 63, 363 (2014).

55. J. Shi and C.W. Tang, Appl. Phys. Lett. 80, 3201 (2002).

56. L. Qian, D. Bera, and P.H. Holloway, J. Chem. Phys. 127, 244707 (2007).

57. S.B. Lee, K.H. Park, C.W. Joo, J.-I. Lee, J. Lee, and Y.-H. Kim, Dyes Pigments 128, 19 (2016).

58. T.M. Figueira-Duarte and K. Müllen, Chem. Rev. 111, 7260 (2011).

59. D. Chercka, S.-J. Yoo, M. Baumgarten, J.-J. Kim, and K. Müllen, J. Mater. Chem. C 2, 9083 (2014).

60. G. Mallesham, C. Swetha, S. Niveditha, M.E. Mohanty, N.J. Babu, A. Kumar, K. Bhanuprakash, and V.J. Rao, J. Mater. Chem. C 3, 1208 (2015).

61. J. Wang, L.M. Leung, S.K. So, C.Y.H. Chan, and M.Y. Wong, Polym. Int. 63, 1797 (2014).

62. I. Natori, S. Natori, H. Sekikawa, and K. Ogino, Polym. J. 42, 875 (2010).

63. A. Botta, S. Pragliola, V. Venditto, A. Rubino, S. Aprano, A.D.G.D. Mauro, M.G. Maglione, and C. Minarini, Polym. Compos. 36, 1110 (2015).

64. A. Cappelli, V. Razzano, G. Fabio, M. Paolino, G. Grisci, G. Giuliani, A. Donati, R. Mendichi, W. Mróz, F. VillafioritaMonteleone, and C. Botta, RSC Adv. 5, 101377 (2015).

65. M.Y. Wong and L.M. Leung, New J. Chem. 41, 512 (2017).

66. T. Nakano, T. Yade, M. Yokoyama, and N. Nagayama, Chem. Lett. 33, 296 (2004).

67. T. Nakano, Polym. J. 42, 103 (2010).

68. H. Li, Z. Wang, C. Song, Y. Wang, Z. Lin, J. Xiao, R. Chen, C. Zheng, and W. Huang, J. Mater. Chem. C 2, 6946 (2014).

69. M.Y. Wong and E. Zysman-Colman, Adv. Mater. 29, 1605444 (2017).

70. Y. Tao, K. Yuan, T. Chen, P. Xu, H. Li, R. Chen, C. Zheng, L. Zhang, and W. Huang, Adv. Mater. 26, 7931 (2014).

71. H. Uoyama, K. Goushi, K. Shizu, H. Nomura, and C. Adachi, Nature 492, 234 (2012).

72. Z. Yang, Z. Mao, Z. Xie, Y. Zhang, S. Liu, J. Zhao, J. Xu, Z. Chi, and M.P. Aldred, Chem. Soc. Rev. 46, 915 (2017).

73. M.Y. Wong, G.J. Hedley, G. Xie, L.S. Kölln, I.D.W. Samuel, A. Pertegás, H.J. Bolink, and E. Zysman-Colman, Chem. Mater. 27, 6535 (2015).

74. Y.J. Cho, B.D. Chin, S.K. Jeon, and J.Y. Lee, Adv. Funct. Mater. 25, 6786 (2015).

75. Y.J. Cho, K.S. Yook, and J.Y. Lee, Adv. Mater. 26, 6642 (2014).

76. A. Endo, K. Sato, K. Yoshimura, T. Kai, A. Kawada, H. Miyazaki, and C. Adachi, Appl. Phys. Lett. 98, 083302 (2011).

77. A.E. Nikolaenko, M. Cass, F. Bourcet, D. Mohamad, and M. Roberts, Adv. Mater. 27, 7236 (2015). 
78. K. Shizu, M. Uejima, H. Nomura, T. Sato, K. Tanaka, H. Kaji, and C. Adachi, Phys. Rev. Applied 3, 014001 (2015).

79. S.A. Bagnich, S. Athanasopoulos, A. Rudnick, P. Schroegel, I. Bauer, N.C. Greenham, P. Strohrieg, and A. Köhler, J. Phys. Chem. C 119, 2380 (2015).

80. R.S. Nobuyasu, Z. Ren, G.C. Griffiths, A.S. Batsanov, P. Data, S. Yan, A.P. Monkman, M.R. Bryce, and F.B. Dias, Adv. Optical Mater. 4, 597 (2016).

81. K. Shizu, H. Noda, H. Tanaka, M. Taneda, M. Uejima, T. Sato, K. Tanaka, H. Kaji, and C. Adachi, J. Phys. Chem. C 119, $26283(2015)$

82. A.P. Monkman, H.D. Burrows, I. Hamblett, S. Navarathnam, M. Svensson, and M.R. Andersson, J. Chem. Phys. 115, 9046 (2001).

83. G. Xie, J. Luo, M. Huang, T. Chen, K. Wu, S. Gong, and C. Yang, Adv. Mater. 29, 1604223 (2017).

84. J. Luo, G. Xie, S. Gong, T. Chen, and C. Yang, Chem. Commun. 52, 2292 (2016)

85. S.Y. Lee, T. Yasuda, H. Komiyama, J. Lee, and C. Adachi, Adv. Mater. 28, 4019 (2016).

86. Y. Zhu, Y. Zhang, B. Yao, Y. Wang, Z. Zhang, H. Zhan, B. Zhang, Z. Xie, Y. Wang, and Y. Cheng, Macromolecules 49 , 4373 (2016).

87. P. Chen, D. Yuan, L. Niu, C. Gao, and Z. Xiong, Org. Electron. 41, 100 (2017).

88. W. Wei, P. Kleine, Y. Karpov, X. Qiu, H. Komber, K. Sahre, A. Kiriy, R. Lygaitis, S. Lenk, S. Reineke, and B. Voit, Adv. Funct. Mater. 27, 1605051 (2017).

89. S. Ho, S. Liu, Y. Chen, F. So, and J. Photon, Energy 5, 057611 (2015).

90. H. Zheng, Y. Zheng, N. Liu, N. Ai, Q. Wang, S. Wu, J. Zhou, D. Hu, S. Yu, S. Han, W. Xu, C. Luo, Y. Meng, Z. Jiang, Y Chen, D. Li, F. Huang, J. Wang, J. Peng, and Y. Cao, Nat. Commun. 4, 1971 (2013).

91. K. Sun, X. Xie, Y. Liu, W. Jiang, X. Ban, B. Huang, and Y. Sun, J. Mater. Chem. C 4, 8973 (2016).

92. L. Derue, S. Olivier, D. Tondelier, T. Maindron, B. Geffroy, and E. Ishow, ACS Appl. Mater. Interfaces 8, 16207 (2016).

93. G. Liaptsis, D. Hertel, and K. Meerholz, Angew. Chem. Int. Ed. 52, 9563 (2013).

94. Y.-J. Pu, T. Chiba, K. Ideta, S. Takahashi, N. Aizawa, T. Hikichi, and J. Kido, Adv. Mater. 27, 1327 (2015).

95. P.K.H. Ho, J.-S. Kim, J.H. Burroughes, H. Becker, S.F.Y. Li, T.M. Brown, F. Cacialli, and R.H. Friend, Nature 404, $481(2000)$.

96. X. Yang, D.C. Müller, D. Neher, and K. Meerholz, Adv. Mater. 18, 948 (2006).

97. S. Wu, M. Aonuma, Q. Zhang, S. Huang, T. Nakagawa, K. Kuwabara, and C. Adachi, J. Mater. Chem. C 2, 421 (2014).

98. H. Gao, D.A. Poulsen, B. Ma, D.A. Unruh, X. Zhao, J.E Millstone, and J.M.J. Fréchet, Nano Lett. 10, 1440 (2010).

99. H. Wettacha, S.S. Jester, A. Colsmann, U. Lemmer, N. Rehmann, K. Meerholz, and S. Höger, Synth. Met. 160, 691(2010).

100. G. Xie, X. Li, D. Chen, Z. Wang, X. Cai, D. Chen, Y. Li, K. Liu, Y. Cao, and S.-J. Su, Adv. Mater. 28, 181 (2016).

101. Y. Xiang, S. Gong, Y. Zhao, X. Yin, J. Luo, K. Wu, Z. Lu, and C. Yang, J. Mater. Chem. C 4, 9998 (2016).

102. T. Nakagawa, S.-Y. Ku, K.-T. Wong, and C. Adachi, Chem. Commun. 48, 9580 (2012).

103. S. Nau, N. Schulte, S. Winkler, J. Frisch, A. Vollmer, N. Koch, S. Sax, and E.J.W. List, Adv. Mater. 25, 4420 (2013)

104. L.V. Kayser, M. Vollmer, M. Welnhofer, H. Krikcziokat, K. Meerholz, and B.A. Arndtsen, J. Am. Chem. Soc. 138, 10516 (2016).

105. C.A. Young, S. Saowsupa, A. Hammack, A.A. Tangonan, P. Anuragudom, H. Jia, A.C. Jamison, S. Panichphant, B.E. Gnade, and T.R. Lee, J. Appl. Polym. Sci. 131, 41162 (2014).

106. J.H. Cook, J. Santos, H. Li, H.A. Al-Attar, M.R. Bryce, and A.P. Monkman, J. Mater. Chem. C 2, 5587 (2014).

107. J.H. Cook, J. Santos, H. Li, H.A. Al-Attar, M.R. Bryce, and A.P. Monkman, J. Mater. Chem. C 3, 9664 (2015).

108. Z. Geng, G. Sato, K. Marumoto, and M. Kijima, J. Poly. Sci. Part A Poly. Chem. 54, 3454 (2016).
109. T.T. Steckler, O. Fenwick, T. Lockwood, M.R. Andersson, and F. Cacialli, Macromol. Rapid Commun. 34, 990 (2013).

110. J.J. Intemann, E.S. Hellerich, B.C. Tlach, M.D. Ewan, C.A. Barnes, A. Bhuwalka, M. Cai, J. Shinar, R. Shinar, and M. Jeffries-EL, Macromolecules 45, 6888 (2012).

111. I. Osken, A.S. Gundogan, E. Tekin, M.S. Eroglu, and T. Ozturk, Macromolecules 46, 9202 (2013).

112. J.J. McDowell, D. Gao, D.S. Seferos, and G. Ozin, Polym. Chem. 6, 3781 (2015).

113. U. Giovanella, C. Botta, F. Galeotti, B. Vercelli, S. Battiatoc, and M. Pasini, J. Mater. Chem. C 1, 5322 (2013)

114. W. Lu, J. Kuwabara, T. Iijima, H. Higashimura, H. Hayashi, and T. Kanbara, Macromolecules 45, 4128 (2012).

115. T. Guo, W. Zhong, A. Zhang, J. Zou, L. Ying, W. Yang, and J. Peng, New J. Chem. 40, 179 (2016).

116. F. Xu, J.-H. Kim, H.U. Kim, J.-H. Jang, K.Y. Yook, J.Y. Lee, and D.-H. Hwang, Macromolecules 47, 7397 (2014).

117. J. Sun, H. Wang, H. Xu, T. Zhang, L. Li, J. Li, Y. Wu, B. Xu, X. Zhang, and W. Lai, Dyes Pigments 130, 191 (2016).

118. J. Zhao, M. Lian, Y. Yu, X. Yan, X. Xu, X. Yang, G. Zhou, and Z. Wu, Macromol. Rapid Commun. 36, 71 (2015).

119. Z. Ma, L. Chen, J. Ding, L. Wang, X. Jing, and F. Wang, Adv. Mater. 23, 3726 (2011).

120. H. Tan, J. Yu, Y. Wang, J. Li, J. Cui, J. Luo, D. Shi, K. Chen, Y. Liu, K. Nie, and W. Zhu, J. Poly. Sci. Part A Poly. Chem. 50, 149 (2012).

121. E. Ravindran, S.J. Ananthakrishnan, E. Varathan, V. Subramanian, and N. Somanathan, J. Mater. Chem. C 3, 4359 (2015)

122. E. Ravindran, E. Varathan, V. Subramanian, and N. Somanathan, J. Mater. Chem. C 4, 8024 (2016).

123. M. Nagai, ECS J. Solid State Sci. Technol. 2, R218 (2013).

124. R. Noriega, J. Rivnay, K. Vandewal, F.P.V. Koch, N. Stingelin, P. Smith, M.F. Toney, and A. Salleo, Nat. Mater. 12, 1038 (2013).

125. H.A. Al-Attar and A.P. Monkman, J. Appl. Phys. 109, 074516 (2011).

126. Z.A. Kösemen, A. Kösemen, S. Öztürk, B. Canimkurbey, S.E. Sana, Y. Yerli, and A.V. Tunç, Microelectron. Eng. 161, 36 (2016).

127. A.V. Tunc, B. Ecker, Z. Dogruyol, S. Jüchter, A.L. Ugur, A. Erdogmus, S.E. San, J. Parisi, and E.V. Hauff, J. Polym. Sci., Part B: Polym. Phys. 50, 117 (2012).

128. G. Moad, E. Rizzardo, and S.H. Thang, Acc. Chem. Res. 41, 1133 (2008)

129. K. Matyjaszewski, Macromolecules 45, 4015 (2012).

130. T. Bura, T. Blaskovits, and M. Leclerc, J. Am. Chem. Soc. 138, 10056 (2016)

131. J.-R. Pouliot, F. Grenier, T. Blaskovits, S. Beaupré, and M. Leclerc, Chem. Rev. 116, 14225 (2016).

132. P. Bujak, I. Kulszewicz-Bajer, M. Zagorska, V. Maurel, I. Wielgusa, and A. Pron, Chem. Soc. Rev. 42, 8895 (2013).

133. Y. Lee and E.D. Gomez, Macromolecules 48, 7385 (2015).

134. R. Hu, N.L.C. Leung, and B.Z. Tang, Chem. Soc. Rev. 43, $4494(2014)$

135. Y. Hong, J.W.Y. Lam, and B.Z. Tang, Chem. Soc. Rev. 40, 5361 (2011).

136. S. Liu, C. Peng, A. Cruz, Y. Chen, and F. So, J. Mater. Chem. C 4, 8696 (2016).

137. H. Becker, I. Bach, M. Holbach, J. Schwaiger, and H. Spreitzer, Dig. Tech. Pap. Soc. Inf. Disp. Int. Symp. 41, 39 (2010).

138. C. Wang, X. Li, Y. Pan, S. Zhang, L. Yao, Q. Bai, W. Li, P. $\mathrm{Lu}$, B. Yang, S. Su, and Y. Ma, ACS Appl. Mater. Interfaces 8, 3041 (2016).

139. H. Soofi and A. Rostami, Jpn. J. Appl. Phys. 54, 094301 (2015).

140. S.M. King, M. Cass, M. Pintani, C. Coward, F.B. Dias, A.P. Monkman, and M. Roberts, J. Appl. Phys. 109, 074502 (2011).

141. Y. Zhang, J. Lee, and S.R. Forrest, Nat. Commun. 5, 5008 (2014). 